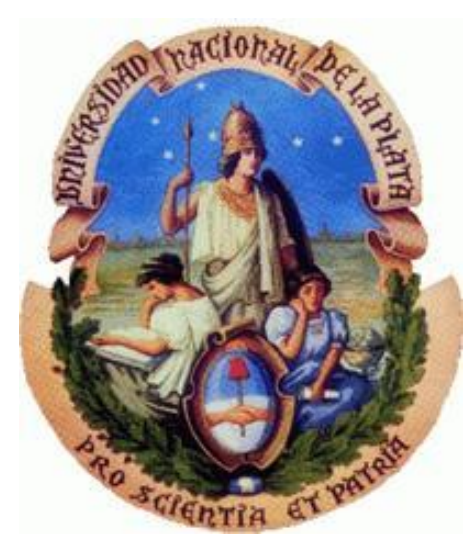

UNIVERSIDAD NACIONAL DE LA PLATA FACULTAD DE CIENCIAS EXACTAS

\title{
EMPLEO DE SUBPRODUCTOS DE LA INDUSTRIA YERBATERA EN EL DESARROLLO DE SISTEMAS DE ENCAPSULACIÓN PARA LA LIBERACIÓN CONTROLADA DE FERTILIZANTES
}

Ing. Alim. LENIN MANUEL LLIVE TRÁVEZ

Trabajo de tesis presentado para optar al grado académico de Magister en Tecnología e Higiene de los Alimentos

Directora: Dra. LORENA DELADINO

Codirectora: Dra. ALINE SCHNEIDER TEIXEIRA

Centro de Investigación y Desarrollo en Criotecnología de Alimentos (CIDCA) La Plata, Buenos Aires 


\section{DEDICATORIA}

A Dios, principio y fin de todo, A mi madre, fuente inagotable de amor y fortaleza A la memoria de mi padre y de mi hermano A mis hermanos, demostración pura de amor y unión. A Natalia, esperando volver a verte sonreír.

Sin ustedes, nada de esto sería real, como siempre a ustedes les pertenece. 


\section{AGRADECIMIENTOS}

Al Gobierno Nacional de la República del Ecuador que mediante la Secretaría de Educación Superior, Ciencia, Tecnología e Innovación (SENESCYT) y el Instituto de Fomento al Talento Humano (IFTH) financiaron mis estudios de cuarto nivel.

Al Instituto Nacional de la Yerba Mate (INYM) y al Consejo Nacional de Investigaciones Científicas y Técnicas (CONICET), por el financiamiento otorgado para la realización de este trabajo.

A la Universidad Nacional de la Plata, a la Facultad de Ciencias Exactas y al Centro de Investigación y Desarrollo en Criotecnología de Alimentos (CIDCA), por facilitarme las instalaciones para el desarrollo de las actividades académicas y experimentales, al equipo de docentes, investigadores, becarios y técnicos por sus contribuciones.

A mi familia, la que a pesar de todos los golpes siempre hemos permanecido juntos, son mi soporte y mi razón de ser.

Muy especial agradecimiento a mis directoras, Dra. Lorena Deladino y Dra. Aline Schneider Teixeira, por confiar en mí, por formarme y por permitirme desarrollar este trabajo en medio de tantas experiencias inolvidables, siempre sintiendo su respaldo y compromiso para conmigo.

Al Profesor Antonio Molina García del ICTAN-Madrid, quien me permitió realizar una estancia de investigación y realizar los ensayos de calorimetría diferencial de barrido y absorción atómica en este instituto, además de sus contribuciones en la realización de este trabajo.

A Estela Bruno, por su valiosa ayuda en las pruebas microbiológicas de este trabajo.

A Leonardo Sechi, gratitud por su invaluable apoyo en todas las gestiones requeridas, desde el inicio hasta la finalización de mis estudios. 
Índice 


\section{Índice}

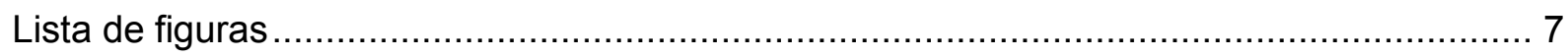

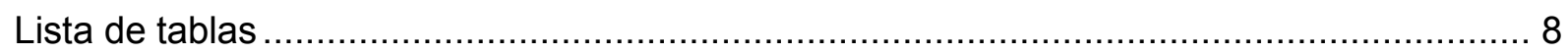

\section{CAPÍTULO I}

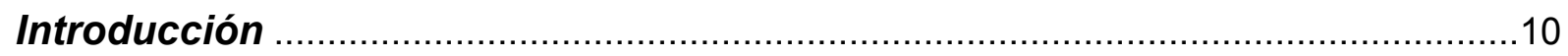

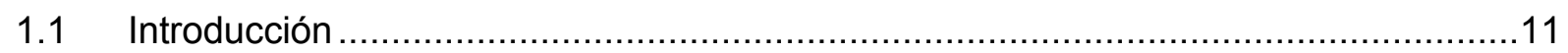

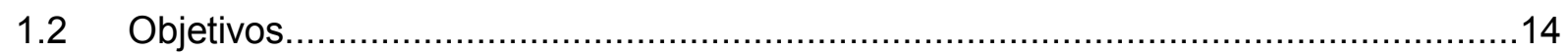

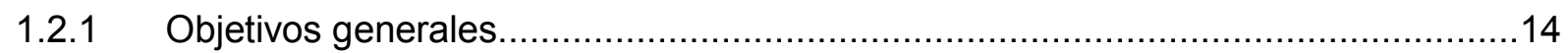

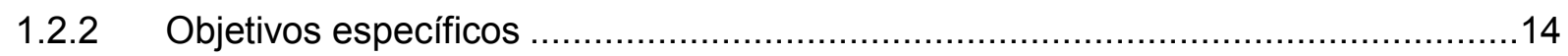

\section{CAPÍTULO II}

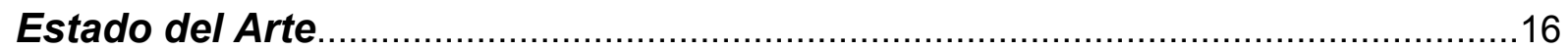

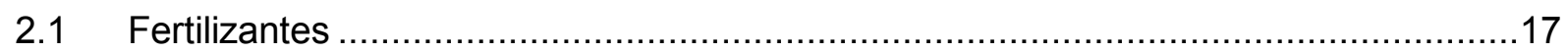

2.1.1 Fertilizantes de liberación lenta y controlada .............................................17

2.1.1.1 Fertilizantes de liberación controlada ...............................................................19

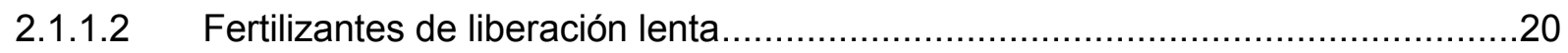

2.1.2 Clasificación de fertilizantes de liberación lenta y controlada ...............................21

2.1.2.1 Fertilizantes con $\mathrm{N}$ orgánico (compuestos de baja solubilidad) .........................21

2.1.2.2 Fertilizantes en los que una barrera física controla la liberación .......................21

2.1.2.3 Fertilizantes inorgánicos de baja solubilidad descompuestos ...........................23

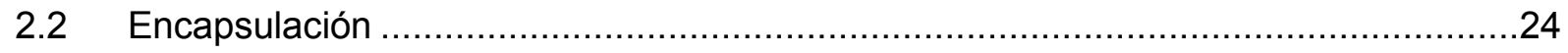

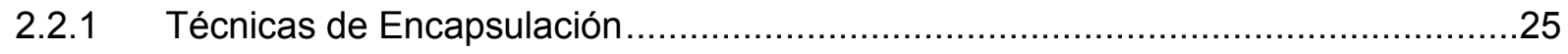

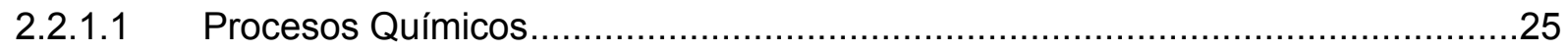

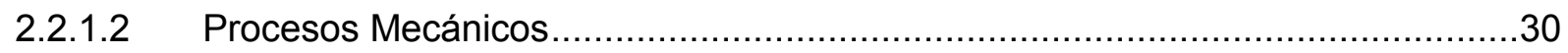

2.2.2 Encapsulación de fertilizantes de liberación controlada......................................32

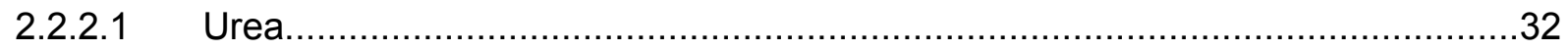

\section{CAPÍTULO III}

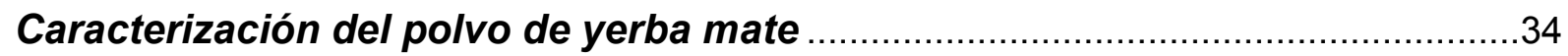

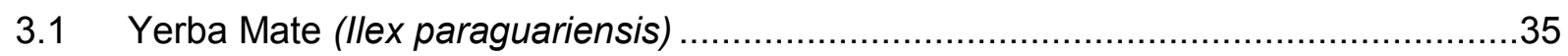

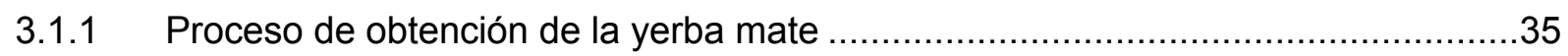

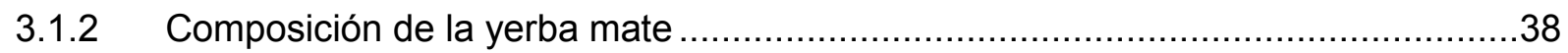

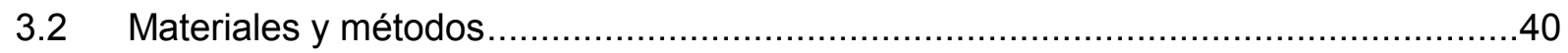

3.2.1 Caracterización del polvo de yerba mate (PYM) ..............................................

3.2.2 Materia seca y contenido total de cenizas .........................................................40

3.2.3 Determinación del contenido de minerales o micronutrientes mediante espectroscopía de absorción atómica 
3.2.4 Determinación del tamaño de partícula ....................................................42

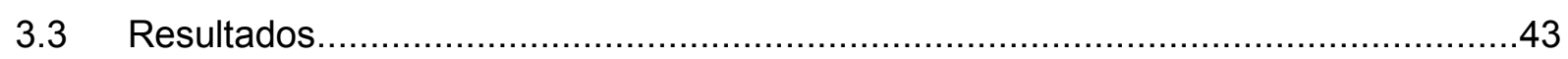

3.3.1 Materia seca y contenido total de cenizas ......................................................43

3.3.2 Determinación del contenido de minerales o micronutrientes mediante espectroscopía de absorción atómica ....................................................................43

3.3.3 Determinación del tamaño de partícula .........................................................44

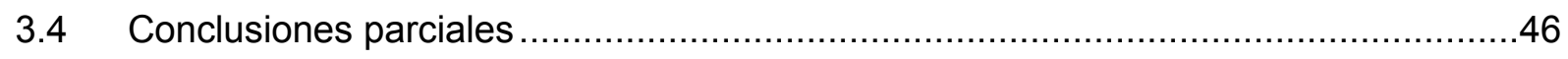

\section{CAPÍTULO IV}

Formulación y caracterización de los encapsulados.........................................47

$4.1 \quad$ Sistemas de Encapsulación .......................................................................48

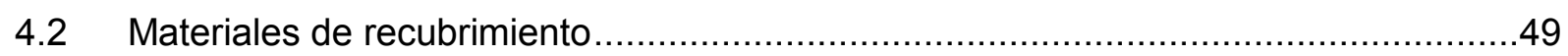

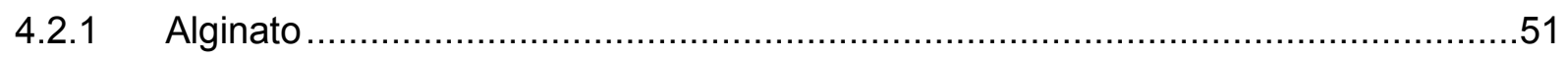

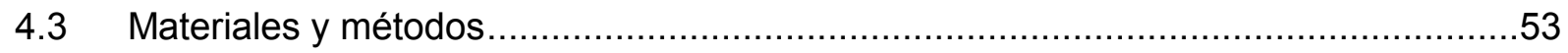

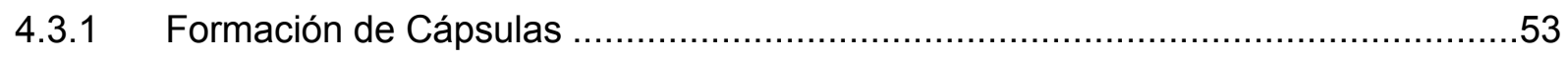

4.3.2 Tamaño y Forma: Análisis digital de imágenes ............................................54

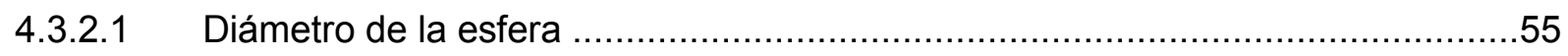

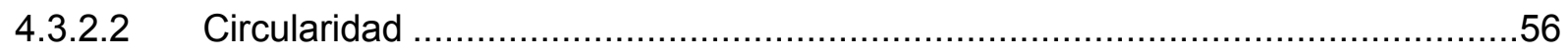

4.3.3 Observación en microscopio electrónico y micro análisis .....................................56

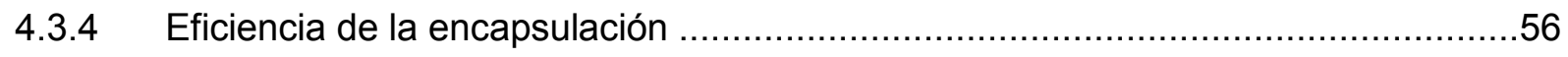

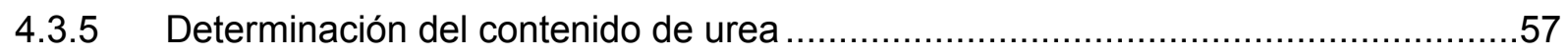

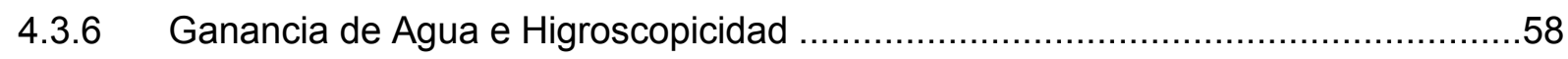

4.3.7 Propiedades mecánicas: Medición de textura ................................................60

4.3.8 Capacidad de flujo: Ángulo de reposo .........................................................61

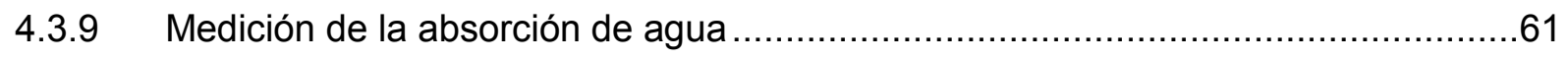

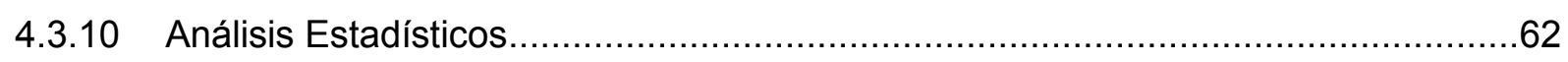

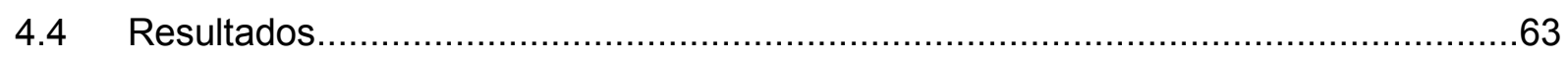

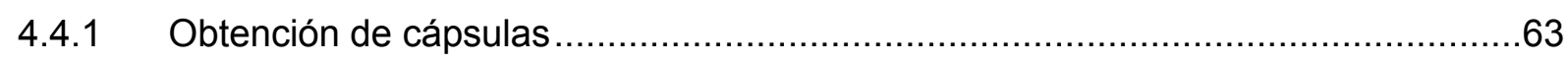

4.4.2 Tamaño y Forma: Análisis digital de imágenes ................................................63

4.4.3 Observación en microscopio electrónico y micro análisis .....................................65

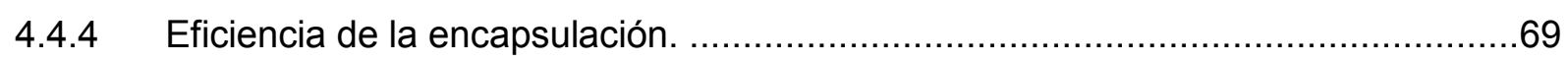

4.4.5 Ganancia de Agua e Higroscopicidad ...................................................... 70

4.4.6 Propiedades físicas de los encapsulados..........................................................

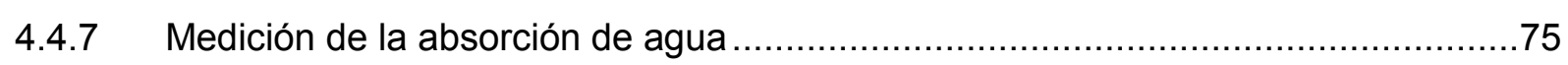

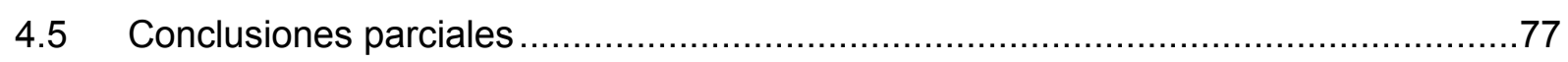




\section{CAPÍTULO V}

Liberación de fertilizantes (Urea) y degradación de los encapsulados . .78

5.1 Mecanismos de liberación de compuestos..............................................................79

5.2 Mecanismos de liberación a través de membranas y matrices poliméricas................79

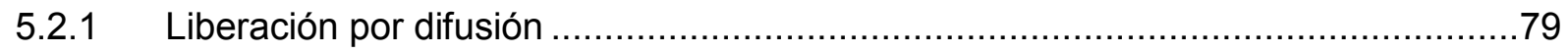

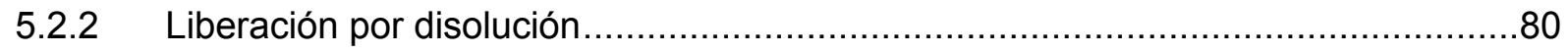

5.2.3 Liberación por degradación o erosión ........................................................... 80

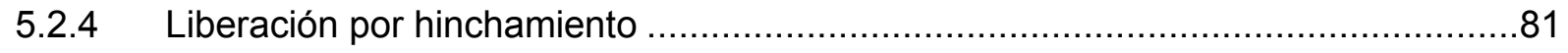

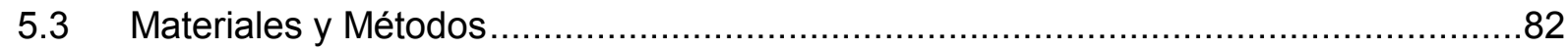

5.3.1 Cinética de liberación de Urea y condiciones de degradación. .............................82

5.3.2 Medición de la absorción de agua en tierra durante la degradación. ......................83

5.3.3 Determinación del contenido de minerales antes y después del ensayo de

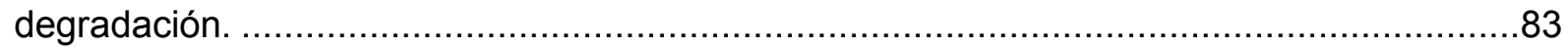

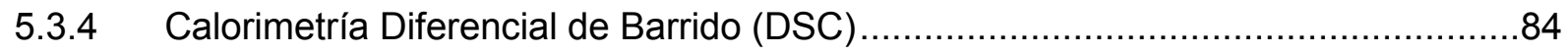

5.3.5 Espectroscopía Infrarroja con Transformada de Fourier (FT-IR) .........................84

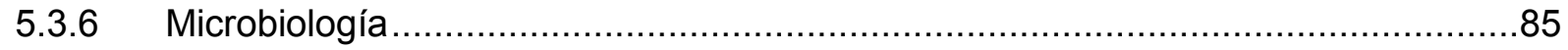

5.3.7 Microscopía Electrónica de Barrido Ambiental (ESEM) .....................................85

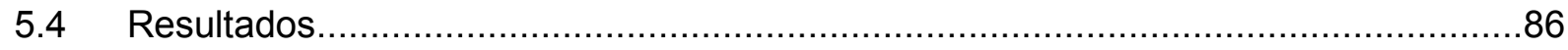

5.4.1 Cinética de liberación de Urea en tierra y condiciones de degradación..................86

5.4.2 Medición de la absorción de agua durante la degradación..................................92

5.4.3 Determinación del contenido de minerales durante el ensayo de degradación.......95

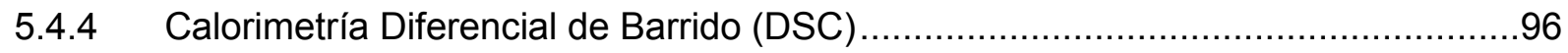

5.4.5 Espectroscopía Infrarroja con Transformada de Fourier (FT-IR) .......................103

5.4.6 Crecimiento microbiano durante el almacenamiento .......................................106

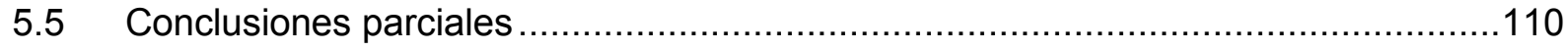

\section{CAPÍTULO VI}

Comparación con sistemas encapsulados que contienen otros fertilizantes

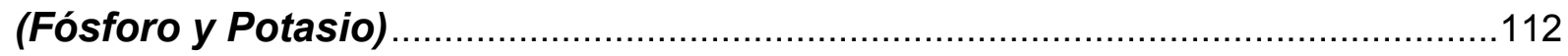

6.1 Sistemas con otros tipos de fertilizantes (Fósforo y Potasio) ..................................113

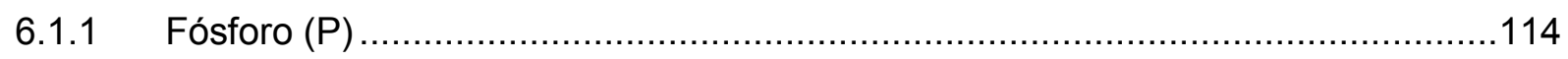

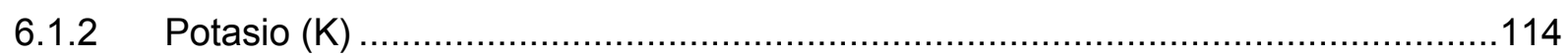

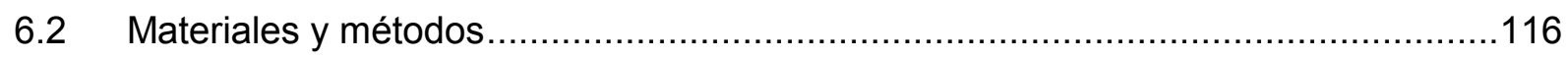

6.2.1 Cinética de liberación de Fertilizantes (urea, fósforo y potasio) ...........................116

6.2.1.1 Cinética de liberación de Urea, Fósforo y Potasio en tierra..............................116

6.2.1.2 Cinética de liberación de Urea, Fósforo y Potasio en agua..............................117

6.2.2 Determinación del contenido de fósforo. .....................................................118 
6.2.3 Determinación del contenido de potasio......................................................118

6.2.4 Porosimetría con intrusión de mercurio ........................................................119

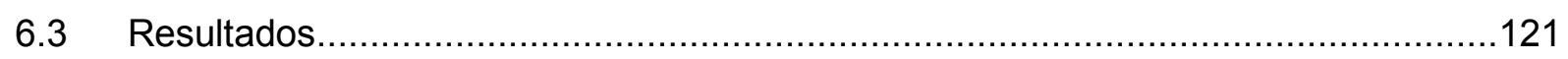

6.3.1 Cinética de liberación de Urea, Fósforo y Potasio en tierra................................121

6.3.2 Cinética de liberación de Urea, Fósforo y Potasio en agua. ................................123

6.3.3 Determinación del contenido de minerales ................................................. 127

6.3.4 Porosimetría con intrusión de mercurio ................................................... 128

6.3.5 Observación en microscopio electrónico ......................................................129

6.3.6 Calorimetría Diferencial de Barrido (DSC) ..................................................130

6.3.7 Espectroscopía Infrarroja con Transformada de Fourier (FT-IR) .......................132

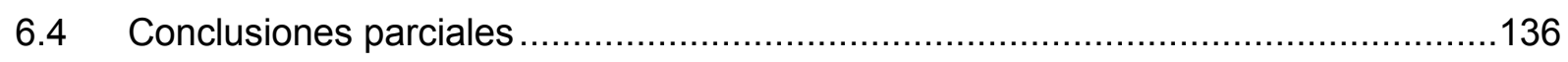

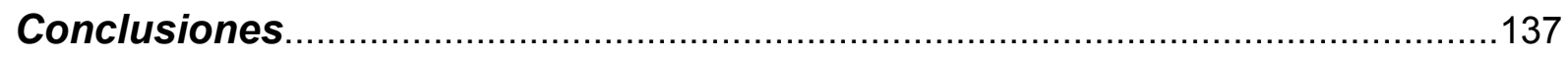

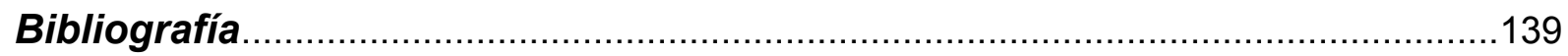




\section{Lista de figuras}

Figura 2.1 Representación esquemática de la cantidad relativa de fertilizante disponible durante el período de crecimiento de una planta.

Figura 2.2 Clasificación de Fertilizantes de Liberación Controlada ..................................22

Figura 2.3 Representación ilustrativa de los sistemas de encapsulación............................25

Figura 2.4 Esquema ilustrativo de las técnicas de encapsulación ......................................26

Figura 3.1 Esquema del Proceso de Obtención de la Yerba Mate ......................................36

Figura 3.2 Ensayo de digestión de muestras para determinación del contenido de minerales.

Figura 3.3 Distribución del tamaño de partícula del polvo de yerba mate .45

Figura 4.1 Estructura química del alginato.

Figura 4.2 Representación esquemática del modelo de "caja de huevos" y coordinación del calcio para las cadenas de guluronato en las zonas de unión del alginato de calcio. .52

Figura 4.3 Esquema de obtención de los encapsulados..............................................54

Figura 4.4 Proceso de tratamiento de imágenes con Image J ..........................................55

Figura 4.5 Muestras coloreadas para la determinación de urea por espectrofotometría ......57

Figura 4.6 Ensayo de absorción de agua

Figura 4.7 Fotografías de las cápsulas húmedas de PYM como matriz y con urea como fertilizante modelo.

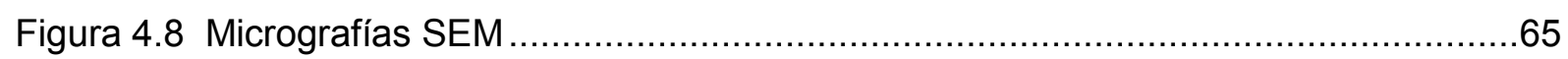

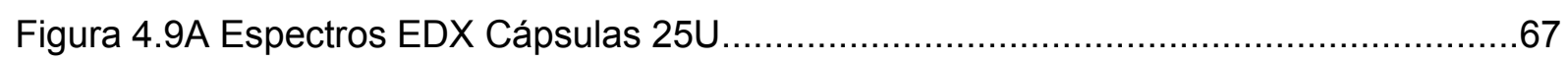

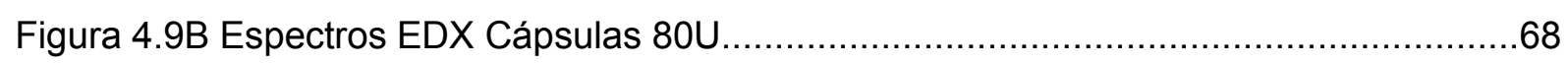

Figura 4.10 Efecto de la concentración del PYM en la eficiencia de encapsulación de urea.

Figura 4.11 Isotermas de adsorción a $20{ }^{\circ} \mathrm{C}$ de cápsulas de PYM en diferentes proporciones, con y sin agregado de urea.

Figura 4.12 Efecto de la Concentración del PYM $(25,50$ y $80 \mathrm{mg} / \mathrm{mL})$ con agregado de urea en la absorción de agua

Figura 5.1 Fotografías de los contenedores donde se almacenaron las macetas a diferentes condiciones de temperatura

Figura 5.2. Liberación (L) de urea y degradación (D) de sistemas encapsulados en base a PYM con urea agregada (25U, $50 \mathrm{U}$ y $80 \mathrm{U})$, a diferentes temperaturas $\left(4,20\right.$ y $\left.30^{\circ} \mathrm{C}\right)$

Figura 5.3. Absorción de agua (WA) en tierra durante el ensayo de degradación en cápsulas (25U, $50 \mathrm{U}$ y $80 \mathrm{U})$, a temperaturas $\left(4,20\right.$ y $\left.30^{\circ} \mathrm{C}\right)$ en tiempos entre 3 y 60 días

Figura. 5.4 Termogramas de cápsulas sin degradar con diferentes proporciones de PYM/alginato (25, 50 y 80 ), con urea $(U)$ y sin urea (C).; Alginato de calcio (AlgCa) y polvo de yerba mate (PYM).

Figura. 5.5 Termogramas de cápsulas con Urea degradadas 30 días; a diferentes 
Figura. 5.6 Espectros IR de materiales control (PYM, AlgCa, AlgCaUrea y Urea)

Figura. 5.7. Espectros FT-IR de cápsulas con urea ( $25 \mathrm{U}$ y $80 \mathrm{U})$ a diferentes temperaturas

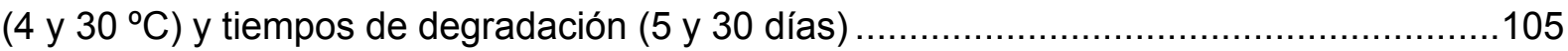

Figura. 5.8. Fotografías del crecimiento microbiano en placas Petri a $4{ }^{\circ} \mathrm{C}$......................107

Figura. 5.9. Micrografías ESEM de cápsulas degradadas ..........................................109

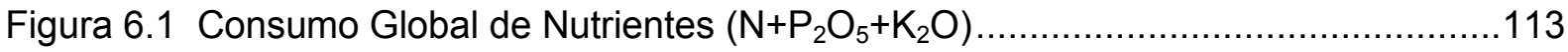

Figura 6.2 Montaje del experimento dinámico para determinación de liberación de Urea,

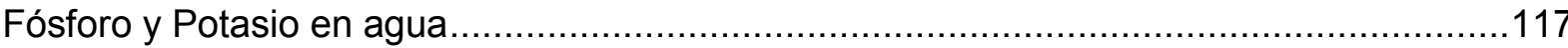

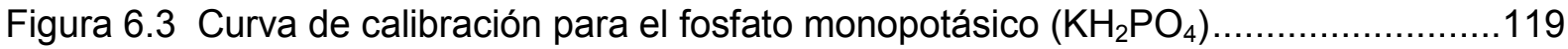

Figura 6.4 Cinética de Liberación de minerales y degradación de sistemas encapsulados en base a polvo de yerba mate con urea, sodio y potasio ............................................121

Figura 6.5 Cinética de Liberación de urea, fósforo y potasio en agua..............................124

Figura 6.6. Distribución del diámetro de poros para las cápsulas de $80 \mathrm{mg}$ de polvo/mL de

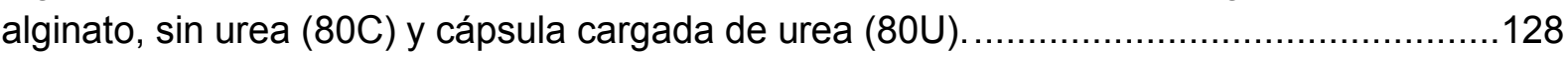

Figura 6.7 Micrografías SEM de cápsulas secas 129

Figura 6.8 Termogramas control de Alginato de calcio (AlgCa), polvo de yerba mate (PYM), Fosfato monopotásico $\left(\mathrm{KH}_{2} \mathrm{PO}_{4}\right)$, cápsulas de $\mathrm{PYM} /$ alginato de calcio $(80 \mathrm{mg} / \mathrm{mL})$ sin fertilizante $(80 \mathrm{C})$, con urea (80U) y con fosfato monopotásico (80PK)

Figura 6.9 Termogramas de cápsulas con fosfato monopotásico (80PK) durante el ensayo de degradación, en tiempos entre 3 y 30 días, almacenadas a $20^{\circ} \mathrm{C}$

Figura. 6.10 Espectros IR de materiales control (PYM, AlgCa, Fosfato monopotásico $\left(\mathrm{KH}_{2} \mathrm{PO}_{4}\right), 80 \mathrm{U}$ y $\left.80 \mathrm{PK}\right)$.

Figura. 6.11. Espectros FT-IR de cápsulas con fosfato monopotásico (80PK) a $20^{\circ} \mathrm{C}$ y tiempos de degradación $(3,5,10,20$ y 30 días $)$.....

\section{Lista de tablas}

Tabla 3.1 Variación de la composición físico-química de la yerba mate en función de sus etapas de procesamiento

Tabla 3.2 Contenido de los Nutrientes Minerales en el polvo de yerba mate.

Tabla 3.3 Determinación del contenido de los nutrientes minerales en el polvo de yerba mate.

Tabla 4.1 Tipos de cubiertas poliméricas y matrices utilizadas en la preparación de Fertilizantes de Liberación Controlada

Tabla 4.2 Factores de tamaño y forma determinados en cápsulas húmedas

Tabla 4.3 Datos experimentales de humedades de equilibrio (X eq.) determinados a $20{ }^{\circ} \mathrm{C}$

Tabla 4.4. Coeficientes de las Ecuaciones de Chirife, GAB, Halsey, Kühn, Mizrahi y White para encapsulados de diferente concentración de PYM, con y sin urea a $20^{\circ} \mathrm{C}$ en un rango de Actividad de Agua (Aw) de 0.33 a 0.83 
Tabla 4.5. Higroscopicidad (HG\%) de cápsulas a diferentes porcentajes de humedad relativa.

Tabla 4.6. Caracterización física de las cápsulas de PYM a diferentes concentraciones y con el agregado de urea.

Tabla 5.1 Parámetros obtenidos en los modelos empíricos para la liberación de urea de distintos sistemas a distintas temperaturas

Tabla 5.2 Contenido de minerales ( $\mathrm{Ca}, \mathrm{Mg}$ y K), antes y después de la degradación 95

Tabla 5.3 Parámetros térmicos (media \pm desviación standard) obtenidos de los termogramas de DSC para las cápsulas de alginato y cápsulas de PYM con y sin urea.

Tabla 5.4 Parámetros térmicos (media \pm desviación standard) en el ensayo de degradación, obtenidos en los termogramas de DSC para las cápsulas con fertilizante $(25 \mathrm{U}, 50 \mathrm{U}$ y $80 \mathrm{U})$ a diferentes temperaturas $\left(4,20\right.$ y $\left.30^{\circ} \mathrm{C}\right)$ y tiempo de almacenamiento (5, 10 y 30 días).

Tabla 5.5 Recuento de bacterias para las cápsulas con fertilizante ( $25 \mathrm{U}, 50 \mathrm{U}$ y $80 \mathrm{U})$ a diferentes temperaturas $\left(4,20\right.$ y $\left.30^{\circ} \mathrm{C}\right)$ y tiempo de almacenamiento bajo tierra $(3,5,10$ y 30 días $)$

Tabla 5.6 Recuento de Mohos para las cápsulas con fertilizante (25U, $50 \mathrm{U}$ y $80 \mathrm{U})$ a diferentes temperaturas $\left(4,20\right.$ y $\left.30^{\circ} \mathrm{C}\right)$ y tiempo de almacenamiento bajo tierra (3, 5,10 y 30 días $)$ 108

Tabla 6.1 Parámetros obtenidos en los modelos empíricos para la liberación en tierra de urea $(80 \mathrm{U})$, fósforo $(80 \mathrm{PK}(\mathrm{P}))$ y potasio $(80 \mathrm{PK}(\mathrm{K}))$.

Tabla 6.2 Valores de f2 calculados para cinéticas de liberación en agua entre diferentes tipos de fertilizantes, Potasio-Fósforo (K-P), Potasio-Urea (K-U) y Fósforo-Urea (P-U)

Tabla 6.3 Valores de f2 para diferencias medias entre perfiles de disolución

Tabla 6.4 Parámetros obtenidos en los modelos empíricos para la liberación en tierra de

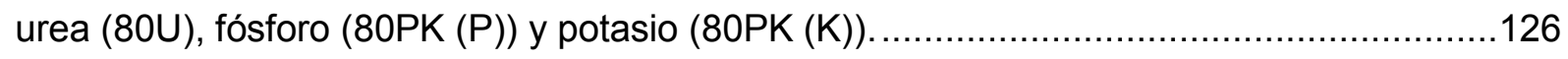

Tabla 6.5 Contenido de minerales ( $\mathrm{Mg}, \mathrm{K}$ y Ca), antes y después de la degradación.

Tabla 6.6 Parámetros térmicos (media \pm desviación standard) en el ensayo de degradación, obtenidos en los termogramas de DSC para las cápsulas con fertilizante (80PK) a $20^{\circ} \mathrm{C}$ y tiempos de almacenamiento $(3,5,10,20$ y 30 días $)$ 
CAPÍTULO I

Introducción 


\subsection{Introducción}

La actividad yerbatera es la base de la economía de los agricultores del Nordeste Argentino. En los últimos años se ha intensificado la búsqueda de alternativas diversas, para paliar sus recurrentes crisis. Esa diversificación no debe significar el abandono de los yerbales, sino más bien un fuerte compromiso con este noble cultivo, que tiene características suficientes para seguir siendo el principal pilar de la economía regional.

A lo largo del proceso de elaboración de la yerba mate se obtienen una serie de productos (palos, hojas, polvos). Durante el secado se produce la pérdida de materia prima en la cinta transportadora, constituyendo un material de descarte. En los establecimientos pequeños, donde se realiza una molienda integral, los palos y las hojas se trituran en forma conjunta, generándose partículas de tamaños reducidos (polvos) que deben ser eliminadas de la yerba mate elaborada, ya que pueden ocasionar problemas cuando ésta se consume. Para obtener la yerba mate elaborada, se mezclan polvos, hojas pequeñas, hojas de mayor tamaño y palos pequeños. Parte del polvo se descarta, ya que no puede ser utilizado en la formulación del producto final, generando un problema en la mayoría de los molinos (Velázquez, Scipioni, Ferreyra, \& Schmalko, 2006).

Según los datos correspondientes al Instituto Nacional de la Yerba Mate (INYM), en todo el año 2017 fueron procesados 689,195.72 kilogramos de hoja verde. Como mínimo, el $5 \%$ de este volumen $(34,909.79 \mathrm{~kg})$ es desperdicio.

Este "polvo de yerba mate" contiene un elevado porcentaje de materia orgánica (alrededor de $90 \%$ ) lo que lo hace perfecto para abono en prácticas agrícolas. Sin embargo, el tamaño de partícula del polvo es muy reducido, más del $95 \%$ tiene un diámetro por debajo de los 500 micrómetros. Por lo tanto, la aplicación directa de este material como abono no constituye una solución práctica. El empleo de abonos orgánicos para mejorar las cualidades físicas, químicas y bioestructurales del suelo es una práctica antigua y de valor comprobado. Constituye una fuente de carbono para los microorganismos, aumenta la capacidad de intercambio catiónico y el poder "buffer" del suelo, mejorando la 
porosidad y la retención de humedad en el mismo (Rodríguez, 1993). La presencia de materia orgánica es importante para atenuar cualquier error de manejo de las dosis de fertilizante químico aplicadas.

El agregado de fertilizantes propicia una descomposición más acelerada de la materia orgánica, perdiéndose del perfil del suelo, junto con sus beneficios. Los fertilizantes son productos de la industria química, la que toma distintos elementos, como rocas, aire o minerales para elaborarlos. En general, son ricos solo en algunos nutrientes y no aportan materia orgánica ni bacterias. El objetivo principal de la fertilización es lograr un aumento en la producción, optimizando la eficacia y la rentabilidad (Burtnik, 2006).

En el caso de los fertilizantes agregados para aportar nutrientes necesarios para el crecimiento de las plantas, pueden volverse potencialmente peligrosos para el medio ambiente por los altos niveles usados para una acción efectiva. Altas concentraciones pueden producir efectos colaterales como daño a los cultivos o contaminación de las napas de agua (Serrano et al., 2006). De acuerdo a Shaviv (2001) el éxito de la fertilización depende principalmente de la posibilidad de sincronizar la provisión de nutrientes con las demandas de la planta. En este sentido la liberación controlada de los nutrientes puede resultar una solución adecuada, permitiendo la disponibilidad continua, aumentando la productividad agrícola, eliminando la necesidad de aplicaciones extras y reduciendo los costos (Akelah, 1996; Al-Zahrani, 2000).

La encapsulación es una tecnología mediante la cual se logra proteger materiales activos con biopolímeros que actúan como recubrimientos y facilitan su dosificación, su liberación en forma controlada y su manipulación industrial (Champagne \& Fustier, 2007). Los vehículos usados para la encapsulación son biocompatibles y biodegradables, a menudo también, son subproductos industriales. Entre ellos se encuentran el almidón nativo y modificado por distintos procesos, quitosanos, alginatos, gelatina, derivados de la celulosa, etc. La combinación de diversas sustancias puede dar lugar a sinergias y significativas mejoras de rendimiento. La selección del tipo de material de encapsulación dependerá además, del compuesto activo a proteger, de las 
condiciones del medio ambiente en el cual se desarrollará la liberación del compuesto, como temperatura, humedad relativa, tipos de suelo, $\mathrm{pH}$ del suelo y su bioactividad (Chen et al., 2018; George \& Abraham, 2006).

Diversos tipos de cápsulas pueden ser obtenidos dependiendo del procedimiento seguido. Los sistemas más comunes consisten en un núcleo que contiene el material activo y un recubrimiento denominado material de cubierta, barrera o encapsulante. Los fertilizantes solubles en forma de gránulos pueden recubrirse con materiales que reduzcan su velocidad de disolución, prolongando el suministro del compuesto activo o de los minerales a las plantas (Han, Chen, \& $\mathrm{Hu}, 2009$; Shaviv, 2001). Además aumentan la eficiencia del fertilizante al disminuir la frecuencia de aplicación y minimizan los potenciales efectos negativos de sobredosificación y toxicidad. La mayoría de los trabajos actuales sobre encapsulación de fertilizantes no incorporan materia orgánica en su formulación, sino que, están enfocados al empleo de materiales superabsorbentes con el fin de ser empleados en suelos semidesérticos ( $\mathrm{Ni}$ et al., 2010; Ni, Lü, \& Liu, 2012). 


\subsection{Objetivos}

\subsubsection{Objetivos generales}

- Desarrollar diferentes sistemas de encapsulación empleando el polvo de yerba mate como parte de la formulación para su aplicación en la industria del agro, apuntando a desarrollar sistemas de encapsulación compuestos como estrategia para la liberación controlada de fertilizantes en diferentes sustratos.

- Encapsular fertilizantes tipo NPK para promover su liberación en forma modulada, desarrollando estrategias de encapsulación adecuadas, basadas en sistemas de encapsulación de alginato de calcio. Se deberán tener en cuenta los fertilizantes (abono químico) y la doble contribución del polvo de yerba mate ya que actuará como abono orgánico y como material de relleno o "de carga" en las matrices encapsulantes.

\subsubsection{Objetivos específicos}

- Desarrollar diferentes formulaciones de mezclas de polvo de yerba mate y matriz encapsulante.

- Seleccionar las formulaciones más adecuadas de mezclas de polvo de yerba mate y matriz encapsulante en base a sus propiedades mecánicas, comportamiento frente a diferentes humedades relativas y absorción de agua.

- Caracterizar los sistemas encapsulantes por su microestructura y propiedades fisicoquímicas: observación microscópica: determinación del tamaño y características morfológicas mediante fotografías digitales y Microscopía electrónica de barrido (SEM). Comportamiento térmico, determinación de temperatura de transición vítrea. Estudio de la interacción entre los distintos componentes de los encapsulados a través de FT-IR. Porosidad. 
- Estudiar los mecanismos de liberación de los fertilizantes encapsulados vinculados con el sustrato de liberación (líquido o sólido). Así como el efecto del polvo de yerba mate como material de relleno y regulador de la matriz. Se analizará la cinética de liberación de los distintos fertilizantes y del polvo de yerba mate encapsulados tanto en medios líquidos como sólidos (suelos). 
CAPÍTULO II

Estado del Arte 


\subsection{Fertilizantes}

El término "fertilizante", se refiere a cualquier sustancia que contenga uno o más reconocidos nutrientes, que son utilizados por las plantas y que están diseñados para este uso o afirman, que tienen el valor de estimular el crecimiento de la planta (Terry, 1990).

Se considera que el fertilizante ideal debe poseer al menos tres características fundamentales: 1) Que necesite una aplicación única a lo largo del período de crecimiento de la planta, con la proporción adecuada de nutrientes para su desarrollo óptimo, 2) Tener una alta productividad agronómica, y 3) Impactos adversos mínimos en tierra, agua y medioambiente (Hurtado et al., 2007; Shavit, Reiss, \& Shaviv, 2002).

\subsubsection{Fertilizantes de liberación lenta y controlada}

Jiménez Gómez (1992) define a la liberación controlada como la transferencia lenta, moderada o gradual, de un material activo desde un sustrato de reserva a otro medio, con el fin de conseguir sobre el mismo una acción determinada. Con ello se consigue aumentar la eficacia del material activo prolongando su acción en el tiempo, se reduce su impacto sobre aquellos otros medios a los que no van especialmente dirigidos, se simplifica su dosificación, se evitan pérdidas por degradación, volatilización y lixiviación.

Los fertilizantes de liberación lenta y controlada, son fertilizantes que contienen nutrientes de forma que: a) retrasan su disponibilidad para la absorción y uso de la planta después de la aplicación o, b) están disponibles para la planta por periodos significativamente mayores que los "fertilizantes de disponibilidad inmediata", como el nitrato de amonio, urea, etc. (AAPFCO, 1995).

Nutralene (1993), describe las principales ventajas de este tipo de fertilizantes: 
a) Reducen la toxicidad: a causa de las altas concentraciones iónicas producidas por la disolución rápida de los fertilizantes convencionales solubles, por ende los fertilizantes de liberación lenta y controlada contribuyen a una mejor seguridad agronómica.

b) Disminuyen las labores en el campo, permitiendo la utilización de un fertilizante más conveniente y contribuyendo a un programa de sistema de cultivo con una sola aplicación del fertilizante.

c) Reducen las posibles pérdidas de nutrientes, particularmente las pérdidas de nitrógeno que se producen entre aplicaciones y permite captar los nutrientes por la planta de forma gradual.

d) Contribuyen a la reducción del impacto ambiental producido por los fertilizantes comunes, ya que reducen las pérdidas por evaporación del $\mathrm{NH}_{3}$ y en consecuencia las emisiones de gases $\left(\mathrm{N}_{2} \mathrm{O}\right)$ a la atmósfera, además de restringir las pérdidas por lixiviación, las cuales son responsables de un problema medioambiental muy grave, ya que produce la contaminación de los suelos y de las aguas subterráneas o superficiales cuando el agua de lluvia arrastra sustancias contaminantes presentes.

De acuerdo a las propuestas realizadas por la CEN (European Standardization Committee), mencionadas por Kloth (1996), un fertilizante puede ser denominado como de liberación lenta, si el nutriente declarado como tal y en condiciones definidas (incluyendo el de una temperatura de 25 $\left.{ }^{\circ} \mathrm{C}\right)$, cumple con los siguientes criterios:

(1) No más del $15 \%$ liberado en 24 horas,

(2) No más del $75 \%$ liberado en 28 días, y

(3) Por lo menos $75 \%$ debe ser liberado en el tiempo programado de liberación.

Los términos, CRF "fertilizantes de liberación controlada" (Controlled-Release Fertilizers), y SRF "fertilizantes de liberación lenta" (Slow-Release Fertilizers), por sus siglas en inglés, son comúnmente considerados análogos (Azeem, 
KuShaari, Man, Basit, \& Thanh, 2014), sin embargo, algunos autores han definido algunas diferencias entre ambos, siendo las más comunes:

\subsubsection{Fertilizantes de liberación controlada}

El término CRF, es aceptable según Shaviv (2001), cuando se aplica a fertilizantes en los que los factores que dominan la tasa, patrón y duración de la liberación son conocidos y controlables.

Para controlar dichos factores, los fertilizantes de liberación controlada suelen revestirse o encapsularse con materiales inorgánicos u orgánicos (G. Liu et al., 2014), insolubles en agua, semipermeables o impermeables con poros, esto controla la penetración del agua y por ende la tasa de disolución, sincronizando la liberación de nutrientes con las necesidades de las plantas (M.E. Trenkel, 2010).

El concepto de desarrollar CRF's se explica esquemáticamente en la Figura 2.1. Este diagrama ilustra la cantidad relativa de fertilizante (por ejemplo: urea disponible para la planta) en función de un ciclo de cultivo, en un tiempo comprendido entre $\mathrm{O}$ y $\mathrm{X}$. El fertilizante convencional permanece activo como se muestra en la curva $A$, mientras que el requerimiento real se expresa en la curva $B$, esto implica que para una parte del ciclo de cultivo, la cantidad cubierta por el área bajo la curva $A$ está en exceso, seguida de una fase que muestra deficiencias representada por la zona sombreada (S). Así, el cultivo no obtendrá la cantidad necesaria de urea en el momento correcto, lo que se traduce en un rendimiento deficiente. Una aplicación adicional de urea, seguiría el camino expresado por la curva $\mathrm{C}$, cubriendo parte de las deficiencias pero generando un aporte ineficiente, de acuerdo al requerimiento del cultivo. 


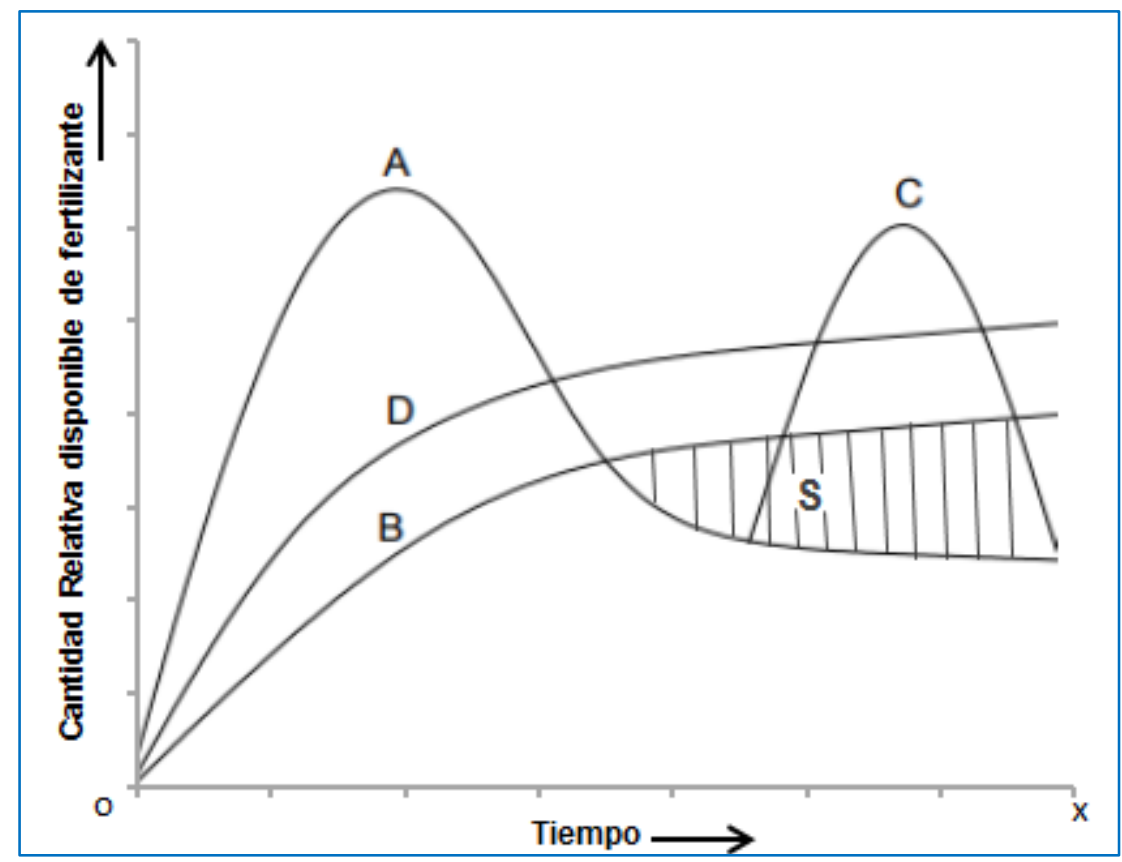

Figura 2.1 Representación esquemática de la cantidad relativa de fertilizante disponible durante el período de crecimiento de una planta.

Fuente: Dave, Mehta, Aminabhavi, Kulkarni \& Soppimath (1999)

Cuando un CRF se encuentra bien diseñado y se aplica en el mismo entorno, se comportaría como muestra la curva $D$, que es paralela a la del requerimiento real (Curva B). Es decir, un fertilizante ideal debería comportarse como la curva $D$, superpuesto a la curva $B$, evitando zonas excesivas o deficientes (Aguilar, 2014; Dave et al., 1999).

\subsubsection{Fertilizantes de liberación lenta}

Los $S R F$, se refieren a aquellos fertilizantes en que la liberación del nutriente se realiza de una manera más lenta que los fertilizantes comunes, sin embargo la tasa, el patrón y duración de la liberación no son bien controladas (Shaviv, 2001). Aunque se ha convertido en una práctica común en denominar como SRFs a los productos nitrogenados descompuestos microbiológicamente, como por ejemplo la ureaformaldehido (Trenkel, 1997). 


\subsubsection{Clasificación de fertilizantes de liberación lenta y controlada}

De acuerdo a la Asociación Americana del Control Oficial de Plantas y Alimentos (AAPFCO, 1997), no existe una diferenciación oficial entre los fertilizantes de liberación lenta y los de liberación controlada, por tanto en estudios como los de Azeem et al. (2014); Shaviv (2001), se utiliza el término "Fertilizantes de liberación controlada" (CRFs) para los dos casos, al igual que en esta investigación.

En la Figura 2.2, se observa una clasificación detallada realizada por Azeem et al. (2014), basada en las opiniones de Liu, Kost, Fishman, \& Hicks (2008); Shaviv (2001); Trenkel (2010). En términos generales, los (CRFs) se clasificaron en tres grandes categorías:

\subsubsection{Fertilizantes con $\mathbf{N}$ orgánico (compuestos de baja solubilidad)}

Estos pueden ser compuestos sometidos a una descomposición biológica (generalmente se basan en productos de condensación urea-aldehído, tales como la urea-formaldehído); y descomposición química, tales como isobutilen-diurea (IBDU) (Shaviv, 2001).

\subsubsection{Fertilizantes en los que una barrera física controla la liberación}

Los fertilizantes pueden aparecer como núcleos o gránulos revestidos de polímeros hidrófobos o como matrices en la que se dispersa el material activo soluble y se restringe la disolución de los fertilizantes. Los fertilizantes recubiertos se pueden dividir en fertilizantes recubiertos con polímeros orgánicos que son termoplásticos o resinas; y fertilizantes revestidos con materiales inorgánicos como el S o minerales. 
Los materiales utilizados para la preparación de matrices también se pueden subdividir en materiales hidrofóbicos como las poliolefinas, caucho, etc., y en polímeros para formación de gel (a veces llamados "hidrogeles"), que son de naturaleza hidrófila y reducen la disolución de los fertilizantes solubles por su alta retención de agua (hinchazón). En general, las matrices son menos comunes en la práctica que los fertilizantes recubiertos (Shaviv, 2001).

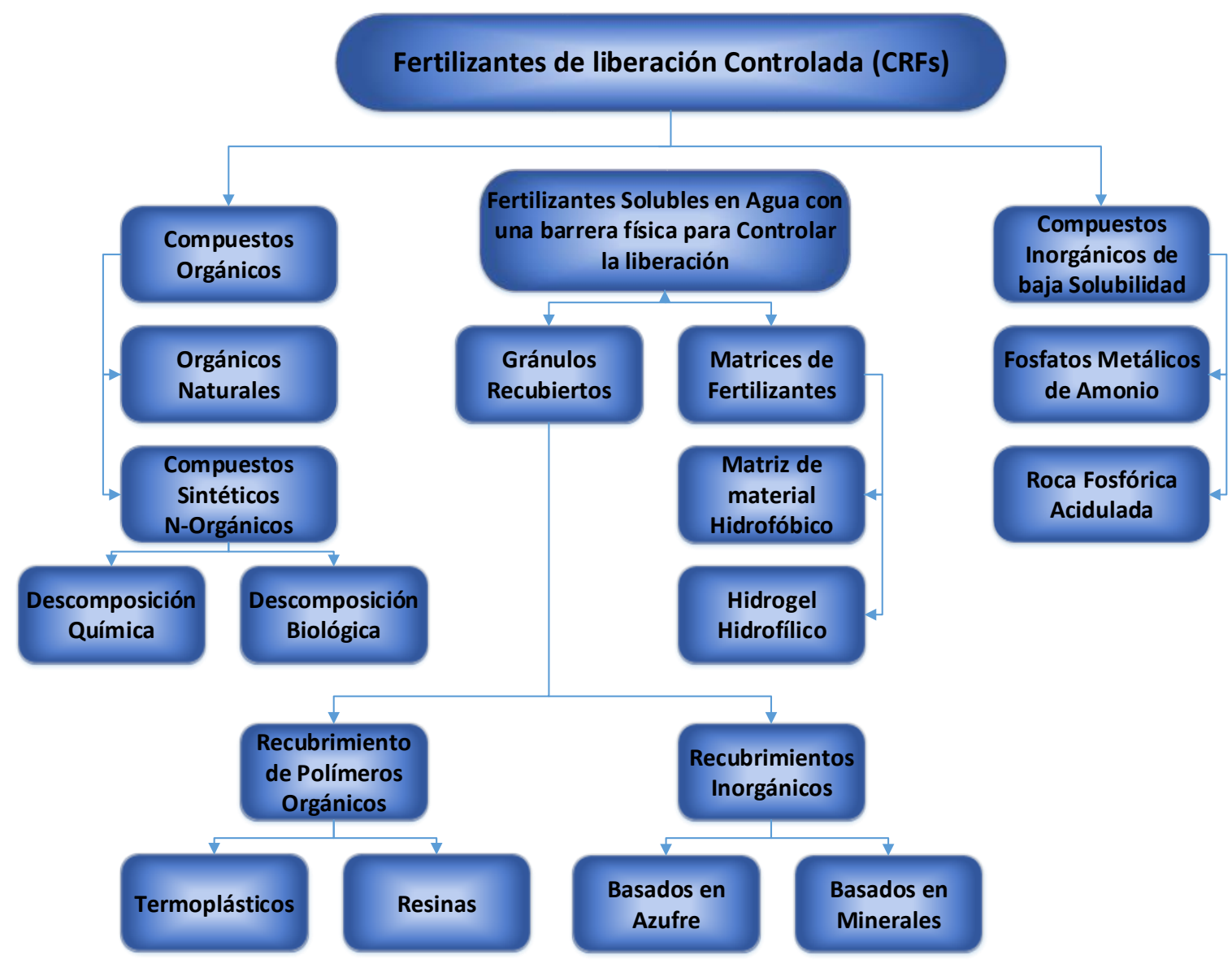

Figura 2.2 Clasificación de Fertilizantes de Liberación Controlada.

Fuente: Azeem et al. (2014) 


\subsubsection{Fertilizantes inorgánicos de baja solubilidad descompuestos}

Los fertilizantes tales como los fosfatos de amonio de metal (por ejemplo, Mg. $\mathrm{NH}_{4} \mathrm{PO}_{4}$ ), y las rocas fosfóricas parcialmente aciduladas (PAPR), son típicos de los fertilizantes de liberación lenta (Shaviv, 2001). 


\subsection{Encapsulación}

La encapsulación es un proceso en el cual un material o una mezcla de materiales son recubiertos o entrampados dentro de otro sistema. El material a ser recubierto es frecuentemente líquido, pero pueden ser también partículas sólidas o gaseosas y se los conoce por diferentes nombres como: material de núcleo, compuestos activos, carga útil o fase interna. Los materiales que son parte de los sistemas de cobertura o revestimiento se denominan como: material de pared, membrana, soporte, envoltura o revestimiento (Risch, 1995).

Las técnicas de encapsulación, permiten el empaquetamiento de diferentes materiales como alimentos, aceites, probióticos, enzimas, pigmentos vegetales, minerales, vitaminas y aditivos alimentarios. Entre los principales agentes utilizados para encapsular se pueden mencionar: polivinil alcohol (PVA), alginatos, lípidos, carbohidratos, gomas y proteínas.

Entre las aplicaciones prácticas de la microencapsulación se destacan la industria farmacéutica, médica, textil, pesticida, cosmética, química, de imprenta, agroquímica, fertilizantes, fragancias, tintes, agentes antimicrobianos, biomédica y de plásticos (Huertas, 2010).

Deladino, Navarro, and Martino (2007), reportaron diversos tipos de microcápsulas, aglomerados o cápsulas que dependen de los ingredientes y del procedimiento de obtención. La Figura 2.3 representa ilustrativamente los sistemas de encapsulación más comunes, entre ellos; los Reservorios, que consisten en un interior constituido por el material activo y un recubrimiento denominado material de cubierta, pared, barrera y puede estar formado por una o varias capas concéntricas (Fig. 2.3a). La Matriz inclusiva, consiste en una mezcla homogénea del ingrediente activo y el material encapsulante (Fig. 2.3b), la liberación en estos sistemas depende del tipo del material de la matriz, la forma de la cápsula y la cantidad de compuesto activo. Los Sistemas mixtos, se forman adicionando una capa extra sobre los sistemas antes mencionados para aumentar la protección del agente activo o retardar su liberación (Fig. 2.3c). 


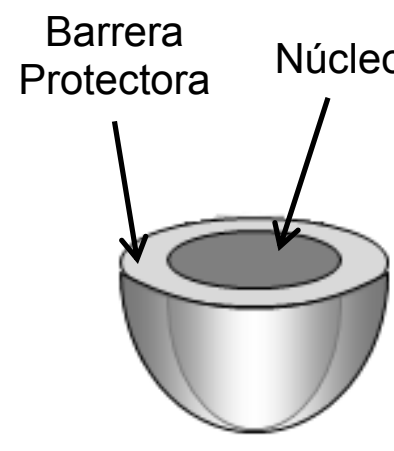

a
Agente activo uniformemente distribuido

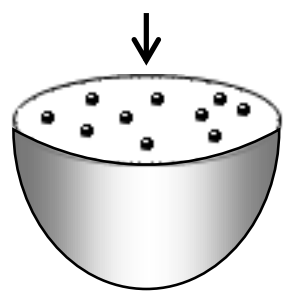

$\mathrm{b}$

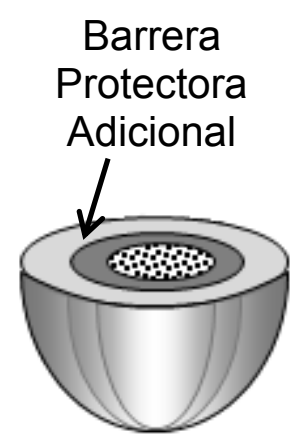

C
Cristales

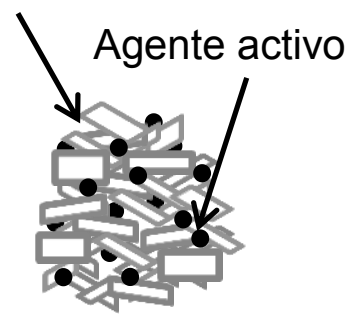

d

Figura 2.3 Representación ilustrativa de los sistemas de encapsulación: a) Reservorio, b) Matriz inclusiva, c) Mixto y d) Aglomerados.

Fuente: Moreno (2016)

Finalmente Los aglomerados, ofrecen una amplia área superficial para contener compuestos activos, facilitar el manipuleo y mejorar su aptitud frente al almacenamiento (Fig. 2.3d).

\subsubsection{Técnicas de Encapsulación}

Madene, Jacquot, Scher \& Desobry (2006) dividieron las técnicas de encapsulación en dos grupos: químicos y mecánicos. En la Figura 2.4 se detallan los principales procesos para encapsular sustancias.

\subsubsection{Procesos Químicos}

\section{Coacervación}

Es un fenómeno que se presenta en soluciones coloidales y se considera como el método original de encapsulación (Risch, 1995). El coacervado consiste en un soluto de polímeros separado en forma de gotas líquidas pequeñas. La deposición de este coacervado alrededor de las partículas 
insolubles dispersas en un líquido forma cápsulas iniciales, que por una gelificación apropiada dan como resultado las cápsulas finales (Madene et al., 2006).

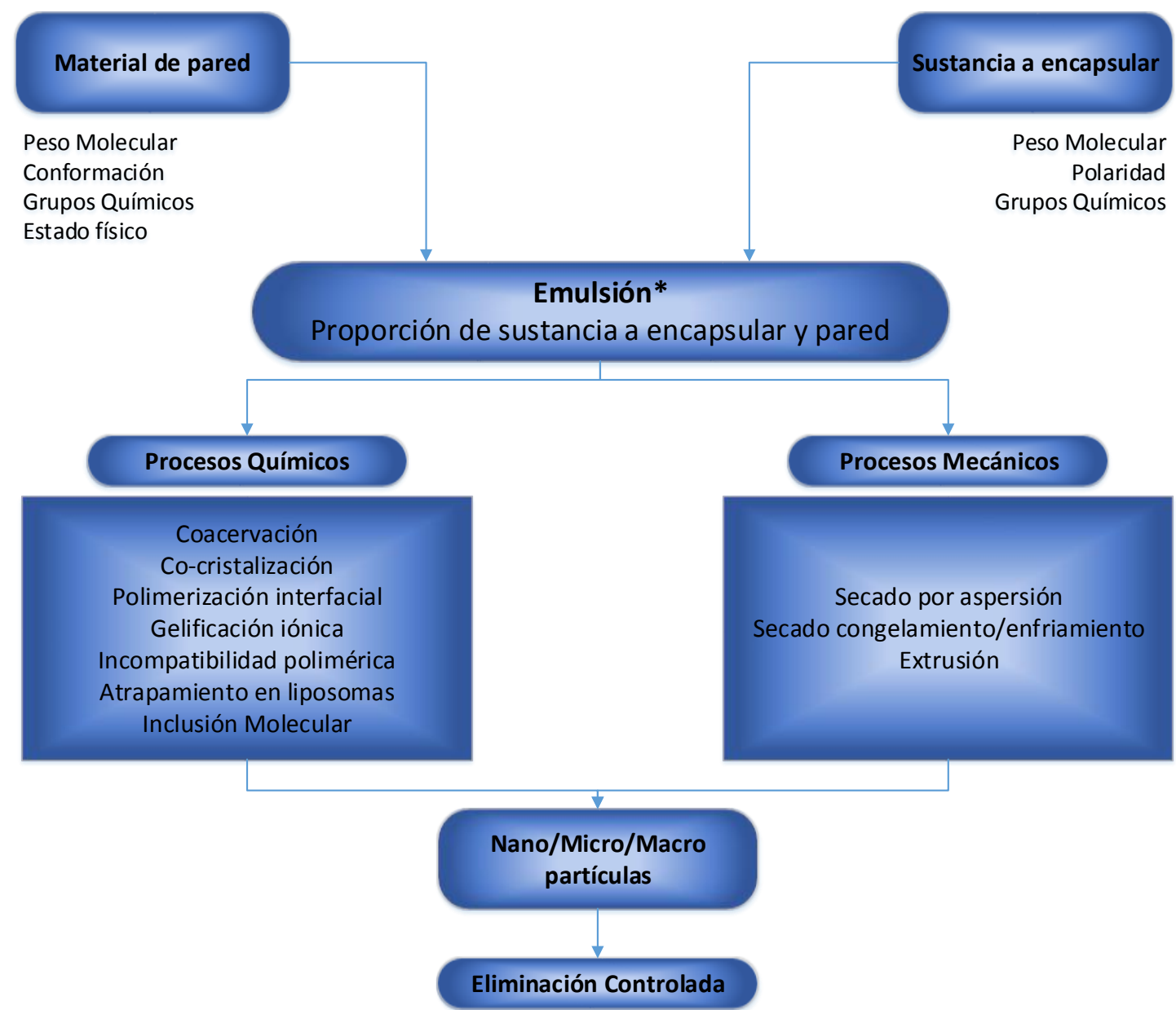

*Proceso requerido en algunas técnicas

Figura 2.4 Esquema ilustrativo de las técnicas de encapsulación.

Fuente: Madene et al. (2006)

Las estrategias para inducir la coacervación dependen principalmente de las características fisicoquímicas del polímero y del centro a recubrir. En la coacervación, la separación de fases es provocada por la adición lenta de un "no-solvente" sobre una solución del polímero que va a formar el recubrimiento, éste contiene suspendido el material que va a encapsularse. El "no-solvente" es aquel disolvente que es miscible con el disolvente del polímero y en el cual el polímero es insoluble. Conforme se 
va adicionando el "no-solvente" se provoca la insolubilización del polímero, el cual, a su vez se va depositando alrededor de las partículas presentes en suspensión. Al final del proceso, un volumen elevado del nosolvente es agregado para endurecer las cápsulas (Villamizar \& Martínez, 2008).

Generalmente, el material central utilizado en la coacervación debe ser compatible con el polímero del recipiente y ser insoluble (o muy poco soluble) en el medio de coacervación. La técnica de coacervación es de dos tipos, la simple que involucra solamente un tipo de polímero con la adición de agentes fuertemente hidrofílicos a la solución coloidal y la coacervación compleja, en la que son utilizados dos o más tipos de polímeros (Madene et al., 2006).

\section{Gelificación iónica}

La gelificación iónica se produce por el entrecruzamiento de unidades de ácido urónico de distintas cadenas de alginato con cationes multivalentes $\left(\mathrm{Ca}^{+2}, \mathrm{Zn}^{+2}, \mathrm{Fe}^{+2 /+3}, \mathrm{Co}^{+2}, \mathrm{Ba}^{+2}, \mathrm{Al}^{+3}\right)$. Las cápsulas más utilizadas son las de alginato de Ca por su sencillez de preparación a escala de laboratorio, por extrusión o emulsificación, incluso en condiciones estériles. Son muy versátiles; virtualmente cualquier compuesto puede ser encapsulado con este sistema, ya sea hidrofóbico o hidrofílico, líquido o sólido (López, Deladino, Navarro, \& Martino, 2011).

Existen dos técnicas de gelificación:

Gelificación externa. En la gelificación externa, la sal de calcio soluble es agregada a una emulsión Agua/Aceite (W/O). El tamaño de partícula no puede ser bien controlado y las partículas tienden a coagular en grandes masas antes de adquirir la consistencia apropiada. Además, el tamaño de partícula que se obtiene es grande entre $400 \mu \mathrm{m}$ y $1 \mathrm{~mm}$ (Rodríguez-Llimos, Chiappetta, Szeliga, Fernández, \& Bregni, 2003). 
Gelificación interna. La gelificación interna se basa en la liberación del ion calcio desde un complejo insoluble en una solución de alginato de sodio. Esto se lleva a cabo por acidificación de un sistema aceite-ácido soluble, con participación en la fase acuosa del alginato. Esta técnica permite obtener partículas de un tamaño de aproximadamente $50 \mathrm{~mm}$ (Poncelet et al., 1992).

De acuerdo con esta técnica, a la fase acuosa, generalmente formada por alginato y carbonato cálcico, se le adiciona la fase oleosa (aceite vegetal, Span 80 y ácido acético) (Villena, Hernández, Lara, \& Martínez, 2009).

\section{Co-cristalización}

La co-cristalización es un proceso de encapsulación donde se incorpora un segundo ingrediente en un producto poroso conglomerado de microcristales de azúcares formado por cristalización espontánea. El proceso se lleva a cabo concentrando, por ejemplo un jarabe de sacarosa hasta sobresaturación y, luego, agregando el material del núcleo, con la mezcla sometida a una agitación intensiva que conduce a nucleación y la aglomeración (Astolfi-Filho, Souza, Reipert, \& Telis, 2005).

\section{Polimerización interfacial}

Este proceso involucra una reacción de polimerización que ocurre en la interface entre una fase oleosa que contiene la sustancia activa y una fase acuosa, formando una membrana, que dará lugar a la pared de las cápsulas. Para esto, en primer lugar se realiza la dispersión de una solución acuosa de un reactante soluble en agua, en una fase orgánica para producir una emulsión de agua en aceite, luego se forma una membrana polimérica en la superficie de las gotas de agua, iniciada por la adición de un complejo soluble en aceite a la emulsión anterior, finalmente se produce la separación de las cápsulas de la fase orgánica y su 
transferencia en agua para dar una suspensión acuosa (Chávez, Olvera, Ganem, \& Quintanar, 2002; Rendón García, Vargas Taborda, \& Castrillón Zuluaga, 2016).

\section{Incompatibilidad Polimérica}

La incompatibilidad polimérica es el mecanismo que induce la separación de fases, este método utiliza el fenómeno de separación de fases en una mezcla de dos polímeros químicamente diferentes e incompatibles en un mismo solvente. El material a encapsular interaccionará sólo con uno de los dos polímeros el cual se adsorbe en la superficie del material a encapsular formando una película que lo engloba. Generalmente este método se realiza en solventes orgánicos y cuando el material a encapsular es sólido (Pedroza-Islas, 2002).

\section{Atrapamiento en liposomas}

Se elaboran con moléculas amfifílicas que poseen sitios hidrofóbicos (ácidos grasos, fosfolípidos, etc) y sitios hidrofílicos (colina, serina, inositol, etc). Por ejemplo cuando los fosfolípidos como la lecitina se colocan en agua, forman vesículas hechas de varias bicapas concéntricas divididas por compartimentos acuosos. En la fase acuosa se coloca en material a encapsular cuando es hidrofílico o bien se agrega en el solvente orgánico donde se disuelven los fosfolípidos, si es lipofílico (Pedroza-Islas, 2002). La liberación del principio activo se realiza por difusión a través de la bicapa, por destrucción de la vesícula, por medio de una concentración crítica de iones de calcio o por un cambio de pH (Huertas, 2010). 


\section{Inclusión Molecular}

Los complejos formados en esta técnica, se definen como el resultado de interacciones entre compuestos en los que molécula más pequeña se adapta y está rodeada por la molécula que actúa como agente encapsulante. Las ciclodextrinas son moléculas de almidones modificados enzimáticamente y son el ejemplo más relevante de este método de encapsulación (Madene et al., 2006).

\subsubsection{Procesos Mecánicos}

\section{Secado por aspersión}

El procedimiento del secado por aspersión involucra tres etapas: preparación de la dispersión o solución, homogenización y atomización. Este proceso consiste en atomizar el material que se encuentra en estado líquido, ya sea como solución o como dispersión, formándose al final gotas finas sobre una corriente de gas calentado, cuando las pequeñas gotas del líquido toman contacto con el gas, y a una mayor temperatura, se produce una rápida evaporación del solvente formándose una fina película del material de recubrimiento. En este método el componente o sustancia a encapsular es rodeado por una matriz protectora, normalmente un polímero como goma, maltodextrina, almidón y carboximetilcelulosa. Entre las ventajas principales de este proceso se encuentran: la disponibilidad de equipos, costo bajo de los procesos, buena retención de volátiles, buena estabilidad del producto final y producción a gran escala en modo continuo (Pedroza-Islas, 2002; Rendón García et al., 2016). 


\section{Aspersión por enfriamiento o congelamiento}

Este método es considerado uno de los más adecuados para el secado de materiales biológicos y alimentos sensibles. La aspersión por enfriamiento y congelamiento involucra la dispersión de ingredientes solubles en agua, en una grasa fundida o cera; esta dispersión se realiza, por ejemplo, a través de inyectores con calefacción dentro de una cámara a temperatura ambiente o temperatura de refrigeración, entre otros métodos para la preparación de dispersiones.

Las microcápsulas son insolubles en el medio y, por ello podría ser liberado su contenido cuando la temperatura del producto alimenticio aumenta por encima de la temperatura de fundición de la grasa o cera (Huertas, 2010).

\section{Extrusión}

La microencapsulación por extrusión involucra el paso de una emulsión del material activo y el material de pared a través de alta presión. La extrusión constituye el segundo proceso más usado, después del secado por aspersión, para la encapsulación de sabores. Un proceso típico involucra la mezcla de sabores con jarabe de maíz o almidón modificado caliente, extrudiendo la mezcla en forma de esferitas (pellets) dentro de un baño con un disolvente frío como el isopropanol. El disolvente frío solidifica el jarabe en un sólido amorfo, bañando los sabores (Huertas, 2010; Yañez et al., 2002).

La selección del método de encapsulación será en función del: tamaño medio de la partícula requerida, de las propiedades físicas del agente encapsulante, de la sustancia a encapsular, de las aplicaciones del material encapsulado propuesto, del mecanismo de liberación deseado y del costo (Villena et al., 2009). 


\subsubsection{Encapsulación de fertilizantes de liberación controlada}

La principal característica aplicable de estos fertilizantes está orientada al rendimiento de los mismos. El nitrógeno, en estado mineral típico de algunos de los fertilizantes comerciales comunes, es el nutriente que presenta una menor eficacia en el suelo, alcanzándose en ocasiones pérdidas de hasta el $50 \%$ de la cantidad del nutriente aportado, por lo tanto, el objetivo central de los fertilizantes de liberación lenta o controlada consiste en aumentar su eficacia mediante la lenta transformación al estado en que el cultivo pueda absorberlo y sincronizando esta transformación con el ritmo de fijación y asimilación del nitrógeno por parte de la planta (Ballester Olmos, 1994).

La encapsulación de nutrientes tipo N-P-K que son los componentes principales de los fertilizantes comerciales, se ha realizado con el objetivo de reducir la disolución inmediata y excesiva del fertilizante, mediante la aplicación de una o varias capas uniformes que retrasen su inmediata disponibilidad para las plantas, sin embargo los recubrimientos utilizados deben cumplir con varias características como el ser: inocuos, inactivos, de baja solubilidad, biodegradables, de aplicación fácil, efectivos y de costos moderados de acuerdo al producto a desarrollar. De acuerdo a estas consideraciones, la idea de desarrollar un fertilizante encapsulado utilizando el polvo de yerba mate (PYM), nos permite utilizar un subproducto de la industria yerbatera, que incorporado en la matriz tendría doble efecto; a) proteger al nutriente encapsulado en sinergia con el polímero utilizado y b) aprovechar los nutrientes minerales existentes en el PYM, para que puedan ser utilizados por las plantas.

\subsubsection{Urea}

La Urea, también conocida como carbamida o carbonildiamida, es el nombre del ácido carbónico de la diamida cuya fórmula química es $\left(\mathrm{NH}_{2}\right)_{2} \mathrm{CO}$. Se presenta como un sólido cristalino y blanco de forma esférica o granular. Es una sustancia higroscópica, es decir, que tiene la 
capacidad de absorber agua de la atmósfera y presenta un ligero olor a amoníaco. Considerada la mayor fuente de nitrógeno en el mundo debido a su alta concentración y a su precio normalmente atractivo por unidad de N. Sin embargo, su aplicación requiere buenas prácticas agrícolas para evitar pérdidas por evaporación de amoníaco en el aire. La urea debería ser aplicada sólo cuando sea posible incorporarla inmediatamente en el suelo después de esparcida o cuando la lluvia se espera en pocas horas después de la aplicación (FAO \& IFA, 2002).

La urea es soluble en agua y no es retenida por el suelo, se hidroliza en contacto con el agua y bajo la acción de la ureasa.

$$
\left(\mathrm{NH}_{2}\right)_{2} \mathrm{CO}+\mathrm{H}_{2} \mathrm{O} \rightarrow 2 \mathrm{NH}_{3}+\mathrm{CO}_{2}
$$

En buenas condiciones de temperatura y humedad dicha hidrólisis puede realizarse en dos o tres días mientras que en condiciones tropicales y subtropicales se puede realizar en pocas horas. En esta primera reacción se observa un comportamiento básico (al pasar de amida a carbonato amónico). Posteriormente la forma amoniacal pasa a forma nítrica (liberando $\mathrm{H}^{+}$al medio), que es la forma en que la mayoría de las plantas asimilan el nitrógeno. Por lo que el comportamiento final de la urea es de carácter ácido. Las pérdidas sustanciales por evaporación de amoníaco ocurrirán, particularmente en suelos alcalinos, mientras que en suelos donde una incorporación superficial es suficiente, el amoníaco es adsorbido como $\mathrm{NH}^{4+}$ en las partículas de la materia orgánica y arcilla del suelo y de este modo protegido contra las pérdidas por evaporación (FAO \& IFA, 2002; Ginés \& Mariscal Sancho, 2002).

La urea, es el insumo más utilizado entre el grupo de los fertilizantes nitrogenados, siendo la República Argentina, el mayor productor de urea en América Latina (Schneider Teixeira, Deladino, \& Zaritzky, 2016). 


\section{CAPÍTULO III}

Caracterización del polvo de yerba mate 


\subsection{Yerba Mate (Ilex paraguariensis)}

El Código Alimentario Argentino, CAA (2002), la define en su capítulo XV Productos estimulantes o fruitivos (Art. 1193): "Con la denominación de Yerba Mate o Yerba se entiende el producto formado por las hojas desecadas, ligeramente tostadas y desmenuzadas, de Ilex paraguariensis Saint Hilaire (Aquifoliácea) exclusivamente, mezcladas o no con fragmentos de ramas secas jóvenes, pecíolos y pedúnculos florales".

El origen de la yerba mate se da entre la región que va desde el Este de Paraguay, pasando por Misiones (Nordeste Argentina), hasta los estados de Paraná y Santa Catarina en Brasil. Antes de la llegada de los europeos a América, la yerba era consumida por los indígenas como una infusión de hojas secas y trituradas (Burtnik, 2006). En esta región las hojas desecadas y molidas se utilizan en la preparación de bebidas como el mate, mate cocido o tereré y son consumidas por millones de personas en proporciones de más de un litro por día, se incluye el consumo también de forma medicinal como estimulante del sistema nervioso central, diúretico y en formulas para reducción de peso (Dellacassa \& Bandoni, 2001; Silva et al., 2011).

\subsubsection{Proceso de obtención de la yerba mate}

El procesamiento de las hojas de yerba mate (Fig. 3.1) puede tener ciertas variantes entre las diferentes industrias, pero en líneas generales se describen las siguientes etapas (Barchuk, 1998; Burtnik, 2006; Valduga, Finzer, \& Mosele, 2003):

1) Cosecha: las hojas verdes y pequeños tallos se cortan de forma manual semimecanizada o completamente mecanizada. Se debe evitar la contaminación con elementos extraños que afecten la calidad del producto, se colocan en bultos cuya capacidad no debe superar los $60 \mathrm{~kg}$ evitando en lo posible presencia de flores y frutos para luego ser llevadas a la planta de procesamiento. 
El procesamiento de la yerba, debe iniciarse dentro de las 24 horas posteriores a la cosecha, con el fin de evitar la fermentación y con ello, su inutilización y pérdida.

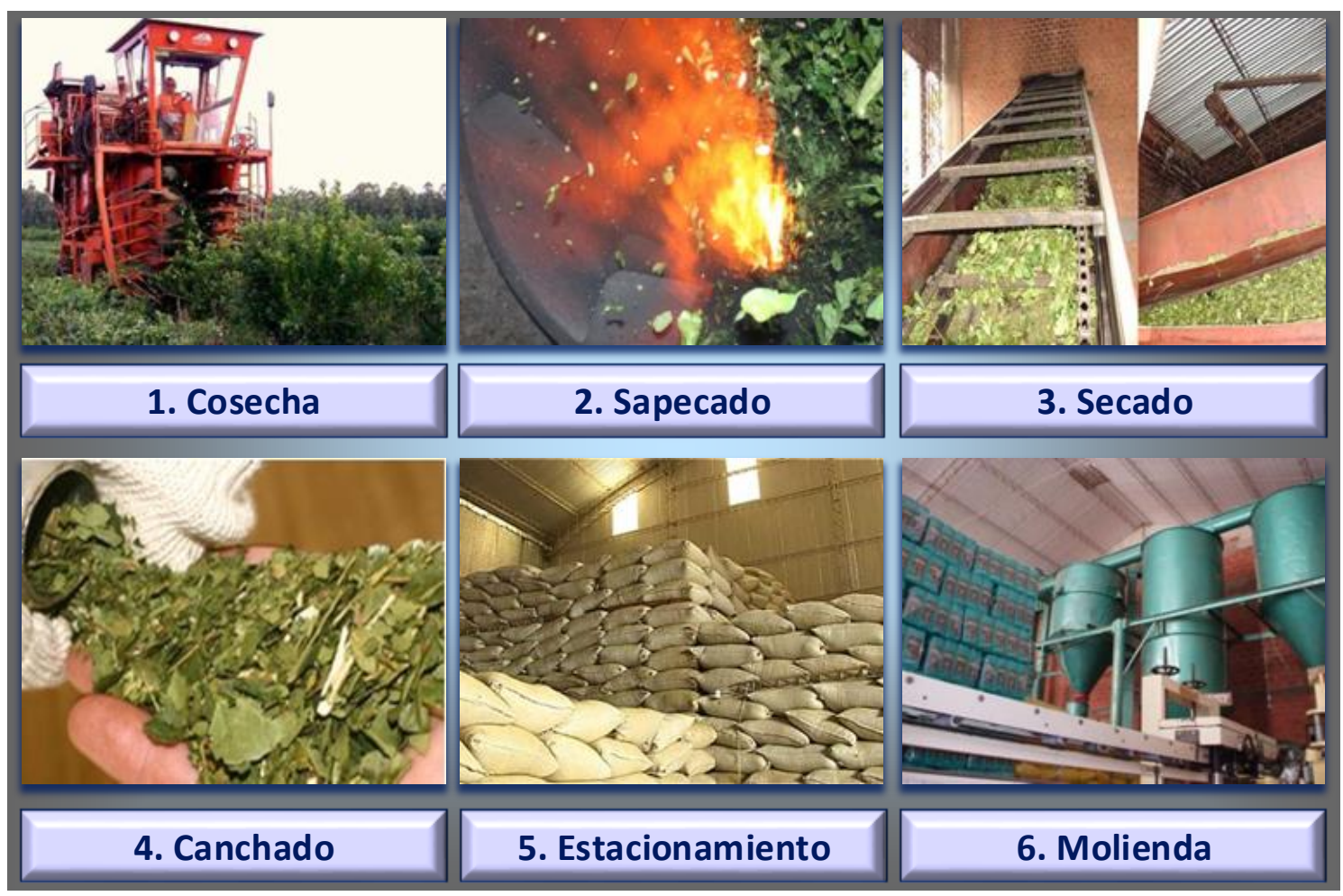

Figura 3.1 Esquema del Proceso de Obtención de la Yerba Mate. Fuente: Instituto Nacional de la Yerba Mate

2) Sapecado: este proceso consiste en la exposición de la yerba verde al fuego directo, y se realiza en un horno rotativo cilíndrico a temperaturas entre 400 y $460{ }^{\circ} \mathrm{C}$ durante 20 a 30 segundos. En esta etapa se produce la inactivación de las enzimas oxidantes para lograr la conservación del color, sabor y aroma de las hojas. En esta etapa se elimina aproximadamente el 25 $\%$ de la humedad original.

3) Secado: Reduce el contenido de humedad de la yerba mate hasta aproximadamente un $5 \circ 6 \%$, su peso disminuye de 100 kilogramos de hoja verde hasta unos 30 a 36 kilogramos de yerba mate seca.

4) Molienda (canchado): Para facilitar el transporte y almacenamiento del producto a la etapa de estacionamiento, se realiza el canchado, que es una 
molienda y trituración gruesa de la yerba después del secado. Se realiza con canchadoras mecánicas provistas de cuchillas que giran a gran velocidad, pasando la yerba mate a través de ellas.

También en esta etapa se realiza un tamizado (en tamices rotatorios) para eliminar los palos de mayor tamaño (1-10\% del material de entrada). La yerba mate canchada se coloca en bolsas de material plástico o arpillera y se envían al estacionamiento.

5) Estacionamiento: es el período de tiempo necesario para que el producto logre desarrollar las características organolépticas como sabor, aroma y color deseados. En el proceso de estacionamiento natural, la yerba se mantiene almacenada en depósito por un lapso que oscila entre los 9 y los 12 meses, a fin de que se produzcan los procesos de transformación espontáneamente. En el proceso de estacionamiento controlado o acelerado, se consigue en cámaras con atmósfera controlada (temperatura, humedad y circulación forzada de aire). El tiempo de permanencia se reduce a 45-60 días adquiriendo la yerba características organolépticas similares a las del estacionamiento natural.

6) Molienda y envasado: En esta última etapa se busca alcanzar una granulometría que permita envasar el producto en diversas presentaciones. Mediante las operaciones de zarandeo, limpieza y molienda, se obtiene el tamaño adecuado de la yerba y se eliminan el polvo y el exceso de palos de gran tamaño. Según su grado de trituración (hoja fina y gruesa; palo fino y grueso; polvo) se distribuyen y almacenan en silos diferentes. Por último, se procede a la mezcla y envasado de acuerdo a la composición característica de cada producto comercial.

Las partículas de tamaño reducido (polvos) generados mayoritariamente en esta etapa deben ser eliminadas del producto que se comercializará ya que pueden ocasionar problemas al momento de ser consumidas (Velázquez et al., 2006). 
Las fracciones de hoja y palo deben cumplir o mejorar la proporción especificada en el Código Alimentario Argentino, CAA (2002): Hoja: mínimo $65 \%$ y Palo: máximo $35 \%$.

\subsubsection{Composición de la yerba mate}

Esmelindro, Toniazzo, Waczuk, Dariva, \& Oliveira (2002), reportaron la composición físico-química de la yerba mate procesada (Tabla 3.1), así como los cambios que sufre la hoja durante su procesamiento, en las etapas de sapecado, secado y canchado en diferente número de días.

Tabla 3.1 Variación de la composición físico-química de la yerba mate en función de sus etapas de procesamiento

\begin{tabular}{lcccccc}
\hline \multirow{2}{*}{ MUESTRA } & \multicolumn{5}{c}{ Composición (\% Base Seca) } \\
\cline { 2 - 7 } & CENIZAS & FIBRA & GRASA & PROTEínA & GLUCOSA & SACAROSA \\
\hline Hoja Seca & 6.01 & 21.10 & 6.76 & 14.49 & 1.50 & 2.27 \\
Sapecador & 5.91 & 18.70 & 7.01 & 14.16 & 1.83 & $1.68^{\mathrm{a}}$ \\
Secador & 5.58 & 24.32 & $5.50^{\mathrm{a}}$ & $12.04^{\mathrm{a}}$ & 1.67 & $1.88^{\mathrm{a}}$ \\
Canchada (5 días) & 6.06 & 22.53 & 5.74 & 12.84 & 1.71 & $1.54^{\mathrm{a}}$ \\
Canchada (21 días) & 6.08 & 22.28 & 6.06 & 13.43 & 1.62 & $1.48^{\mathrm{a}}$ \\
\hline
\end{tabular}

(a) Diferencia significativa a un nivel del 5\% en relación a la hoja seca

Fuente: Esmelindro et al. (2002)

Durante este estudio se observa que el contenido de cenizas no varía significativamente durante las etapas de procesamiento, esto es importante saberlo, pues los minerales que se encuentran en la yerba mate, probablemente serán los mismos que encontremos en el polvo de yerba mate, que es el componente principal en la matriz de los encapsulados.

EI PYM es el subproducto que se utilizó en la formación de los encapsulados en este trabajo y fue caracterizado por Schneider Teixeira et al. (2016), quienes reportaron su composición mineral detallada como se indica en la (Tabla 3.2). 
Tabla 3.2 Contenido de los Nutrientes Minerales en el polvo de yerba mate

\begin{tabular}{cc}
\hline Mineral & g mineral/100 g de cenizas \\
\hline $\mathrm{Mn}$ & $0.70 \pm 0.03$ \\
$\mathrm{Fe}$ & $0.30 \pm 0.01$ \\
$\mathrm{Ca}$ & $25.3 \pm 0.50$ \\
$\mathrm{Mg}$ & $5.1 \pm 0.10$ \\
$\mathrm{Cu}$ & $0.0096 \pm 0.0006$ \\
$\mathrm{~K}$ & $9.0 \pm 0.10$ \\
$\mathrm{Zn}$ & $0.147 \pm 0.009$ \\
$\mathrm{Na}$ & $0.39 \pm 0.02$ \\
\hline
\end{tabular}

Fuente: Schneider Teixeira et al. (2016)

El contenido mineral de la Yerba Mate ha sido determinado en varios estudios (Giulian et al., 2007; Heinrichs \& Malavolta, 2001; Maiocchi, Moyano, Martínez, \& Avanza, 2002), con resultados similares a los reportados por Schneider Teixeira et al. (2016) para el polvo de yerba mate. 


\subsection{Materiales y métodos}

\subsubsection{Caracterización del polvo de yerba mate (PYM)}

El polvo de yerba mate fue gentilmente provisto por el Instituto Nacional de la Yerba Mate (INYM, Argentina), el cual fue recolectado de las industrias locales.

\subsubsection{Materia seca y contenido total de cenizas}

El agua residual se cuantificó gravimétricamente, colocando muestras de polvo de yerba mate $(2 \mathrm{~g})$ en un horno (San Jor H701P, Argentina) a $105^{\circ} \mathrm{C}$ hasta alcanzar peso constante. Los resultados fueron cuantificados como porcentaje (\%) respecto del peso inicial. Las cenizas totales también se determinaron gravimétricamente por sextuplicado, después de la incineración en una mufla (Indef 331 , Córdoba, Argentina) a $550{ }^{\circ} \mathrm{C}$. El porcentaje (\%) de cenizas totales fue calculado en base seca (IRAM, 1996).

\subsubsection{Determinación del contenido de minerales o micronutrientes mediante espectroscopía de absorción atómica}

\section{Digestión de las muestras}

Las muestras se pesaron y se digirieron en un Microwave Digestion Labstation Milestone, mod. Ethos 1 (Milestone, Shelton, USA) con $\mathrm{HNO}_{3}$ (Hiperpur, Panreac Química S.A, Barcelona, España) y $\mathrm{H}_{2} \mathrm{O}_{2}$ (PA, Panreac Química S.A, Barcelona, España) dentro de vasos cerrados de teflón (TFM) (Fig. 3.2). 


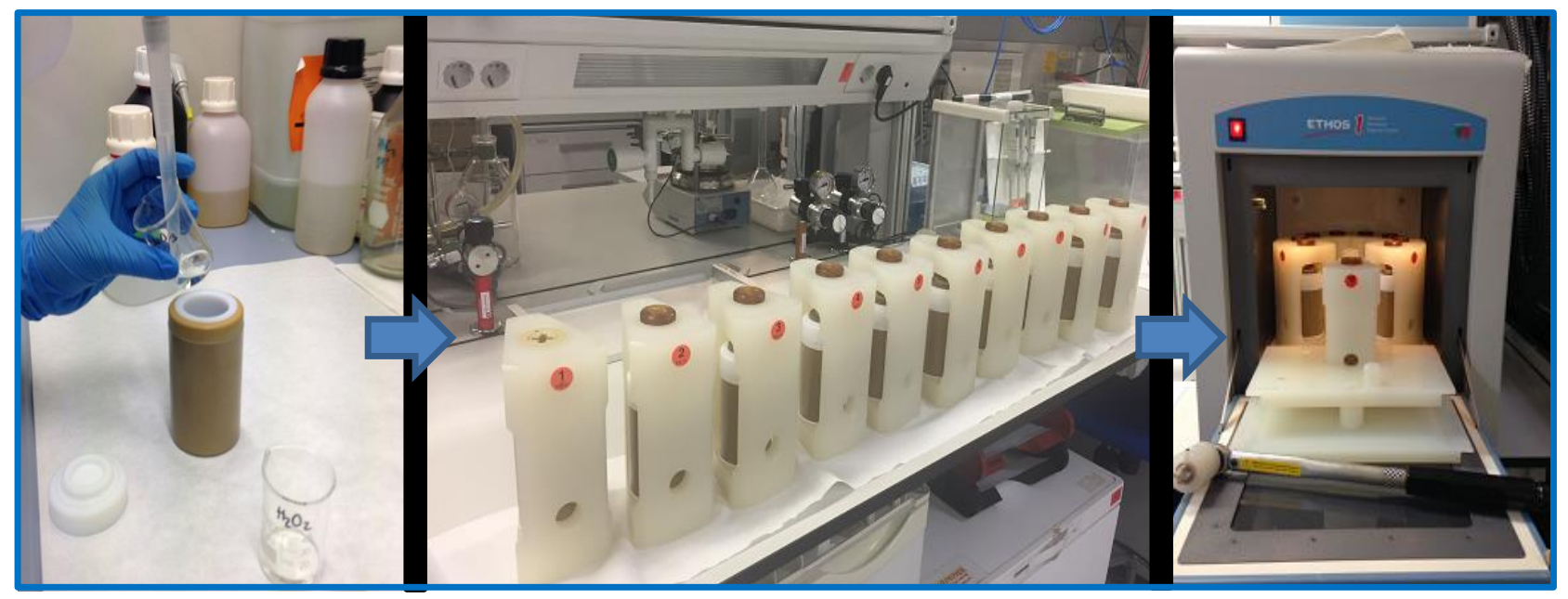

Figura 3.2 Ensayo de digestión de muestras para determinación del contenido de minerales.

Las muestras una vez digeridas se diluyeron con agua desionizada ultrapura (18.2 $\mathrm{M} \Omega$-cm resistividad a $25^{\circ} \mathrm{C}$, Millipore, Bedford, MA, USA).

\section{Determinación de elementos (Mg, $\mathrm{K}$ y Ca)}

El análisis se realizó por Espectroscopía de Absorción Atómica, mediante un espectrómetro con fuente continua de alta resolución (tecnología HS CS AAS), modelo ContrAA 700 (Analytik Jena AG, Jena, Alemania), equipado con lámpara de arco corto de xenón (GLE, Berlin, Alemania). El calcio se determinó con una llama rica en óxido nitroso-acetileno, y el potasio y el magnesio se determinan por llama de aire-acetileno. Para cada elemento, se realizó una recta de calibración a diferentes concentraciones, preparada a partir de patrones comerciales individuales, de $\mathrm{Ca}, \mathrm{K}$ y de $\mathrm{Mg}$, todos de concentración 1000 mg/L (Panreac Química S.A, Barcelona, España). 


\subsubsection{Determinación del tamaño de partícula}

El PYM fue tamizado con un conjunto de mallas de entre 2 y $0.250 \mathrm{~mm}$. El método de determinación, consiste en colocar los tamices, uno sobre otro en orden creciente de abertura y luego transferir la muestra al tamiz superior. El tamizado de los productos se realizó con movimientos laterales, verticales y circulares durante 5 minutos, o hasta que con 3 minutos adicionales no se observaron cambios en cualquier fracción del tamiz $(<0.5 \%$ del peso total de la muestra) (AOAC, 1984). Se empleó un tamiz que forma parte del equipo CEN (Banco para el estudio del manejo de sólidos) (Armfield, Inglaterra).

La distribución del tamaño del polvo fue calculado por el peso de la fracción retenida en cada tamiz. Específicamente, las partículas que pasaron la malla de $710 \mu \mathrm{m}$ fueron utilizadas para la obtención de las cápsulas. 


\subsection{Resultados}

\subsubsection{Materia seca y contenido total de cenizas}

El contenido total de cenizas del Polvo de Yerba Mate fue de alrededor del $10.16 \% \pm 0.10$, promedio de seis réplicas, lo cual nos indica que el restante $89.84 \%$ corresponde a materia orgánica disponible para actuar como un potencial suministro para mejorar la calidad del suelo. Velázquez et al. (2006), obtuvieron resultados similares durante su estudio respecto de los subproductos de la yerba mate, en el cual no presenta diferencias significativas entre los parámetros físico químicos analizados de muestras provenientes de secadores y molinos; excepto para cenizas totales, donde se observó la presencia de materiales extraños en las muestras provenientes de molinos, las cuales pudieron incidir en el contenido de las mismas.

\subsubsection{Determinación del contenido de minerales o micronutrientes mediante espectroscopía de absorción atómica}

Los minerales estudiados en el polvo de yerba mate fueron $\mathrm{Ca}$, Mg y $\mathrm{K}$ y son mostrados en la Tabla 3.3. Los valores determinados para Mg y $\mathrm{K}$ son similares a los reportados por Maiocchi et al. (2002) en hojas de yerba mate comercial y Vieira et al. (2008) en polvo de yerba mate, mientras que el contenido de Ca fue de casi cuatro veces mayor a lo reportado por estos autores. En el caso de los tres minerales los valores determinados fueron similares a los presentados por Schneider Teixeira et al. (2016) para el polvo de yerba mate.

El calcio es considerado un nutriente secundario esencial de las plantas que se absorbe como $\mathrm{Ca}^{2+}$ y que aportaría beneficios a los cultivos donde se aplique el fertilizante encapsulado (Timilsena et al., 2015). 
Tabla 3.3 Determinación del contenido de los nutrientes minerales en el polvo de yerba mate

\begin{tabular}{cc}
\hline Mineral & g mineral/100 g de producto \\
\hline $\mathrm{Ca}$ & $3.37 \pm 0.18$ \\
$\mathrm{Mg}$ & $0.48 \pm 0.05$ \\
$\mathrm{~K}$ & $1.12 \pm 0.04$ \\
\hline
\end{tabular}

La acción del calcio en el crecimiento de la planta es importante en diferentes niveles. El crecimiento celular depende de la función físico-química de este elemento (Orcutt \& Nilsen, 2000). El calcio activa y regula la división y el alargamiento celular. Influye en la compartimentación de la célula relacionada con la especialización de los órganos celulares, en consecuencia, resulta imprescindible para el desarrollo de órganos de crecimiento como raíces, brotes, frutos, etc. Carencias de calcio se manifiestan en deficiencias en la formación de la pared celular de los tejidos nuevos (puntas de las raíces, hojas jóvenes y brotes) (Marschner, 2012).

\subsubsection{Determinación del tamaño de partícula}

La yerba mate como producto comercial, está compuesta de porciones de hojas pequeñas y grandes, fragmentos de tallo de tamaño pequeño (palos) y polvo, en diferentes proporciones. Con respecto al PYM, un porcentaje máximo del $15 \%$ en el producto final, está regulado por el Código Alimentario Argentino, CAA (2002).

La distribución del tamaño de partícula del polvo de yerba mate se muestra en la Figura 3.3; el tamaño de partícula predominante en el polvo se encontró por debajo de $250 \mu \mathrm{m}$. 
Para la realización de los experimentos de formación de encapsulados, las partículas de más de $710 \mu \mathrm{m}$, que representaban solo el $5 \%$ del polvo de yerba mate fueron descartadas.

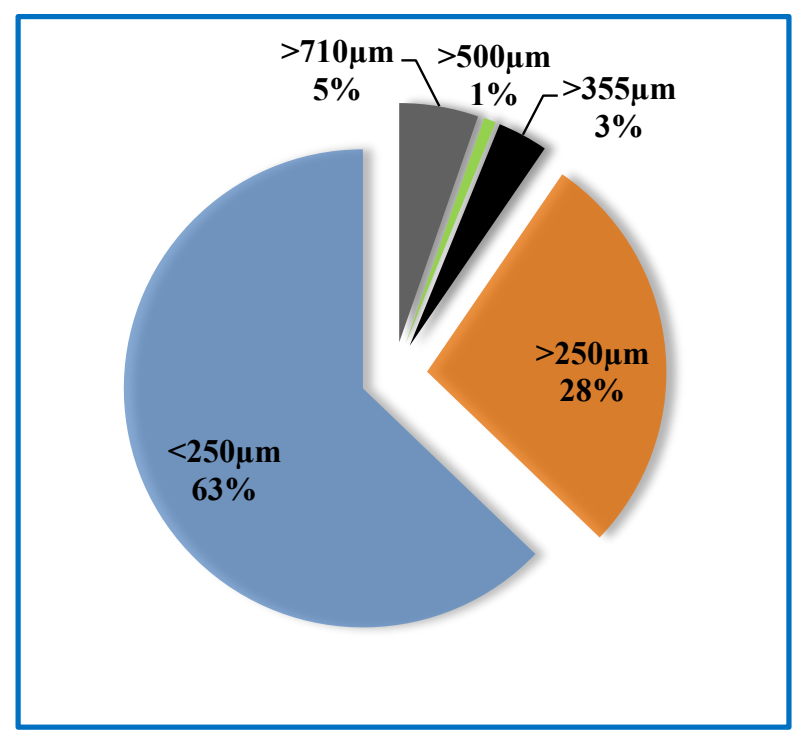

Figura 3.3 Distribución del tamaño de partícula del Polvo de Yerba Mate.

Una gran proporción de este polvo (90 \%) tiene un tamaño de partícula inferior a $<355 \mu \mathrm{m}$ y está clasificado como polvo moderadamente fino por la Farmacopea Argentina (2012); esta fracción no se usa pues la aplicación directa en los cultivos no es viable debido al reducido tamaño de partícula, lo cual dificulta su dispersión, creando así una gran cantidad de residuos industriales. Teniendo en cuenta este escenario el empleo de subproductos de la industria yerbatera en el desarrollo de sistemas de encapsulación para la liberación controlada de fertilizantes se presenta como una alternativa ecológica y de bajo costo. 


\subsection{Conclusiones parciales}

- El polvo de yerba mate posee un elevado contenido de minerales principalmente calcio, magnesio y potasio, importantes para el desarrollo de los cultivos.

- En la obtención de los fertilizantes encapsulados un 95\% del subproducto sería reutilizado; 


\section{CAPÍTULO IV}

Formulación y caracterización de los encapsulados 


\subsection{Sistemas de Encapsulación}

La encapsulación se basa en la inclusión de un compuesto dentro de una matriz polimérica, que crea un microambiente capaz de controlar las interacciones entre la parte interna y externa de la cápsula y tiene como objetivo mantener la actividad de los compuestos por aislamiento del entorno hasta su liberación en el momento y lugar adecuados (Borgogna, Bellich, Zorzin, Lapasin, \& Cesàro, 2010).

La versatilidad de esta tecnología ha provocado que sea estudiada extensamente en los campos de la biomedicina (Smidsrød \& Skja, 1990), y en la industria alimentaria (Champagne \& Fustier, 2007; López et al., 2011). Estas características que provee la encapsulación, la convierten en una técnica apropiada para la industria de los fertilizantes, donde se busca que los compuestos activos se liberen gradualmente conforme a las necesidades y las características de cada cultivo.

Dentro del grupo de CRFs que incluyen nutrientes en una matriz (ceras, turbas, vermiculita, lignina, etc.), se han estudiado algunos sistemas basados en partes de plantas o residuos vegetales y se han desarrollado como formulaciones de liberación controlada.

En la actualidad varias son las investigaciones que se han realizado para recubrir fertilizantes con polímeros sintéticos (Azeem et al., 2014) por la capacidad que tienen de reducir los procesos de descomposición química en el suelo, pero sus costos de producción son altos debido a la rigurosidad que se debe mantener durante los procesos de producción. Sin embargo, los trabajos donde se emplean productos naturales per se o sin tratamientos químicos agresivos como en el presente trabajo son escasos.

González et al. (2005), estudiaron la encapsulación de un fertilizante convencional, utilizando algas marinas como parte de la matriz, con el objetivo de aportar macro y micro elementos beneficiosos para los cultivos y potenciando el efecto ecológico de los mismos, gracias a la disminución de la contaminación 
ambiental al evitar las pérdidas por lixiviación que pueden producir los fertilizantes convencionales.

Los materiales de desecho como la paja de trigo, las ramas de morera y el aserrín de langosta se han utilizado con éxito en la formulación de fertilizantes ecológicos (Xie, Liu, Ni, \& Wang, 2012; Zhang et al., 2016; Zhang, Liang, Yang, Liu, \& Yao, 2014).

\subsection{Materiales de recubrimiento}

Los materiales de recubrimiento pueden ser polímeros orgánicos o inorgánicos, en este contexto, diversos tipos de materiales se han ensayado en el recubrimiento de fertilizantes con el objetivo de reducir su inmediata disponibilidad para las plantas y lograr una acción lenta de liberación. Las cubiertas que han demostrado lograr estas características con un costo aceptable son las hechas en base de azufre, ciertas ceras, varios polímeros y compuestos de polímeros a base de cloruro de vinilideno, cloruro de vinilo, acetato de vinilo, entre otros. Entre las características que se buscan de estos materiales se pueden citar: ser muy poco solubles, inactivos, inocuos, biodegradables, de fácil aplicación y presentar una buena efectividad a pequeñas concentraciones (Ballester Olmos, 1994; Liu et al., 2008).

En la Tabla 4.1 se resumen algunos ejemplos de sistemas de liberación controlada de fertilizantes tipo NPK con cubiertas en base de polímeros sintéticos y naturales (Aguilar, 2014). 
Tabla 4.1 Tipos de cubiertas poliméricas y matrices utilizadas en la preparación de Fertilizantes de Liberación Controlada.

\begin{tabular}{|c|c|c|c|c|}
\hline Fertilizante & Matriz & Cubierta 1 & Cubierta 2 & Referencia \\
\hline Urea & $\begin{array}{l}\text { Polivinil } \\
\text { pirrilodina } \\
\text { (hidrogel) }\end{array}$ & Etilcelulosa & $\begin{array}{l}\text { Poli(ácido acrílico- } \\
\text { co-acrilamida) }\end{array}$ & (Ni, Liu, \& Lü, 2009) \\
\hline Urea & --- & Lignina & --- & $\begin{array}{l}\text { (Mulder, Gosselink, } \\
\text { Vingerhoeds, Harmsen, } \\
\text { \& Eastham, 2011) }\end{array}$ \\
\hline Urea & $\begin{array}{l}\text { Ácido poliacrilico } \\
\text { (hidrogel) }\end{array}$ & --- & --- & (He et al., 2007) \\
\hline Urea & $\begin{array}{c}\text { Almidón-g- } \\
\text { poli(vinil acetato) }\end{array}$ & --- & --- & (Niu \& Li, 2012) \\
\hline Urea & --- & $\begin{array}{l}\text { k-Carragenina - } \\
\text { Alginato }\end{array}$ & $\begin{array}{l}\text { kC-g-poli(ácido } \\
\text { acrilico)/Celita }\end{array}$ & $\begin{array}{c}\text { (Wang, Liu, Ni, \& Xie, } \\
\text { 2012) }\end{array}$ \\
\hline Urea & Atapulgita & Etilcelulosa & $\begin{array}{l}\text { Carboximetilcelulosa/ } \\
\text { hidroxietilcelulosa } \\
\text { (hidrogel) }\end{array}$ & $\begin{array}{l}\text { (Ni, Liu, Lü, Xie, \& } \\
\text { Wang, 2011) }\end{array}$ \\
\hline Urea & $\begin{array}{l}\text { Atapulgita - } \\
\text { Alginato }\end{array}$ & $\begin{array}{l}\text { Pajilla de trigo-g- } \\
\text { poli (ácido } \\
\text { acrílico)/atapulgita }\end{array}$ & --- & $\begin{array}{c}\text { (Xie, Liu, Ni, Zhang, \& } \\
\text { Wang, 2011) }\end{array}$ \\
\hline Urea & --- & Ácido poliláctico & --- & $\begin{array}{c}\text { (Devassine, Henry, } \\
\text { Guerin, \& Briand, 2002) }\end{array}$ \\
\hline Urea & $\begin{array}{l}\text { Ramas de mora- } \\
\text { g-Poli (ácido } \\
\text { acrílico- } \\
\text { coacrilamida) } \\
\end{array}$ & --- & --- & $\begin{array}{c}\text { (Liang, Zhang, Liu, \& } \\
\text { Yao, 2012) }\end{array}$ \\
\hline NPK & --- & $\begin{array}{l}\text { Almidón-Polivinil } \\
\text { alcohol }\end{array}$ & --- & (Han et al., 2009) \\
\hline NPK & --- & $\begin{array}{l}\text { Poliacrilamida, } \\
\text { polivinil cloruro, } \\
\text { caucho natural, } \\
\text { ácido poliláctico }\end{array}$ & --- & $\begin{array}{l}\text { (Hanafi, Eltaib, \& } \\
\text { Ahmad, 2000) }\end{array}$ \\
\hline NPK & --- & Quitosano & $\begin{array}{l}\text { Poli(ácido acrílico- } \\
\text { co-acrilamida) }\end{array}$ & (Wu \& Liu, 2008) \\
\hline NPK & --- & $\begin{array}{c}\text { Resinas } \\
\text { hidrosolubles }\end{array}$ & --- & $\begin{array}{c}\text { (Dai, Fan, Yu, Fang, \& } \\
\text { Zhang, 2008) }\end{array}$ \\
\hline $\mathrm{KNO}_{3}$ & $\begin{array}{l}\text { Poliacrilamida } \\
\text { (hidrogel) }\end{array}$ & --- & --- & (He et al., 2007) \\
\hline
\end{tabular}

Fuente: Aguilar (2014) 


\subsubsection{Alginato}

Los alginatos son polímeros muy utilizados en la microencapsulación. Ellos pertenecen a una familia de polisacáridos lineales no ramificados, compuestos de residuos de ácido $\alpha$-L-gulurónico $(G)$ y de ácido $\beta-D$ manurónico $(\mathrm{M})$, unidos mediante enlaces $1 \rightarrow 4$, principalmente extraídos de algas marrones, entre ellas se destacan: Laminaria hyper-borea, Ascophyllum nodosum y Macrocystis pyrifera.

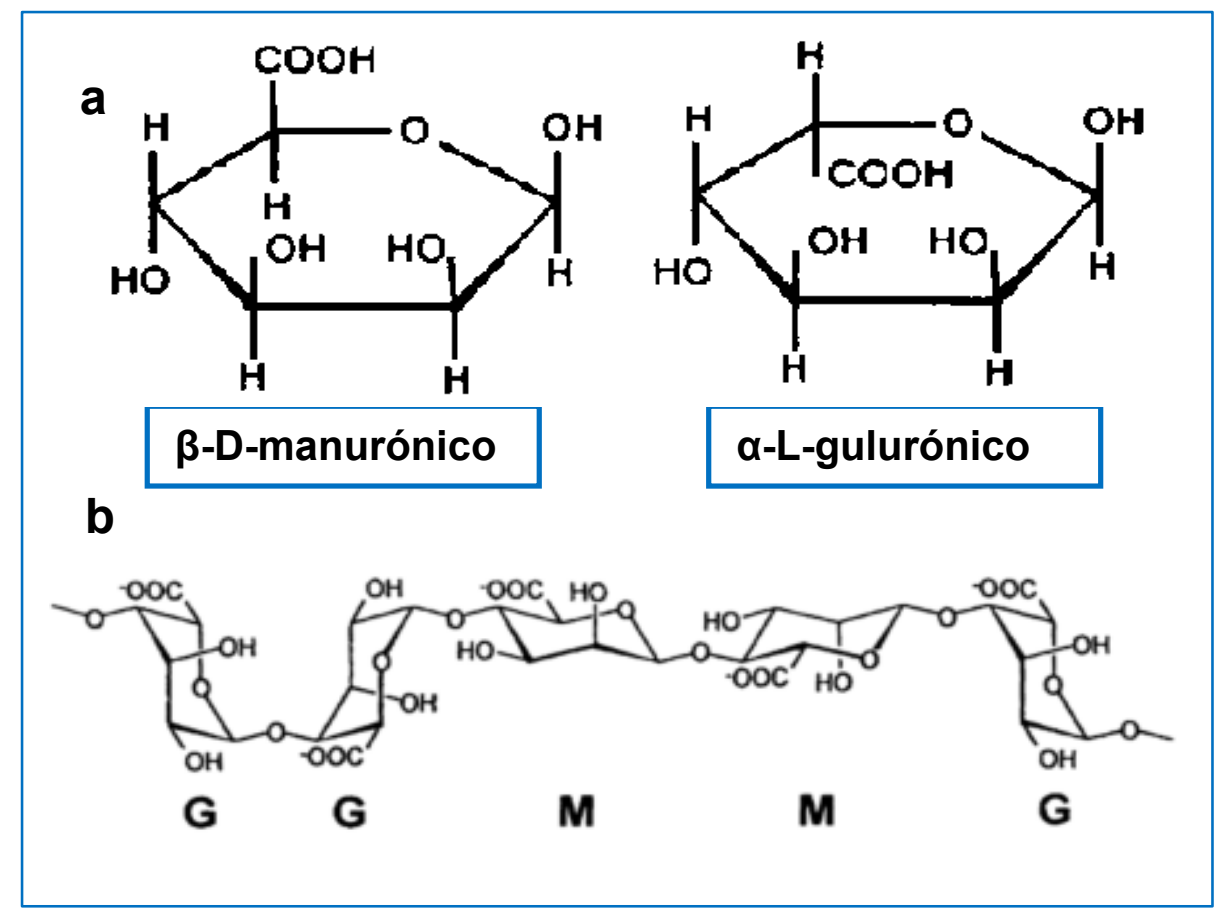

Figura 4.1 Estructura química del alginato. a) Monómeros del alginato b) Conformación de la cadena de alginato.

Fuente: Draget, Smidsrød \& Skjåk-Bræk (2005)

La gelificación de alginato, con el calcio es instantánea en la superficie. El bloque $\mathrm{G}$ responde a la reticulación del calcio más rápido que los bloques $\mathrm{M}$, debido a su conformación molecular tridimensional de "caja de huevos", cuya estructura acomoda iones $\mathrm{Ca}^{2+}$ para formar puentes salinos, que corresponden a zonas de unión entre cadenas poliméricas adyacentes (es decir, compresión de cadenas de gulurónico). 


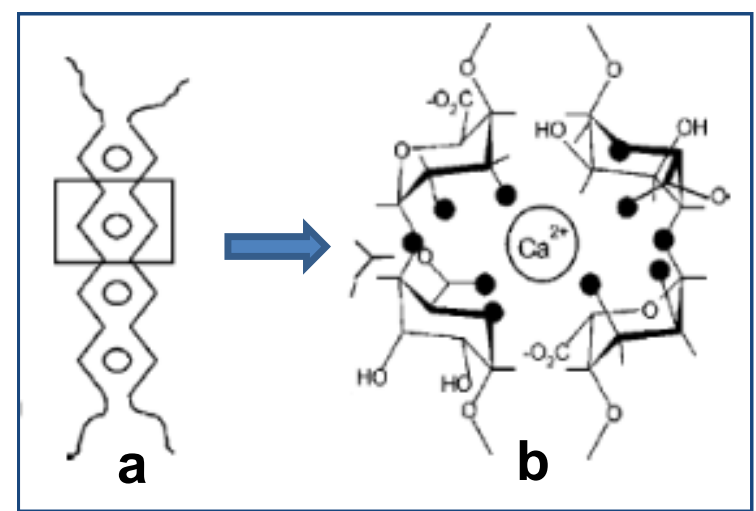

Figura 4.2 Representación esquemática del modelo de "caja de huevos" y coordinación del calcio para las cadenas de guluronato en las zonas de unión del alginato de calcio.

Fuente: Sikorski, Mo, Skjåk-Bræk \& Stokke (2007)

Sin embargo, los segmentos de manurónico (bloques $M$ ) también pueden asociarse a través de puentes de sal de $\mathrm{Ca}^{2+}$ formando geles más rígidos y de buena estabilidad térmica (Donati et al., 2005). 


\subsection{Materiales y métodos}

\subsubsection{Formación de Cápsulas}

Las cápsulas que usan el Polvo de Yerba Mate (PYM) como parte fundamental de la matriz del encapsulado se obtuvieron en base a estudios previos (Schneider Teixeira et al., 2016). En el presente trabajo se optimizaron las condiciones de obtención de los encapsulados con el objetivo de maximizar el contenido de PYM y la eficiencia en la encapsulación de la urea la cual fue empleada como fertilizante modelo en la obtención de las cápsulas fertilizantes. Para este efecto, se ensayaron concentraciones mayores a $50 \mathrm{mg} / \mathrm{mL}$ (PYM/alginato de calcio), hasta alcanzar un máximo de $80 \mathrm{mg} / \mathrm{mL}$. Este máximo se determinó por cuestiones operativas, agregando cada vez más polvo a la solución y observando el funcionamiento de la bomba peristáltica hasta determinarse este valor como el máximo posible, limitado por la elevada viscosidad de la solución.

Las cápsulas fueron obtenidas mediante gelificación iónica, como muestra el esquema en la Figura 4.3. Se preparó una solución de alginato de sodio $2.0 \%$ w/v en agua, utilizando Algogel 6020, gentilmente proporcionado por Cargill, Argentina (Peso Molecular: 328.31 kDa, relación Gulurónico/Manurónico (56/44)). Diferentes cantidades de PYM (25, 50 y $80 \mathrm{mg} / \mathrm{mL})$ se incorporaron en la solución de alginato de sodio, agitándose a temperatura ambiente, en agitador magnético. Una vez homogeneizada, la solución fue forzada con una bomba peristáltica a $45 \mathrm{rpm}$ (Gilson Minipuls 3, Francia) en un tubo de silicona (de $3 \mathrm{~mm}$ de diámetro). La solución se dejó gotear a una altura de $10 \mathrm{~cm}$, en una solución de cloruro de calcio dihidrato (Biopack, Argentina) a una concentración de $0,1 \mathrm{~mol} / \mathrm{L}$ determinada mediante ensayos previos. Las cápsulas se mantuvieron en el baño gelificante para endurecerlas durante 1 min. A continuación, las cápsulas se filtraron, el exceso de solución fue retenido en papel absorbente y posteriormente se secaron en una estufa (GMX 9203A PEET LAB, EE.UU.) a $70{ }^{\circ} \mathrm{C}$ hasta peso constante. Estas cápsulas se denominarán como $25 \mathrm{C}, 50 \mathrm{C}$ y $80 \mathrm{C}$, lo que representa cápsulas control (sin fertilizantes minerales). Para las cápsulas que contienen el 
fertilizante mineral, dos gramos de urea (Anedra, Argentina) se disolvieron en $100 \mathrm{~mL}$ de solución de alginato-PYM para obtener el fertilizante encapsulado y estos sistemas se denominarán como $25 \mathrm{U}, 50 \mathrm{U}$ y $80 \mathrm{U}$ (con fertilizantes minerales: urea).

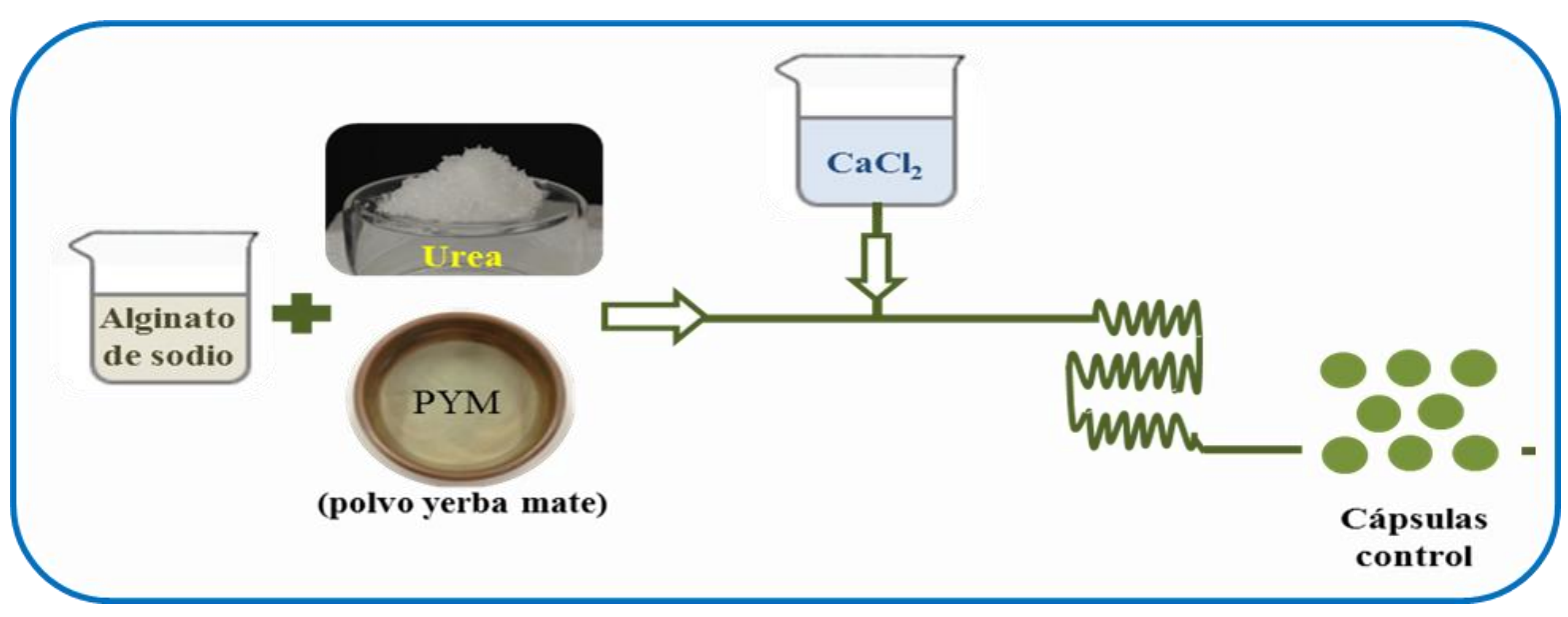

Figura 4.3 Esquema de obtención de los encapsulados.

La mayor parte de este trabajo se realizó empleando urea como fertilizante modelo, sin embargo una vez halladas las condiciones óptimas se obtuvieron otros sistemas fertilizantes que contienen como minerales fósforo y potasio. Estos encapsulados se formaron agregando 2 gramos de Fosfato monopotásico $\left(\mathrm{KH}_{2} \mathrm{PO}_{4}\right.$, Anedra, Argentina) en $100 \mathrm{~mL}$ de solución de alginato-PYM $(80 \mathrm{mg} / \mathrm{mL})$, y serán denominados como $80 \mathrm{PK}$.

\subsubsection{Tamaño y Forma: Análisis digital de imágenes}

La determinación del tamaño y la forma de las cápsulas fue realizada mediante análisis de imágenes digitales tomadas con un dispositivo móvil. Las imágenes fueron procesadas y analizadas con el software ImageJ 1.52a (National Institutes of Health, USA). El área ( $A)$, el perímetro $(P)$, el diámetro y la circularidad $(C)$ de al menos 40 cápsulas fueron analizados. 
Para el procesamiento de las imágenes, se estableció una escala de calibración mediante la fijación de una sección conocida, para poder transformar las medidas tomadas por la imagen (píxeles) en una unidad de medida adecuada $(\mathrm{cm})$. Posteriormente, se procedió a transformar la imagen original en una de tipo 8-bites y a ajustar el umbral de brillo (Fig. 4.4).

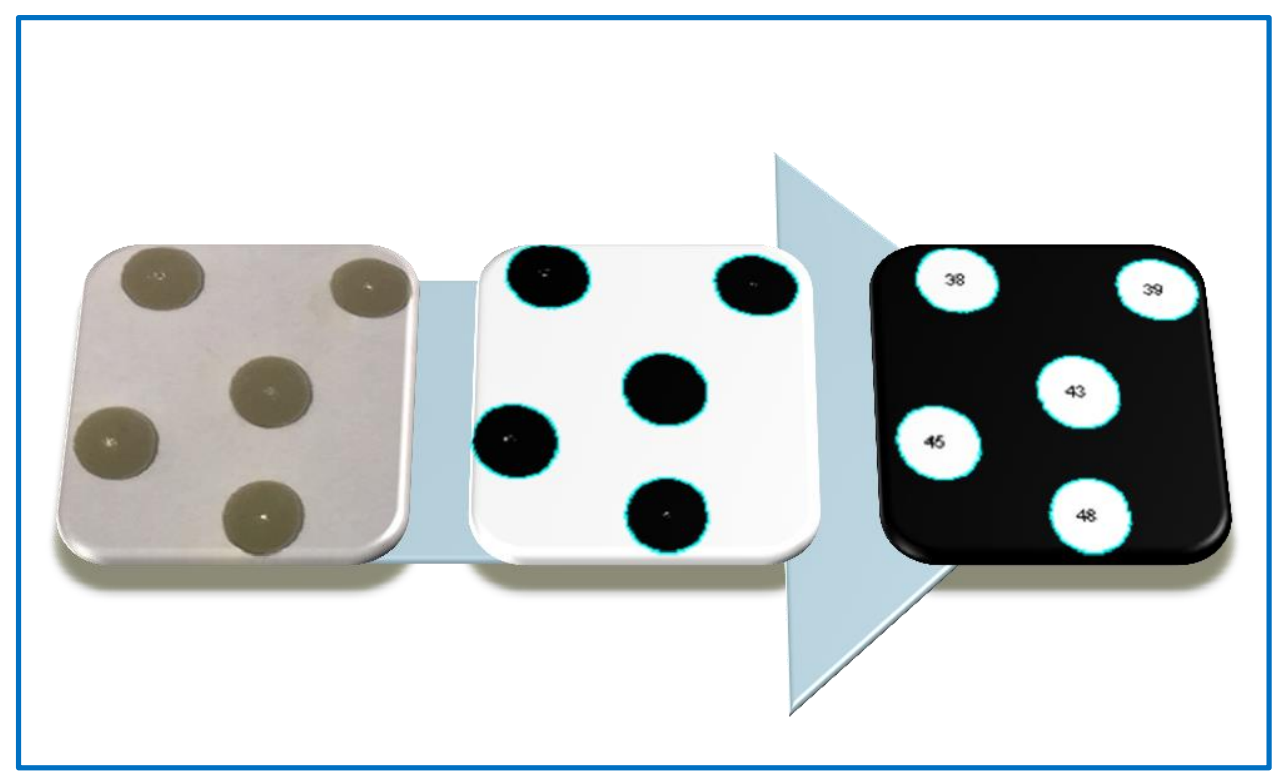

Figura 4.4 Proceso de tratamiento de imágenes con ImageJ

Finalmente, se establecen los parámetros a analizar en las partículas para recolectar los datos requeridos.

\subsubsection{Diámetro de la esfera}

El diámetro de Feret $\left(d_{F}\right)$, representa la distancia entre dos líneas paralelas que son tangenciales al contorno de la proyección de la partícula, mientras que el diámetro de una esfera de área proyectada equivalente $\left(d_{a}\right)$, es el diámetro de una esfera que posee igual área proyectada (A) que la partícula que se desea caracterizar. Esta medida depende de la orientación de la partícula al momento de la medición y es calculado utilizando la Ecuación 4.1 (Bucalá, 2013; Garrido, 2017).

$$
d_{a}=\left(\frac{4 * \mathrm{~A} r e a}{\pi}\right)^{1 / 2}
$$




\subsubsection{Circularidad}

La circularidad $(\mathrm{C})$ o redondez se refiere a la similitud de la partícula respecto de un círculo perfecto, un valor cercano a 1 indica la proximidad a un círculo perfecto, mientras que si el valor se acerca a 0 , supone una forma cada vez más elongada. Se calcula mediante la Ecuación 4.2 (Aguirre Calvo \& Santagapita, 2016; Tyagi et al., 2017).

$$
C=\left(\frac{4 \pi * \text { Área }}{\text { Perímetro }^{2}}\right) \quad \text { Ec. } 4.2
$$

\subsubsection{Observación en microscopio electrónico y micro análisis}

Se realizaron observaciones de microscopía electrónica de barrido (SEM) con un microscopio FEI, Quanta 200 (Eindhoven, Países Bajos). Para las micrografías de los encapsulados por duplicado, estos fueron adheridos con una cinta doble faz al portamuestras, recubiertos con una capa de oro y se examinaron utilizando un voltaje de aceleración de $20 \mathrm{kV}$.

Para el análisis de energía dispersiva de rayos $X$ (EDX), se utilizó un microscopio JSM-6490 LV (JEOL, Japón). Las muestras no tuvieron ningún tratamiento previo y se utilizó un voltaje de $15 \mathrm{kV}$ para las determinaciones.

\subsubsection{Eficiencia de la encapsulación}

La eficiencia de la encapsulación de fertilizantes (\%Ee) de las diferentes formulaciones, fue calculada mediante la siguiente ecuación:

$$
\% E e=\left(\frac{m_{e}}{m_{t}}\right) \times 100
$$


Donde $m_{e}$ corresponde a la masa del fertilizante encapsulado, y $m_{t}$ es la masa teórica del fertilizante agregado en cada formulación. El valor de $m_{e}$ se determinó moliendo $0.15 \mathrm{~g}$ de cápsulas secas en un mortero, este polvo fue disuelto en $50 \mathrm{~mL}$ de agua y la concentración de urea fue determinada mediante espectrofotometría como está descrito en la sección (4.3.5).

\subsubsection{Determinación del contenido de urea}

El contenido de nitrógeno tanto en cápsulas enteras como en cápsulas degradadas fue cuantificado por el método enzimático ureasa-salicilato, BioSystems, S.A. (Barcelona, España). Primero, $0.15 \mathrm{~g}$ de cápsulas secas fueron molidas en un mortero y se disolvieron en $50 \mathrm{~mL}$ de agua. Este método usa la enzima ureasa para hidrolizar la urea. El amoníaco producido reacciona con hipoclorito alcalino y salicilato de sodio en presencia de un catalizador para formar indofenol. El complejo coloreado fue medido espectrofotométricamente en un Shimadzu UV mini 1240 UV-VIS (Kyoto, Japón) a una longitud de onda de 600 nm (Fig. 4.5).

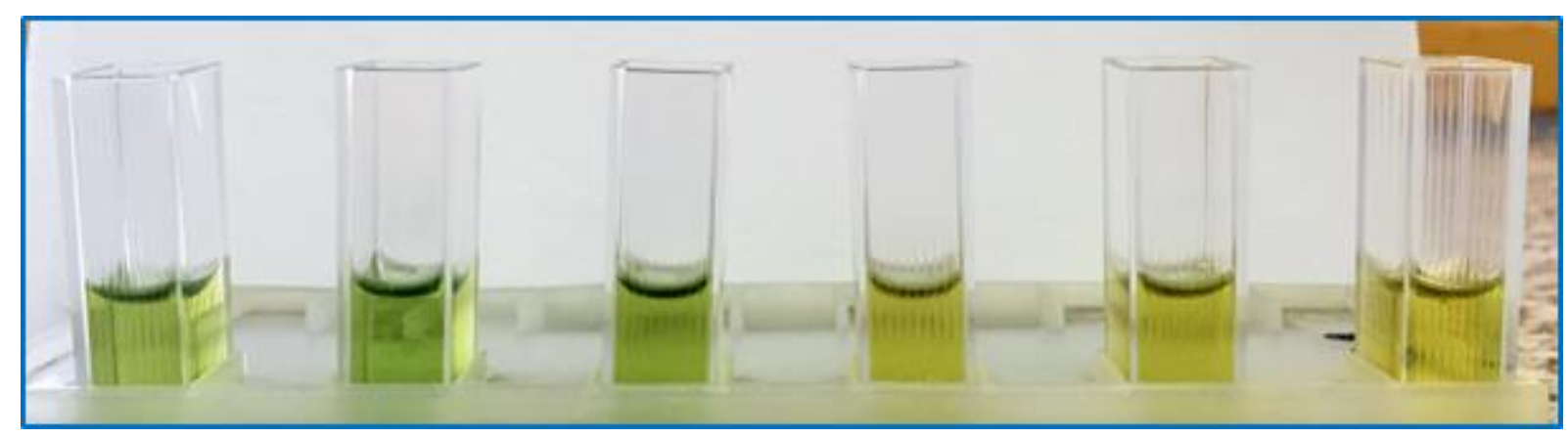

Figura 4.5 Muestras coloreadas para la determinación de urea por espectrofotometría.

Los resultados son expresados como gramos de urea por gramos de cápsula seca. La eficiencia de este método fue validado contra la determinación de nitrógeno por análisis elemental (Schneider Teixeira et al., 2016). 


\subsubsection{Ganancia de Agua e Higroscopicidad}

El estudio de las características de adsorción y actividad de agua son de importancia relevante en la agroindustria, pues permite hacer predicciones de vida útil, reacciones de deterioro por aumento de humedad, crecimiento de microorganismos y puntos finales óptimos de secado en relación a la estabilidad del producto (Ajibola, Aviara, \& Ajetumobi, 2003; Ceballos, Giraldo, \& Orrego, 2009).

La relación existente entre la actividad del agua del producto y el contenido de humedad en equilibrio a una temperatura establecida, se representan mediante las isotermas de adsorción (Toğrul \& Arslan, 2007).

Las isotermas de sorción fueron obtenidas mediante el método gravimétrico estático al equilibrar $1 \mathrm{~g}$ de muestra en pesa filtros, colocados en recipientes plásticos herméticamente sellados con soluciones de sales sobresaturadas dentro del intervalo de $33 \%$ a $85 \%$ de Humedad Relativa (\%HR): Cloruro de Magnesio (33\%HR), Carbonato de Potasio (43\%HR), Nitrato de Magnesio (54 \%HR), Cloruro de Sodio (75 \%HR) y Cloruro de Potasio (85\%HR) (Ceballos et al., 2009; Gabas, Telis, Sobral, \& Telis-Romero, 2007; Mathlouthi, 2001), y se almacenaron a $20{ }^{\circ} \mathrm{C}$. Las muestras se extrajeron en diferentes tiempos y su aumento de peso se determinó hasta valor constante, las isotermas se realizaron por duplicado y los valores reportados son el promedio de las dos repeticiones.

Para describir el mejor ajuste de los datos experimentales de las isotermas de adsorción se utilizaron los modelos de Bradley (1936), Chen (1978), GAB (1988), Day \& Nelson (1965), Halsey (1948), Kühn (1964), Mizrahi (1970), Oswin (1946), Smith (1947), Iglesias y Chirife (1978), White y Eiring (1978) (Boente, González, Martinez, Pollio, \& Resnik, 1996; Chirife \& Iglesias, 1978; Fontan, Chirife, Sancho, \& Iglesias, 1982).

De estas ecuaciones, las que se ajustaron mejor al comportamiento de las isotermas, se describen a continuación: 
Modelo de Iglesias y Chirife

$$
X=B_{1}\left(\frac{a_{w}}{\left(1-a_{w}\right)}\right)+B_{2}
$$

Modelo de GAB

$$
X=\left(\frac{\left(B_{2}-1\right) X_{m} B_{1} a_{w}}{1+\left(B_{2}-1\right) B_{1} a_{w}}\right)+\left(\frac{X_{m} B_{1} a_{w}}{1-B_{1} a_{w}}\right)
$$

Modelo de Halsey

$$
X=\exp \left(a+b \ln \left(-\ln a_{w}\right)\right)
$$

Ec. 4.6

Modelo de Kühn

$$
X=a+b\left(\frac{1}{\ln a_{w}}\right)
$$

Modelo de Mizrahi

$$
X=a\left(\frac{a_{w}}{\left(1-a_{w}\right)}\right)+b\left(1-a_{w}\right)^{-1}
$$

Ec. 4.8

Modelo de White and Eiring

$$
X=\left(\frac{1}{a+b a_{w}}\right)
$$

Ec. 4.9 
donde $X$ es el contenido de humedad expresado en base seca, $X m$ es el contenido de humedad de la monocapa de GAB expresada en base seca, $a_{w}$ es la actividad acuosa de las soluciones de sal supersaturadas, $B_{1}$ y $B_{2} \circ a$ y $b$ son parámetros de ajuste empleados para describir la isoterma.

La Higroscopicidad (HG \%) en las muestras se expresó como el contenido de humedad final alcanzado después de exponer las muestras en las condiciones mencionadas anteriormente. Se empleó la ecuación modificada de Jaya \& Das (2004) para calcular la ganancia de agua en base seca de la siguiente manera:

$$
H G(\%)=\left(\frac{b+H}{a-H}\right) * 100
$$

Donde: $b$ es el incremento de peso (g), a es el peso inicial de la muestra (g) y $H$ es el contenido inicial de agua en la muestra $(g)$.

\subsubsection{Propiedades mecánicas: Medición de textura}

Un texturómetro (TA-TX2i, Stable Micro Systems, Reino Unido) fue utilizado para determinar la resistencia a la compresión "crushing strength" (CS). Este parámetro fue medido aplicando presión en cápsulas individuales (cápsulas secas) de un diámetro entre 1.5 a $2 \mathrm{~mm}$. La presión ejercida sobre la cápsula fue continuamente incrementada a una velocidad de $0.5 \mathrm{~mm} / \mathrm{s}$ hasta que se observó la destrucción de la cápsula. Este valor de carga máxima (promedio de 15 mediciones) fue considerado como el "crushing strength" (CS). (Tomaszewska \& Jarosiewicz, 2002; Wang, Liu, Ni, \& Xie, 2011). 


\subsubsection{Capacidad de flujo: Ángulo de reposo}

Las muestras secas, fueron analizadas usando una cámara de ángulo de reposo la cual forma parte de un banco de manejo de sólidos (CEN, Armfield, Reino Unido). Este dispositivo consiste en un cilindro rotatorio graduado de acrílico transparente (Deladino, Navarro, \& Martino, 2013). El cilindro fue llenado hasta la mitad del volumen con la muestra y la superficie fue nivelada. El aparato fue girado hasta que las partículas empezaron a deslizarse, en este momento, una lectura fue registrada. Luego, el cilindro plano fue rotado en la dirección opuesta hasta que las partículas se deslizaron nuevamente, en ese momento una segunda lectura fue realizada. El promedio del valor de las dos lecturas corresponde al ángulo de reposo de la muestra. Todas las mediciones fueron realizadas por sextuplicado y a temperatura ambiente.

\subsubsection{Medición de la absorción de agua}

Muestras de $1 \mathrm{~g}$ de cápsulas secas se sumergieron en $50 \mathrm{~mL}$ de agua corriente y se dejaron a temperatura ambiente $\left(20^{\circ} \mathrm{C}\right)$ durante un mes.

En diferentes intervalos de tiempo las cápsulas hinchadas se filtraron para eliminar el agua y se registró su peso (Fig.4.6). Las muestras se pesaron cada $48 \mathrm{~h}$ la primera semana y luego, una vez a la semana.

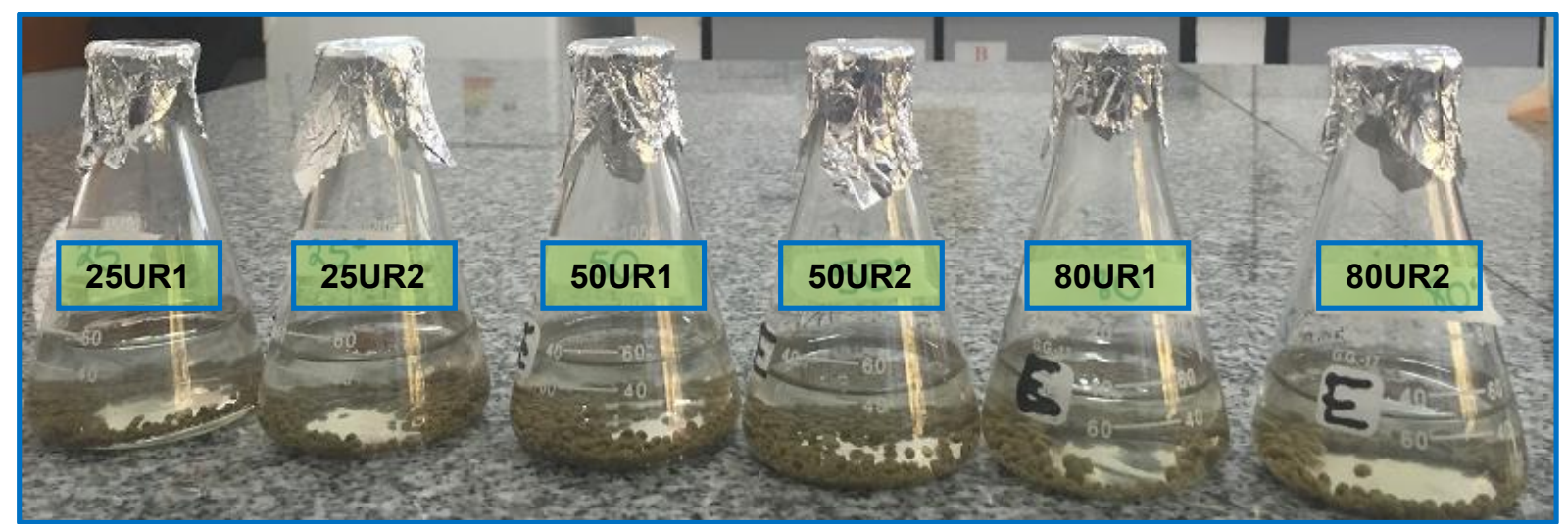

Figura 4.6 Ensayo de absorción de agua. 
Para evitar el crecimiento microbiano, el agua se renovó en cada tiempo de medición. La absorción de agua se calculó utilizando la siguiente ecuación:

$$
W A=\left(\frac{M-M_{0}}{M_{0}}\right)
$$

Donde $M$ y $M_{0}$ denotan el peso de las cápsulas hinchadas y secas respectivamente y $W A$ es la absorción de agua por gramo de cápsula seca.

\subsubsection{Análisis Estadísticos}

Los análisis estadísticos de este trabajo se llevaron a cabo con el software InfoStat versión 2011 (Córdoba, Argentina). Se realizaron análisis de varianza (ANOVA) y comparaciones de medias mediante Test LSD de Fisher. Además, se realizaron regresiones no lineales de modelos empíricos para los ajustes de las isotermas de adsorción y para el análisis de datos de la liberación de urea y degradación de las cápsulas (Capítulos $\mathrm{V}$ y $\mathrm{VI}$ ) con el programa Statgraphics Centurion XVI, StatPoint Technologies, Inc. 1982-2010. En todos los análisis se utilizó un nivel de confianza del $95 \%(\alpha=0.05)$. 


\subsection{Resultados}

\subsubsection{Obtención de cápsulas}

Se obtuvieron cápsulas con polvo de yerba mate como matriz de los encapsulados, muestras control (25C, 50C y $80 \mathrm{C})$ y cápsulas con urea como fertilizante modelo $(25 \mathrm{U}, 50 \mathrm{U}$ y $80 \mathrm{U})$. En la Figura 4.7 se muestran las cápsulas obtenidas, en estado húmedo y con urea agregada para las diferentes proporciones del PYM.

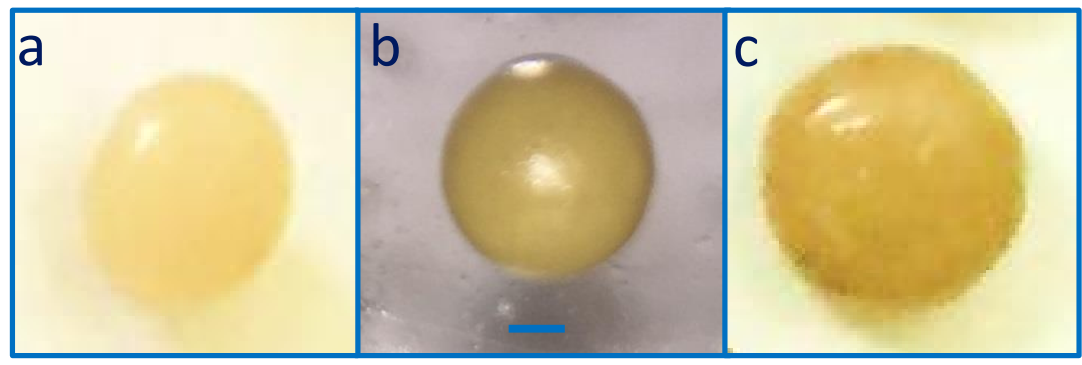
a) $25 \mathrm{U}$
b) $50 U$
c) $80 U$

Figura 4.7 Fotografías de las cápsulas húmedas de PYM como matriz y con urea como fertilizante modelo. Barra $=1 \mathrm{~mm}$.

\subsubsection{Tamaño y Forma: Análisis digital de imágenes}

Varios estudios consideran que el tamaño, forma y caracterización morfológica de las cápsulas de alginato en aplicaciones de encapsulación son relevantes, ya que podrían tener un impacto en diferentes propiedades fisicoquímicas, como la sorción de agua y liberación del agente encapsulado (Aguirre Calvo \& Santagapita, 2016; Lee, Ravindra, \& Chan, 2013).

En la Tabla 4.2 se muestran los resultados del análisis digital de imágenes, donde se observa que el aumento de concentración de PYM (25, 50 y 80 $\mathrm{mg} / \mathrm{mL}$ alginato), afecta de manera directamente proporcional en el tamaño de la cápsula $(80>50>25)$, determinados por los parámetros de diámetro, área y perímetro. También se observa que el agregado del fertilizante modelo (urea) 
no afectó, ni sensible ni uniformemente el tamaño de cápsula, puesto que en el caso de las cápsulas de $25 \mathrm{C}$ vs $25 \mathrm{U}$ y $50 \mathrm{C}$ vs $50 \mathrm{U}$ el agregado de urea hizo reducir el perímetro de la cápsula, mientras que al comparar el diámetro de Feret y el perímetro de las cápsulas $80 \mathrm{C}$ vs $80 \mathrm{U}$, observamos que el agregado de urea generó un aumento en el tamaño.

Tabla 4.2 Factores de tamaño y forma determinados en cápsulas húmedas.

\begin{tabular}{cccccc}
\hline \multirow{5}{*}{ Muestra } & $\begin{array}{c}\text { Diámetro área } \\
\text { proyectada } \\
\mathbf{d}_{\mathbf{a}}(\mathbf{c m})\end{array}$ & $\begin{array}{c}\text { Diámetro de } \\
\text { Feret } \\
\mathbf{d}_{\mathbf{F}}(\mathbf{c m})\end{array}$ & $\begin{array}{c}\text { Área } \\
\mathbf{A}\left(\mathbf{c m}^{2}\right)\end{array}$ & $\begin{array}{c}\text { Perímetro } \\
\mathbf{P}(\mathbf{c m})\end{array}$ & $\begin{array}{c}\text { Circularidad } \\
\mathbf{C}\end{array}$ \\
\hline $\mathbf{2 5 C}$ & $0.439 \pm 0.013^{\mathrm{ab}}$ & $0.464 \pm 0.017^{\mathrm{ab}}$ & $0.151 \pm 0.009^{\mathrm{ab}}$ & $1.489 \pm 0.061^{\mathrm{b}}$ & $0.858 \pm 0.048^{\mathrm{b}}$ \\
$\mathbf{2 5 U}$ & $0.433 \pm 0.015^{\mathrm{a}}$ & $0.458 \pm 0.019^{\mathrm{a}}$ & $0.148 \pm 0.010^{\mathrm{a}}$ & $1.452 \pm 0.056^{\mathrm{a}}$ & $0.878 \pm 0.020^{\mathrm{c}}$ \\
$\mathbf{5 0 C}$ & $0.443 \pm 0.015^{\mathrm{b}}$ & $0.467 \pm 0.021^{\mathrm{b}}$ & $0.154 \pm 0.010^{\mathrm{b}}$ & $1.482 \pm 0.056^{\mathrm{b}}$ & $0.880 \pm 0.020^{\mathrm{c}}$ \\
$\mathbf{5 0 U}$ & $0.440 \pm 0.010^{\mathrm{b}}$ & $0.463 \pm 0.015^{\mathrm{ab}}$ & $0.152 \pm 0.007^{\mathrm{ab}}$ & $1.475 \pm 0.037^{\mathrm{ab}}$ & $0.876 \pm 0.021^{\mathrm{c}}$ \\
$\mathbf{8 0 C}$ & $0.465 \pm 0.015^{\mathrm{c}}$ & $0.492 \pm 0.019^{\mathrm{c}}$ & $0.170 \pm 0.010^{\mathrm{c}}$ & $1.564 \pm 0.059^{\mathrm{c}}$ & $0.874 \pm 0.028^{\mathrm{bc}}$ \\
$\mathbf{8 0 U}$ & $0.471 \pm 0.017^{\mathrm{c}}$ & $0.512 \pm 0.029^{\mathrm{d}}$ & $0.174 \pm 0.013^{\mathrm{c}}$ & $1.642 \pm 0.096^{\mathrm{d}}$ & $0.817 \pm 0.074^{\mathrm{a}}$ \\
\hline
\end{tabular}

Media $\pm D E(n=40)$

Valores de la misma columna seguidos por letras diferentes son significativamente diferentes $(p<0.05)$

En general las cápsulas muestran una forma bastante homogénea y esto se comprueba en los datos de circularidad altos, lo cual nos indica la cercanía a esferas perfectas. La circularidad de todas las cápsulas muestran valores sobre (0.858), excepto las muestras $80 \mathrm{U}$ (0.817) que visualmente se observan menos uniformes que el resto de los tratamientos y es el único tratamiento que es significativamente distinto a todos los demás $(p<0.05)$.

La uniformidad del tamaño y la alta esfericidad de las cápsulas obtenidas también se pueden atribuir al control de las variables del proceso de gelificación iónica, entre ellos: concentración de la solución de alginato, tamaño de orifico de goteo, distancia de caída de la gota, velocidad de goteo, temperatura, concentración y tiempo de inmersión en la solución de $\mathrm{CaCl}_{2}$. La obtención de encapsulados de forma y tamaño homogéneo facilita su manipulación y procesamiento (Lee et al., 2013). 


\subsubsection{Observación en microscopio electrónico y micro análisis}

Las imágenes de microscopía SEM obtenidas para todos los sistemas encapsulados, con diferente concentración de PYM (25, 50 y 80 mg/mL de alginato), con urea $(\mathrm{U})$ y sin urea $(\mathrm{C})$ agregada, son mostradas en la Figura 4.8 .

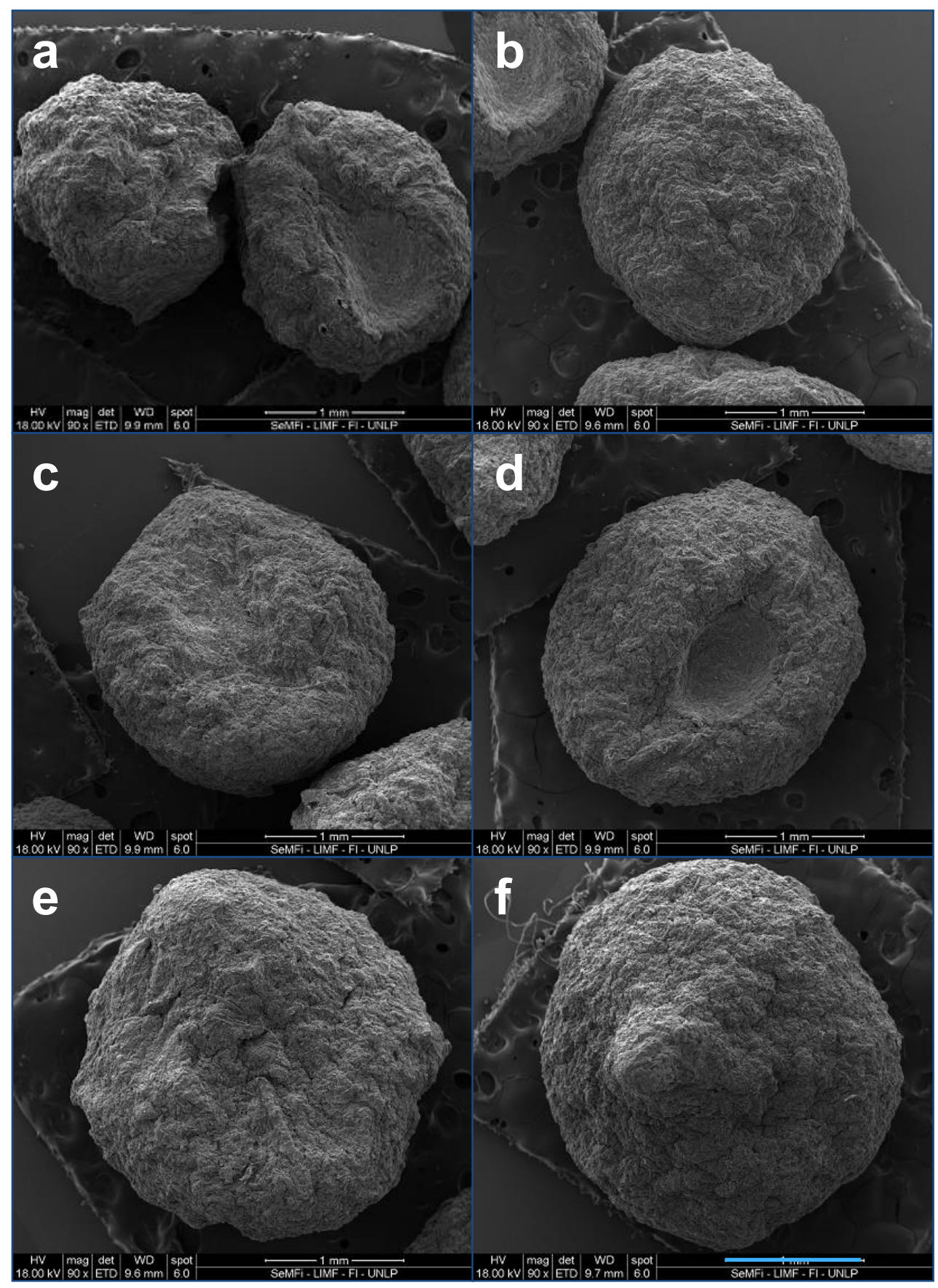

Figura 4.8 Micrografías SEM a) $25 \mathrm{C}$ b) $25 \mathrm{U}$ c) $50 \mathrm{C}$ d) $50 \mathrm{U}$ e) $80 \mathrm{C}$ y f) $80 \mathrm{U}$. Barra $=1 \mathrm{~mm}$. 
En las micrografías SEM se puede observar una distribución homogénea de los componentes (alginato y polvo de yerba mate) para todos los encapsulados, similar a lo reportado por Schneider Teixeira et al. (2016) en cápsulas elaboradas con alginato y menor contenido de PYM.

Respecto de la forma y el tamaño, las micrografías muestran cierta pérdida de circularidad de las cápsulas después del secado, este efecto es más marcado para las cápsulas con menos contenido de PYM $(25>50>80)$, lo cual se relacionaría a que conforme el contenido de PYM se aumenta, la relación del alginato disminuye y es este gel el que se contrae durante el secado, mientras que el PYM contribuye a mantener su forma homogénea actuando como un relleno. El agregado de urea también denota una contribución en la forma de las cápsulas durante el secado, lo cual no se podía verificar en las cápsulas húmedas, ya que como se observa en la Figura 4.8 los encapsulados con urea presentan una forma más circular que las cápsulas control (25U>25C; $50 U>50 \mathrm{C} ; 80 U>80 \mathrm{C}$ ). El tamaño de las cápsulas estuvo ligado al contenido del PYM $(80>50>25)$, tal como se lo relacionó en el análisis de imágenes de cápsulas húmedas en la sección 4.4.2.

El microanálisis de energía dispersiva de rayos $X$ (EDX) reveló la presencia del calcio, magnesio y potasio distribuidos uniformemente en la superficie de los encapsulados. Los mapeos del análisis EDX realizados en las cápsulas $25 \mathrm{U}$ y $80 \mathrm{U}$ se presentan en la Figura $4.9 \mathrm{~A}$ y $4.9 \mathrm{~B}$ respectivamente. 


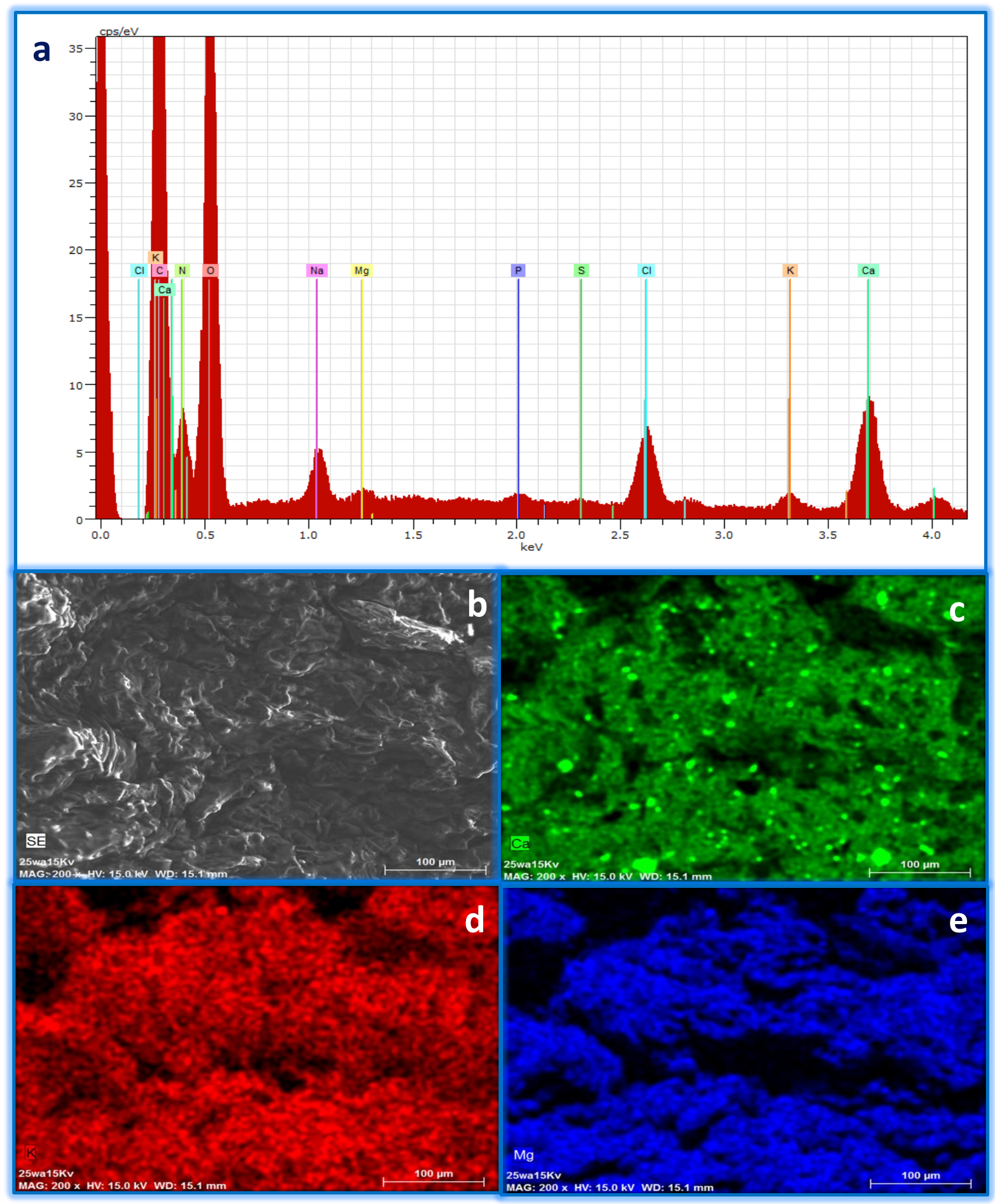

Figura 4.9A Cápsulas 25U a) Espectro EDX b) Micrografía SEM (200X), c) Mapeo superficial de calcio (200X), d) Mapeo superficial de potasio (200X) y e) Mapeo superficial de magnesio (200X). 


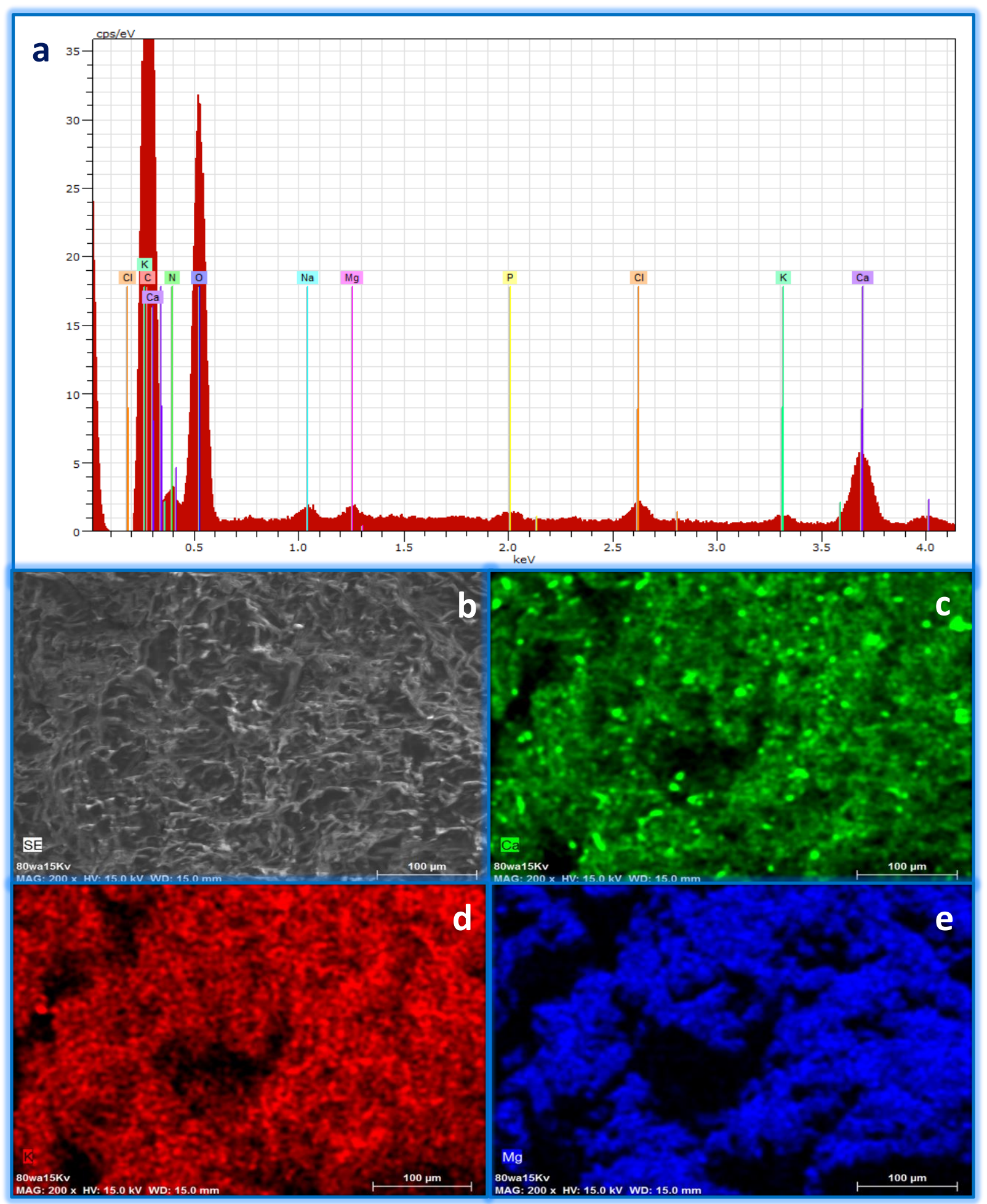

Figura 4.9B Cápsulas 80U a) Espectro EDX b) Micrografía SEM (200X), c) Mapeo superficial de calcio (200X), d) Mapeo superficial de potasio (200X) y e) Mapeo superficial de magnesio (200X).

En los análisis se observa una mayor cantidad de calcio en los encapsulados $25 \mathrm{U}$, debido a la mayor cantidad de alginato de calcio presente en la matriz, 
mientras que las cantidades de magnesio y potasio son mayores en las cápsulas $80 \mathrm{U}$, atribuidas a la prevalencia del contenido de polvo de yerba mate en la matriz.

\subsubsection{Eficiencia de la encapsulación.}

Se analizó la influencia de la concentración del PYM en la eficiencia de la encapsulación de Urea.

Como se muestra en la Fig. 4.10, se obtuvo una eficiencia promedio de 43.44 $\% \pm 0.01$ para el sistema con menor contenido de PYM (25U), mientras que en los tratamientos con mayor contenido de PYM (50U y 80U), se obtuvieron eficiencias significativamente mayores $(p<0.05)$, con valores de $64.64 \% \pm$ 0.07 y $62.45 \% \pm 0.01$, respectivamente. Este hecho puede atribuirse a que al aumentar el contenido de polvo este actúa como material de relleno favoreciendo la inclusión de la urea en una matriz menos permeable.

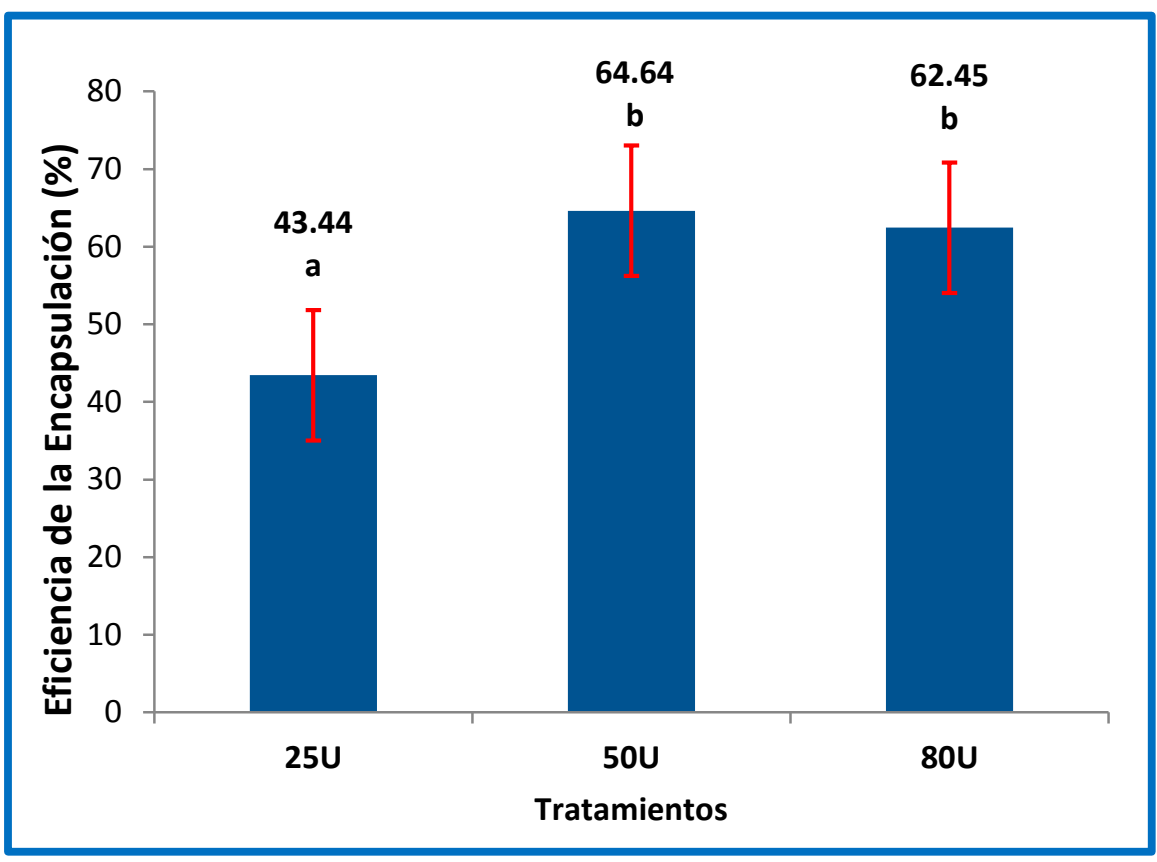

Letras diferentes sobre las barras indican medias significativamente diferentes $(p<0.05)$

Figura 4.10 Efecto de la concentración del PYM en la eficiencia de encapsulación de Urea. 
Un efecto similar se encontró en estudios anteriores, los cuales reportaron que la adición de almidón en hidrogeles de alginato de calcio mejoró la capacidad de atrapamiento de compuestos activos (Córdoba, Deladino, \& Martino, 2013; Rassis, Saguy, \& Nussinovitch, 2002; Sultana et al., 2000).

Los tratamientos de $50 \mathrm{U}$ y $80 \mathrm{U}$, no presentaron diferencias significativas entre ellos, pero para efectos de los objetivos de incorporar la mayor cantidad de nutrientes a través del PYM, su relevancia se considerará en apartados posteriores.

\subsubsection{Ganancia de Agua e Higroscopicidad}

Los contenidos de humedad de equilibrio $(X e q)$ en $\mathrm{g}$ agua/g de materia seca, fueron obtenidos experimentalmente a $20^{\circ} \mathrm{C}$, para muestras con y sin urea en diferentes proporciones de PYM $(25 \mathrm{C}, 25 \mathrm{U}, 50 \mathrm{C}, 50 \mathrm{U}, 80 \mathrm{C}$ y $80 \mathrm{U})$ y se reportan en la Tabla 4.3.

Tabla 4.3 Datos experimentales de humedades de equilibrio ( $X$ eq.) determinados a $20^{\circ} \mathrm{C}$.

\begin{tabular}{cccccc}
\hline & \multicolumn{5}{c}{ Actividad de Agua (aw) } \\
\cline { 2 - 6 } Tratamientos & $\mathbf{0 . 3 3}$ & $\mathbf{0 . 4 4}$ & $\mathbf{0 . 5 4}$ & $\mathbf{0 . 7 5}$ & $\mathbf{0 . 8 5}$ \\
\cline { 2 - 6 } & \multicolumn{5}{c}{$\boldsymbol{X}$ eq. (g agua/g materia seca) } \\
\hline 25C & $0.141 \pm 0.007$ & $0.154 \pm 0.019$ & $0.177 \pm 0.009$ & $0.277 \pm 0.015$ & $0.368 \pm 0.019$ \\
$\mathbf{2 5 U}$ & $0.158 \pm 0.006$ & $0.185 \pm 0.016$ & $0.234 \pm 0.003$ & $0.397 \pm 0.021$ & $0.578 \pm 0.031$ \\
$\mathbf{5 0 C}$ & $0.120 \pm 0.008$ & $0.132 \pm 0.017$ & $0.150 \pm 0.010$ & $0.223 \pm 0.009$ & $0.295 \pm 0.010$ \\
$\mathbf{5 0 U}$ & $0.125 \pm 0.002$ & $0.147 \pm 0.020$ & $0.179 \pm 0.006$ & $0.304 \pm 0.023$ & $0.434 \pm 0.017$ \\
$\mathbf{8 0 C}$ & $0.111 \pm 0.002$ & $0.122 \pm 0.012$ & $0.140 \pm 0.006$ & $0.199 \pm 0.010$ & $0.261 \pm 0.012$ \\
$\mathbf{8 0 U}$ & $0.106 \pm 0.006$ & $0.122 \pm 0.008$ & $0.150 \pm 0.001$ & $0.247 \pm 0.011$ & $0.353 \pm 0.011$ \\
\hline \multicolumn{5}{c}{ Media $\pm D E(n=2)$}
\end{tabular}

Las isotermas de adsorción se construyeron con los valores promedios de las dos réplicas determinadas a $20{ }^{\circ} \mathrm{C}$ y se muestran en la Fig. 4.11. Como se puede observar, en todos los casos las muestras con urea (25U, $50 \mathrm{U}$ y $80 \mathrm{U})$ llegan al equilibrio en valores mayores de humedad que las cápsulas sin urea (25C, 50C y $80 \mathrm{C}$ ), esto puede ser consecuencia de la higroscopicidad que 
aporta la presencia de la urea en estas cápsulas, por otro lado, la cantidad del PYM incluidos en las cápsulas también influye en la humedad de equilibrio y se comporta de manera inversamente proporcional ya que a mayor contenido de PYM, la humedad de equilibrio se alcanza a valores inferiores.

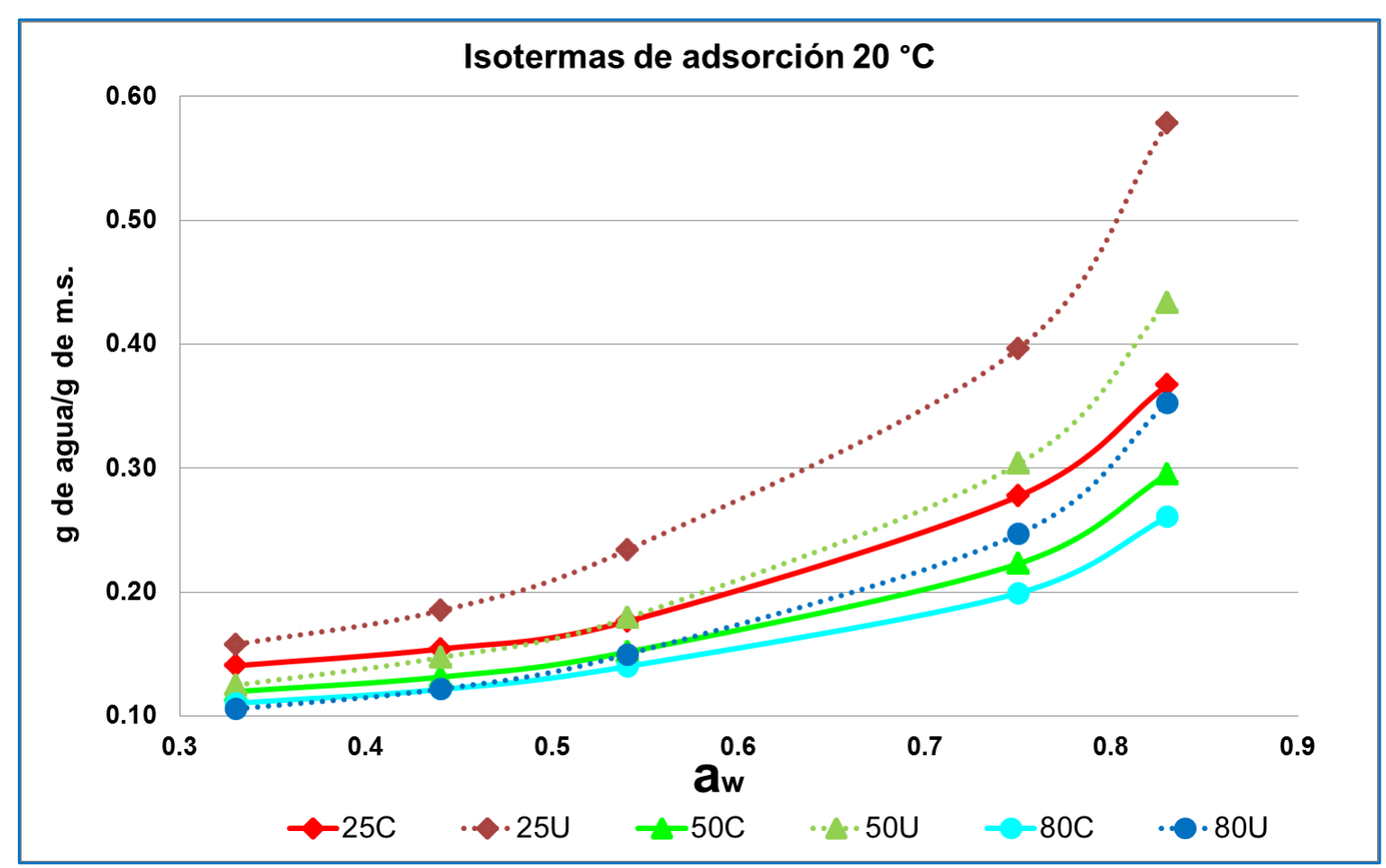

Figura 4.11 Isotermas de adsorción a $20{ }^{\circ} \mathrm{C}$ de cápsulas de PYM en diferentes proporciones, con y sin agregado de urea.

Para el ajuste de los datos se empleó el programa STATGRAPHICS Centurion 16.1 .03 y se obtuvieron los coeficientes indicados en la sección 4.3.6 que se muestran en la Tabla 4.4. Los mejores modelos se seleccionaron en base al coeficiente de correlación $\left(R^{2}\right)$ y el análisis de los gráficos de residuos. 
Tabla 4.4. Coeficientes de las Ecuaciones de Chirife, GAB, Halsey, Kühn, Mizrahi y White para encapsulados de diferente concentración de PYM, con y sin urea a $20^{\circ} \mathrm{C}$ en un rango de Actividad de Agua (Aw) de 0.33 a 0.85 .

\begin{tabular}{|c|c|c|c|c|c|c|c|}
\hline \multirow{2}{*}{ Modelos } & \multirow{2}{*}{ Parámetros } & \multicolumn{6}{|c|}{ Tratamientos } \\
\hline & & $25 \mathrm{C}$ & $25 \mathrm{U}$ & $50 \mathrm{C}$ & $50 \mathrm{U}$ & $80 \mathrm{C}$ & $80 \mathrm{U}$ \\
\hline \multirow{5}{*}{ Iglesias y Chirife } & B1 & 0.052 & 0.095 & 0.040 & 0.070 & 0.034 & 0.056 \\
\hline & B2 & 0.115 & 0.114 & 0.102 & 0.093 & 0.096 & 0.080 \\
\hline & MAE & 0.010 & 0.012 & 0.008 & 0.010 & 0.006 & 0.006 \\
\hline & MAPE (\%) & 4.639 & 4.109 & 4.715 & 4.430 & 3.812 & 3.405 \\
\hline & $\mathbf{R}^{2}$ & 0.985 & 0.992 & 0.985 & 0.991 & 0.985 & 0.996 \\
\hline \multirow{6}{*}{ GAB } & B1 & 0.899 & 0.982 & 0.868 & 0.973 & 0.845 & 0.966 \\
\hline & B2 & $3.89 \times 10^{10}$ & $2.31 \times 10^{9}$ & $5.36 \times 10^{9}$ & $7.06 \times 10^{10}$ & $-6.53 \times 10^{10}$ & $3.83 \times 10^{10}$ \\
\hline & $\mathrm{Xm}$ & 0.092 & 0.107 & 0.081 & 0.083 & 0.076 & 0.070 \\
\hline & MAE & 0.010 & 0.0121 & 0.008 & 0.010 & 0.007 & 0.006 \\
\hline & MAPE (\%) & 5.185 & 4.002 & 5.092 & 4.394 & 4.416 & 3.266 \\
\hline & $\mathbf{R}^{2}$ & 0.982 & 0.992 & 0.979 & 0.990 & 0.979 & 0.995 \\
\hline \multirow{5}{*}{ Halsey } & A & -1.975 & -1.826 & -2.125 & -2.061 & 2.198 & -2.237 \\
\hline & B & -0.573 & -0.753 & -0.529 & -0.722 & -0.498 & -0.703 \\
\hline & MAE & 0.011 & 0.012 & 0.008 & 0.011 & 0.007 & 0.006 \\
\hline & MAPE (\%) & 5.375 & 4.123 & 5.076 & 5.096 & 4.302 & 3.336 \\
\hline & $\mathbf{R}^{2}$ & 0.981 & 0.990 & 0.980 & 0.989 & 0.981 & 0.993 \\
\hline \multirow{5}{*}{ Kühn } & A & 0.094 & 0.075 & 0.086 & 0.065 & 0.082 & 0.057 \\
\hline & B & -0.052 & -0.094 & -0.039 & -0.069 & -0.033 & -0.055 \\
\hline & MAE & 0.010 & 0.012 & 0.008 & 0.010 & 0.006 & 0.006 \\
\hline & MAPE (\%) & 4.639 & 4.007 & 4.715 & 4.249 & 3.713 & 3.308 \\
\hline & $\mathbf{R}^{2}$ & 0.985 & 0.992 & 0.985 & 0.991 & 0.985 & 0.996 \\
\hline \multirow{5}{*}{ Mizrahi } & A & -0.063 & -0.019 & -0.062 & -0.024 & -0.063 & -0.024 \\
\hline & B & 0.115 & 0.114 & 0.102 & 0.093 & 0.096 & 0.080 \\
\hline & MAE & 0.010 & 0.012 & 0.008 & 0.010 & 0.006 & 0.006 \\
\hline & MAPE (\%) & 4.639 & 4.109 & 4.715 & 4.430 & 3.813 & 3.404 \\
\hline & $\mathbf{R}^{2}$ & 0.985 & 0.992 & 0.985 & 0.991 & 0.985 & 0.996 \\
\hline \multirow{5}{*}{ White \& Eiring } & A & 10.741 & 9.402 & 12.350 & 11.883 & 13.151 & 14.196 \\
\hline & B & -9.629 & -9.235 & -10.727 & -11.526 & -11.133 & -13.664 \\
\hline & MAE & 0.010 & 0.012 & 0.008 & 0.010 & 0.007 & 0.006 \\
\hline & MAPE (\%) & 5.127 & 4.019 & 5.119 & 4.216 & 4.461 & 3.219 \\
\hline & $\mathbf{R}^{2}$ & 0.982 & 0.992 & 0.979 & 0.990 & 0.979 & 0.995 \\
\hline
\end{tabular}

MAE Error Absoluto Medio (Valor Promedio de los residuos)

MAPE Error Porcentual Absoluto Medio

Las isotermas de sorción fueron ajustadas adecuadamente tanto para las tres concentraciones de PYM ensayadas como para los 6 modelos utilizados. 
El análisis de estos modelos, resultan herramientas útiles para predecir el comportamiento de los fertilizantes durante su acopio y asociados a estudios de análisis físicos como resistencia a la compresión y fluidez permiten conocer las condiciones óptimas de almacenamiento, manejo y aplicación de los encapsulados.

El porcentaje de higroscopicidad fue calculado a partir del punto final de las curvas de sorción de agua, para las diferentes humedades relativas ensayadas y en cápsulas con y sin agregado de urea. Los valores se encuentran reportados en la Tabla 4.5.

Schneider Teixeira et al. (2016), reportaron porcentajes bajos de higroscopicidad al analizar muestras de polvo de yerba mate: $21.31 \%, 15.96$ $\%$ y $11.88 \%$ a 75,54 y $43 \%$ de humedad relativa respectivamente, lo cual nos permitiría aprovechar esta propiedad del polvo de yerba mate en la elaboración de los encapsulados, puesto que el manejo del producto para aplicación en campo y almacenamiento a granel se ve afectado por las propiedades higroscópicas del producto.

Tabla 4.5. Higroscopicidad (HG\%) de cápsulas a diferentes porcentajes de humedad relativa.

\begin{tabular}{cccccc}
\hline & \multicolumn{5}{c}{ HG (\%) } \\
\cline { 2 - 6 } Muestra & $\mathbf{3 3} \%$ & $\mathbf{4 4} \%$ & $\mathbf{5 4} \%$ & $\mathbf{7 5} \%$ & $\mathbf{8 5} \%$ \\
\hline $\mathbf{2 5 C}$ & $20.94^{\mathrm{ab}} \pm 2.47$ & $22.37^{\mathrm{ab}} \pm 3.75$ & $24.61^{\mathrm{b}} \pm 2.81$ & $35.20^{\mathrm{bc}} \pm 4.04$ & $44.67^{\mathrm{bc}} \pm 5.13$ \\
$\mathbf{2 5 U}$ & $23.53^{\mathrm{a}} \pm 0.88$ & $26.57^{\mathrm{a}} \pm 3.59$ & $31.71^{\mathrm{a}} \pm 2.62$ & $48.79^{\mathrm{a}} \pm 5.59$ & $67.50^{\mathrm{a}} \pm 7.32$ \\
$\mathbf{5 0 C}$ & $18.12^{\mathrm{b}} \pm 2.36$ & $19.36^{\mathrm{ab}} \pm 3.36$ & $21.41^{\mathrm{b}} \pm 2.76$ & $28.81^{\mathrm{bc}} \pm 3.01$ & $36.50^{\mathrm{cd}} \pm 3.84$ \\
$\mathbf{5 0 U}$ & $18.73^{\mathrm{b}} \pm 2.46$ & $21.09^{\mathrm{ab}} \pm 4.39$ & $24.06^{\mathrm{b}} \pm 2.74$ & $37.17^{\mathrm{b}} \pm 5.37$ & $50.84^{\mathrm{b}} \pm 5.71$ \\
$\mathbf{8 0 C}$ & $17.42^{\mathrm{b}} \pm 0.84$ & $18.59^{\mathrm{b}} \pm 1.88$ & $20.43^{\mathrm{b}} \pm 1.29$ & $26.62^{\mathrm{c}} \pm 2.05$ & $32.98^{\mathrm{d}} \pm 2.60$ \\
$\mathbf{8 0 U}$ & $17.35^{\mathrm{b}} \pm 1.87$ & $19.13^{\mathrm{ab}} \pm 0.22$ & $21.91^{\mathrm{b}} \pm 0.97$ & $32.04^{\mathrm{bc}} \pm 0.69$ & $43.02^{\mathrm{bcd}} \pm 1.20$ \\
\hline \multicolumn{6}{c}{ Media $\pm D E(n=2)$} \\
Letras diferentes en cada columna indican diferencias significativas $(p<0.05)$
\end{tabular}

A los diferentes porcentajes de humedad relativa, se ve la influencia del contenido de PYM sobre la higroscopicidad, cumpliéndose en todos los casos 
que las formulaciones con mayor contenido de yerba mate presentaron menor absorción de agua $(25>50>80)$ como se muestra en la Tabla 4.5.

Mediante LSD test, se determinó que la presencia de urea afectó significativamente la absorción de agua en las cápsulas $25 \mathrm{C}$ vs $25 \mathrm{U}$, en humedades relativas de 54, 75 y $85 \%$; para las cápsulas $50 \mathrm{C}$ y $50 \mathrm{U}$ este comportamiento fue significativo $(p<0.05)$ a $85 \% \mathrm{HR}$, mientras que las cápsulas de $80 \mathrm{mg} \mathrm{PYM} / \mathrm{mL}$ de alginato, no mostraron diferencias significativas entre sí por el agregado de urea.

\subsubsection{Propiedades físicas de los encapsulados}

La resistencia a la compresión "Crushing strength" y el ángulo de reposo son parámetros de interés para las aplicaciones agroindustriales. La resistencia a la compresión es una medida de la resistencia de las cápsulas a la deformación o fractura bajo una presión ejercida sobre ella. Esta es una propiedad importante para el manejo y el almacenamiento de bolsas (Salman, 1989). Todos los valores obtenidos en este trabajo son más altos que los informados en la Organización de las Naciones Unidas para el Desarrollo Industrial (ONUDI) en su "Manual de fertilizantes" (Fertilizer, 1998). Fulton and Port (2016) resumieron los valores típicos de los fertilizantes adquiridos en EE. UU., por ejemplo, la urea granulada mostró valores de "Crushing strength" en el orden de 15 a $35 \mathrm{~N}$ y otros fertilizantes conocidos como fosfato de diamonio o fosfato monoamónico granular mostraron valores máximos de 49 $\mathrm{N}$, cercanos a los obtenidos en este trabajo (Tabla 4.6). 
Tabla 4.6. Caracterización física de las cápsulas secas de PYM a diferentes concentraciones y con el agregado de urea.

\begin{tabular}{ccc}
\hline Cápsulas & CS (N) & Ángulo de Reposo $\left(^{\circ}\right)$ \\
\hline $25 U$ & $44.36^{\mathrm{a}} \pm 5.60$ & $44.4^{\mathrm{a}} \pm 1.56$ \\
$50 \mathrm{U}$ & $55.98^{\mathrm{b}} \pm 4.41$ & $42.6^{\mathrm{a}} \pm 3.05$ \\
$80 \mathrm{U}$ & $57.79^{\mathrm{b}} \pm 6.64$ & $41.2^{\mathrm{a}} \pm 2.71$ \\
\hline
\end{tabular}

La fluidez se refiere a la capacidad de un material para fluir en determinadas condiciones, por lo que es una propiedad importante a considerar durante la manipulación y dosificación de fertilizantes (Fulton \& Port, 2016). Los polvos con ángulos de reposo inferiores a $40^{\circ}$ no son cohesivos y los polvos con ángulos de reposo superiores a $50^{\circ}$ pueden dar lugar a problemas de fluidez (Peleg, 1977). Como los fertilizantes obtenidos en el presente trabajo muestran parámetros comprendidos entre estos valores, podrían considerarse partículas de "flujo libre". Según Salman (1989), cuando los fertilizantes fluyen libremente, no habrá necesidad de bolsas forradas de polietileno en el envío. El envío a granel sin la adición de acondicionadores (mejoradores de fluidez) también será posible, lo que reduce los costos. En segundo lugar, el material fertilizante será fluido y fácil de aplicar para el agricultor ya sea manualmente o mediante maquinaria.

\subsubsection{Medición de la absorción de agua}

La absorción de agua es una propiedad importante ya que los sistemas necesitan hidratarse para solubilizar la urea y PYM para su posterior liberación y aprovechamiento en los cultivos (Schneider Teixeira et al., 2016). Es muy importante en los períodos de sequedad, porque denota la capacidad de retener la humedad. Los valores obtenidos en el presente trabajo se muestran en la Figura 4.12. 


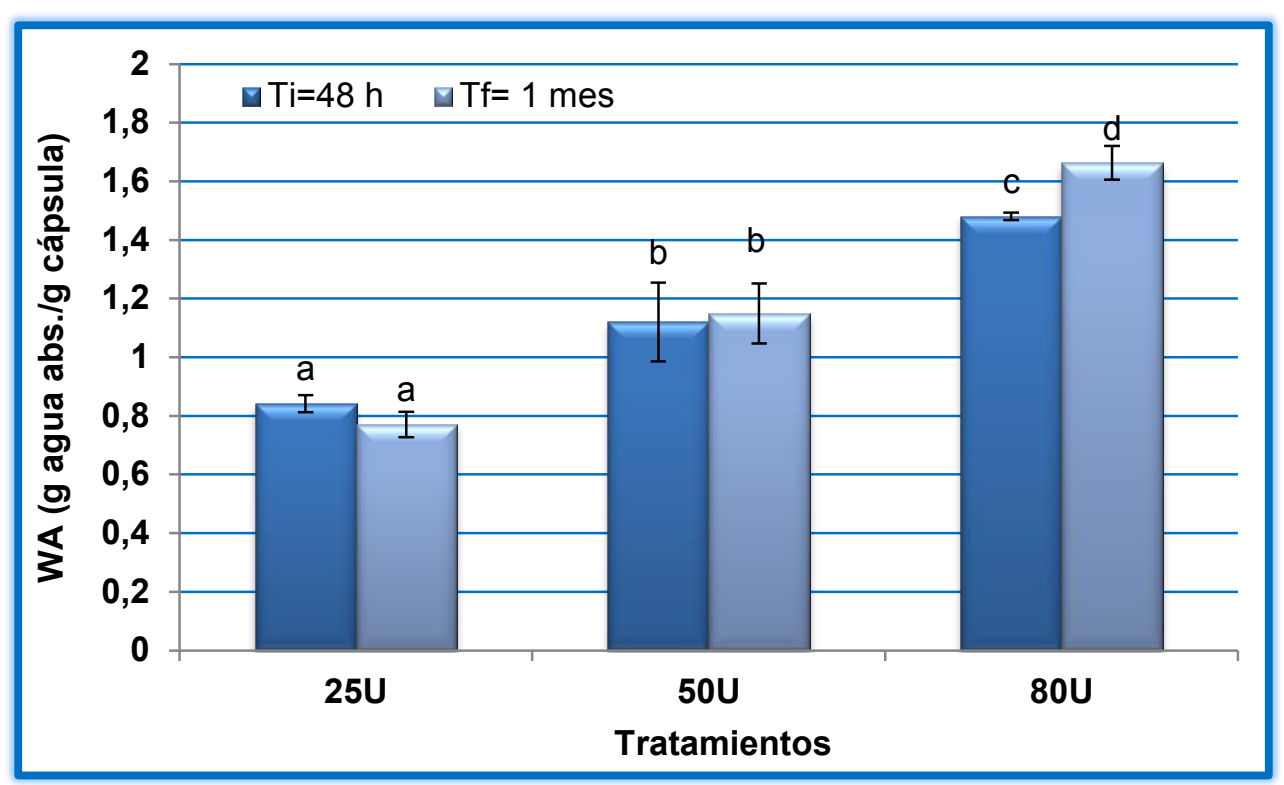

Figura 4.12 Efecto de la Concentración del PYM (25, 50 y $80 \mathrm{mg} / \mathrm{mL})$ con agregado de urea en la absorción de agua. $\mathrm{Ti}=$ Tiempo inicial (48 horas) y Tf = Tiempo final (1 mes).

La presencia de urea no afectó la absorción de agua $(p<0.05)$. El contenido de PYM y el tiempo de inmersión resultaron significativos, como se esperaba (Figura 4.12), dando un valor promedio de WA máximo de $1.663 \mathrm{~g}$ agua absorbida/g cápsula seca, después de un mes de inmersión para las cápsulas con mayor contenido de PYM (80U). 


\subsection{Conclusiones parciales}

- Es factible obtener fertilizantes encapsulados en matrices elaboradas con contenidos de polvo de yerba mate superiores a $50 \%$ y alginato de sodio gelificados con cloruro de calcio.

- La eficiencia de la encapsulación aumentó con el contenido de polvo de yerba mate en la matriz, siendo las formulaciones $50 U$ y $80 U$ las más eficientes.

- Los fertilizantes encapsulados resultaron estables en un amplio rango de humedades relativas incluidas la ambiente, hallándose modelos empíricos para predecir su comportamiento.

- Los fertilizantes obtenidos mostraron excelentes propiedades de fluidez y resistencia a la compresión (CS), demostrando su aptitud para el manejo a granel y su aplicación en los cultivos, las muestras $50 \mathrm{U}$ y $80 \mathrm{U}$ mostraron mayores valores de CS. 


\section{CAPÍTULO V \\ Liberación de fertilizantes (Urea) y degradación de los encapsulados}




\subsection{Mecanismos de liberación de compuestos.}

La liberación controlada de compuestos activos, es definida como el mecanismo mediante el cual uno o más compuestos activos pueden dirigirse a un lugar específico, en tiempo y velocidad modulada (Arifin, Lee, \& Wang, 2006).

La velocidad de liberación estará afectada por factores internos y externos, como por ejemplo: la geometría del sistema, el tipo de matriz del encapsulante, naturaleza del compuesto activo, cantidad de compuesto encapsulado, temperatura, solvente de liberación, velocidad de agitación, presión, pH (ácido, base, buffer), acción enzimática, entre otros (Pothakamury \& Barbosa-Cánovas, 1995; Siepmann \& Siepmann, 2008).

\subsection{Mecanismos de liberación a través de membranas y matrices poliméricas}

Una gran cantidad de fertilizantes y otras formulaciones agroquímicas liberan los compuestos mediante una difusión de primer orden, cuya velocidad de liberación del $60 \%$ del fertilizante es proporcional al tiempo. No obstante, en los casos en los que la matriz polimérica es susceptible de sufrir hinchamiento, la velocidad de liberación puede verse afectada por otros procesos (Aguilar, 2014).

Los factores que gobiernan el mecanismo de liberación a través de matrices polimérica son: difusión, fractura o disolución, degradación o erosión del polímero e hinchamiento (Dave et al., 1999).

\subsubsection{Liberación por difusión}

Uno de los sistemas más utilizado para la liberación de un agente activo atrapado en una matriz polimérica es el encapsulamiento, en este sistema, una membrana polimérica envuelve al compuesto activo, siendo la membrana una interface que separa dos medios y restringe el transporte de especies 
entre ambos. La difusión de sustancias a través de una membrana (permeante); se conoce como Primera Ley de Fick: (Ecuación 5.1)

$$
J=-D \cdot\left(\frac{\partial C}{\partial x}\right)
$$

Donde $J$ es velocidad de flujo por unidad de área, $\mathrm{dC} / \mathrm{dx}$ es el gradiente de concentración del compuesto que difunde en dirección $x$ y $D$ es el coeficiente de difusión. El signo negativo indica que la dirección de flujo es contra el gradiente de concentración (Nakamatsu, 2017).

\subsubsection{Liberación por disolución}

La liberación por disolución implica la transferencia del soluto desde la fase sólida hacia el medio, el cual puede ser agua, polímero o suelo. La solubilidad del soluto en el medio, es definida como la concentración del soluto en medio saturado, en equilibrio con la forma sólida. Las altas concentraciones de soluto suelen ser termodinámicamente inestables, y con el tiempo cristalizan fuera de la solución hasta igualar la concentración de saturación. En el diseño de sistemas de liberación controlada se aplica una ley empírica que indica que la concentración de saturación aumenta con la compatibilidad química entre el soluto y el medio circundante. Si bien la solubilidad es una propiedad termodinámica del sistema, la velocidad de disolución es una propiedad cinética. La tasa de disolución, comúnmente controlada por la difusión aumenta con la solubilidad y disminuye con el tamaño de partícula del soluto (Aguilar, 2014; Siegel \& Rathbone, 2012).

\subsubsection{Liberación por degradación o erosión}

La degradación es el proceso mediante el cual las cadenas del polímero matriz sufren ruptura o hidrólisis de sus enlaces, generándose cadenas más 
cortas, sin pérdida de materia, pero también puede darse el caso (erosión) de que la matriz polimérica (se hinche o no) se disuelva o sea erosionada en el medio; esto puede ocurrir por acción de reactivos químicos, $\mathrm{pH}, \quad \mathrm{o}$ microorganismos. En este caso, la velocidad de liberación del agente activo será controlada por: difusión a través de la matriz, por la disolución, erosión química o biológica del polímero o por varios de estos mecanismos combinados (Nakamatsu, 2017).

\subsubsection{Liberación por hinchamiento}

En algunos dispositivos, debido a sus propiedades, el polímero absorbe parte del solvente (agua en el caso de los hidrogeles) del entorno y se hincha, lo cual afecta su forma, volumen y cinética de la liberación. En el caso de muchos polímeros, el hinchamiento será el paso previo a su disolución, sin embargo, si el agua y el polímero son poco compatibles, si la longitud de cadena es suficientemente larga, o si la estructura del polímero es entrecruzada, el hinchamiento puede ocurrir sin disolución. La extensión del hinchamiento depende de la compatibilidad del agua con el material polimérico y la densidad de entrecruzamientos entre las cadenas del polímero. El hinchamiento es un mecanismo por el cual se puede activar la liberación del compuesto activo incorporado en la matriz polimérica. Si el hinchamiento es rápido, entonces el proceso de difusión a través del polímero hinchado es el proceso que controla la liberación, pero si el hinchamiento es lento, entonces este será el mecanismo que controlará la velocidad de liberación (Aguilar, 2014; Nakamatsu, 2017). 


\subsection{Materiales y Métodos}

\subsubsection{Cinética de liberación de urea y condiciones de degradación.}

Se colocó una masa $(0.1 \mathrm{~g})$ de cápsulas secas en bolsas de nylon de malla fina $(1 \mathrm{~mm}$ ) (Gasatex, Argentina) y se enterraron $5 \mathrm{~cm}$ por debajo de la superficie del suelo (Terrafertil, Argentina) en macetas de polietileno de alta densidad de $240 \mathrm{~mL}$. Tres variables independientes: tipo de cápsula (25U, $50 \mathrm{U}$ y $80 \mathrm{U})$, temperatura de almacenamiento $\left(4,20\right.$ y $\left.30^{\circ} \mathrm{C}\right)$ y períodos de incubación $(3,5,10,20,30,60$ y 90 días) fueron analizados como factores en un diseño factorial completo. Para cada combinación, se preparó un recipiente individual y el diseño experimental completo se replicó dos veces. Los contenedores se almacenaron bajo condiciones controladas a las temperaturas mencionadas (Fig. 5.1). A lo largo de los experimentos, la muestra de suelo (tierra) se mantuvo con un contenido de humedad de 35-40 $\%$ mediante pesada periódica y agregado de agua del grifo cuando sea necesario.

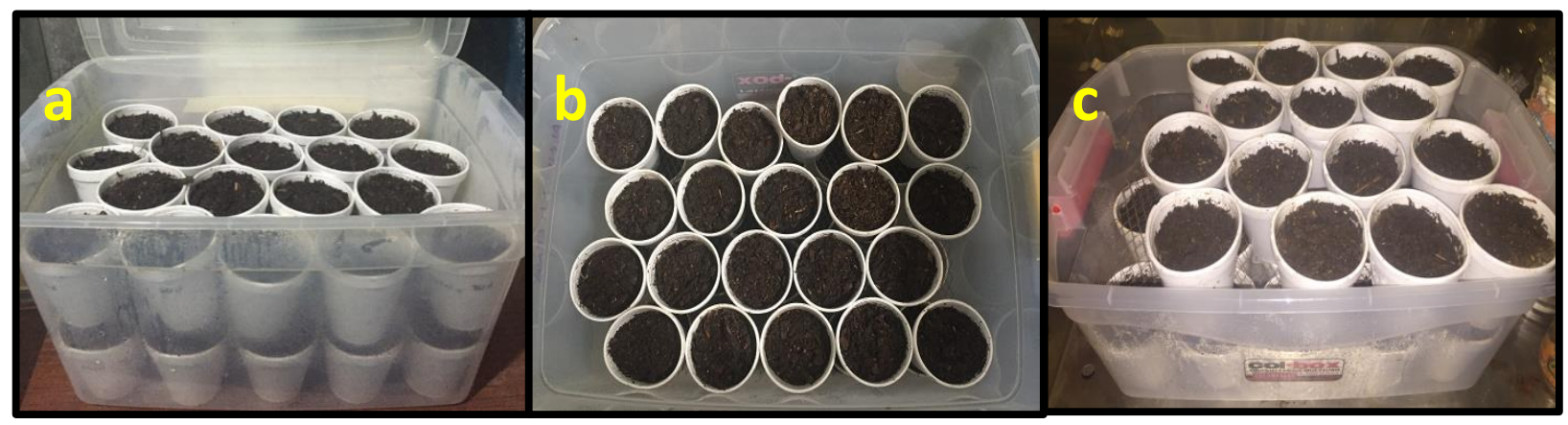

Figura 5.1 Fotografías de los contenedores donde se almacenaron las macetas a diferentes condiciones de temperatura. a) $4{ }^{\circ} \mathrm{C}$, b) $20^{\circ} \mathrm{C}$ y c) $30^{\circ} \mathrm{C}$.

Después de cada período de incubación, las cápsulas restantes en los vasos se retiraron y el exceso de tierra fue removido. Con el fin de evaluar la degradación durante el período analizado, se verificó el peso de las muestras en estado húmedo y seco a $105{ }^{\circ} \mathrm{C}$ durante 24 horas para cada tiempo. Luego, las muestras se pulverizaron en un mortero, se disolvieron en agua y su contenido de urea se determinó mediante el método colorimétrico que se describe en la sección 4.2.3. La cantidad de urea liberada se calculó por 
diferencia. El pH (Hach, sensION 3, EE. UU) se verificó en todos los vasos, manteniendo valores $(\sim 7.5)$ durante todo el ensayo. La tasa de degradación fue determinada por la Ecuación 5.2 (Zhang et al., 2014):

$$
\begin{array}{ll}
\text { Degradación }(\%)=\frac{\left(W_{1}-W_{2}\right)}{W_{2}} * 100 \quad \text { Ec. } 5.2
\end{array}
$$

donde $W_{1}$ y $W_{2}$ son los pesos de las cápsulas secas antes y después de ser enterradas en suelo $(\mathrm{g})$, respectivamente.

\subsubsection{Medición de la absorción de agua en tierra durante la degradación.}

Con las muestras obtenidas en la sección anterior (5.3.1) y con los datos de los pesos en estado húmedo y seco a $105^{\circ} \mathrm{C}$ se determinó la absorción de agua a cada tiempo de degradación, mediante la Ecuación 5.3 (Luzi et al., 2015).

$$
W A_{s}=\left(\frac{W_{w}-W_{t}}{w_{t}}\right)
$$

Donde $W_{w}$ y $W_{t}$ denotan el peso de las cápsulas húmedas y secas respectivamente, a cada tiempo de degradación y $W A_{s}$ es la absorción de agua en el suelo por gramo de cápsula seca.

\subsubsection{Determinación del contenido de minerales antes y después del ensayo de degradación.}

Utilizando el método descrito en la sección 3.2.3, se analizaron los contenidos de $\mathrm{Ca}, \mathrm{K}$ y $\mathrm{Mg}$ en tres tipos de cápsulas (25U, $50 \mathrm{U}$ y $80 \mathrm{U})$, a diferentes temperaturas $\left(4{ }^{\circ} \mathrm{C}, 20{ }^{\circ} \mathrm{C}\right.$ y $\left.30{ }^{\circ} \mathrm{C}\right)$ y a dos de los diferentes tiempos 
ensayados (0 y 30 días). La condición de 30 días fue elegida porque a ese tiempo aún se cuentan con cápsulas enteras para todas las muestras, que posibilitan realizar las mediciones a las diferentes temperaturas, lo cual no ocurre a tiempos mayores.

\subsubsection{Calorimetría Diferencial de Barrido (DSC)}

Se utilizó un equipo Q100 DSC (TA Instruments, EE.UU.) calibrado con un estándar de indio. Las muestras de 5-10 mg se colocaron en crisoles herméticamente sellados y un crisol vacío se utilizó como referencia. Las muestras analizadas fueron: cápsulas de alginato de calcio con polvo de yerba mate, con y sin urea $(25 \mathrm{C}, 25 \mathrm{U}, 50 \mathrm{C}, 50 \mathrm{U}, 80 \mathrm{C}$ y $80 \mathrm{U})$, además, se monitorearon las cápsulas durante la degradación a diferentes temperaturas $\left(4,20\right.$ y $\left.30^{\circ} \mathrm{C}\right)$ y tiempos $(5,10$ y 30 días). Las muestras se calentaron desde 25 a $300{ }^{\circ} \mathrm{C}$ a una velocidad de calentamiento de $10{ }^{\circ} \mathrm{C} / \mathrm{min}$. Más tarde, las cápsulas se pincharon y se secaron en un horno a $105^{\circ} \mathrm{C}$ durante $72 \mathrm{~h}$ para corregir el peso de la muestra. Los termogramas se analizaron siguiendo procedimientos estándar (Universal Analysis Program, TA Instruments).

\subsubsection{Espectroscopía Infrarroja con Transformada de Fourier (FT-IR)}

Se empleó un equipo Nicolet IS-10 (Thermo Scientific, Inc, EE.UU) en el rango de 400 a $4000 \mathrm{~cm}^{-1}$, tomando 64 escaneos por experimento a una resolución de $4 \mathrm{~cm}^{-1}$. Las muestras molidas se colocaron en el cristal de diamante ATR (accesorio Smart iTX) del equipo. El análisis espectral se realizó con el software versión Omnic 9 (Thermo Scientific) mediante la corrección por línea de base. El estudio se realizó en las siguientes muestras: cápsulas de alginato de calcio con polvo de yerba mate, con y sin urea (25C, $25 U, 50 \mathrm{C}, 50 \mathrm{U}, 80 \mathrm{C}$ y $80 \mathrm{U})$, además, se monitorearon las cápsulas durante la degradación a diferentes temperaturas $\left(4,20\right.$ y $\left.30^{\circ} \mathrm{C}\right)$ y tiempos $(0,3,5,10$, 20 y 30 días). 


\subsubsection{Microbiología}

El efecto del almacenamiento a diferentes temperaturas $\left(4,20\right.$ y $\left.30^{\circ} \mathrm{C}\right)$ y del tipo de cápsula $(25,50$ y $80 \mathrm{mg}$ de $\mathrm{PYM} / \mathrm{mL}$ alginato) con urea sobre el crecimiento microbiano y de hongos se estudió de la siguiente manera: dos muestras de cápsulas se homogeneizaron asépticamente con $1.50 \mathrm{~mL}$ de agua en vórtice. Se realizaron diluciones decimales seriadas en agua estéril y se sembraron en placas en dos medios de cultivo, agar nutritivo (Britania, Argentina) y Sabouraud glucosa agar (Britania, Argentina), por duplicado. Después de la dispersión, las placas se incubaron a $37^{\circ} \mathrm{C}$ durante $24 \mathrm{~h}$ para bacterias y $28{ }^{\circ} \mathrm{C}$ durante 7 días para mohos. Luego de una incubación adecuada, se cuantificó el número de colonias desarrolladas.

\subsubsection{Microscopía Electrónica de Barrido Ambiental (ESEM)}

Las cápsulas provenientes de los ensayos de biodegradación a diferentes temperaturas $\left(4,20\right.$ y $\left.30{ }^{\circ} \mathrm{C}\right)$ y diferentes tiempos de degradación (10 y 30 días) se observaron mediante ESEM (FEI, Quanta 200 microscope, Holanda) sin ningún tratamiento previo a la introducción en el microscopio.

Las imágenes se tomaron con una pistola de aceleración electrones a voltaje de $20 \mathrm{kV}$, a temperatura ambiente, una humedad relativa de 30-40 \% y 3.22 Torr. Se examinaron al menos dos cápsulas por tratamiento (para dos lotes diferentes) y se tomaron fotografías. 


\subsection{Resultados}

\subsubsection{Cinética de liberación de Urea en tierra y condiciones de degradación.}

La cinética de liberación de la urea y la degradación de los sistemas a diferentes temperaturas bajo tierra, se muestran en la Figura. 6.2 Adicionalmente se pueden observar fotografías que muestran el aspecto visual de las cápsulas después de 60 días de degradación y se ubicaron a la derecha de cada figura.

Para la degradación el análisis estadístico reveló que tanto las cápsulas como las temperaturas tuvieron un efecto significativo $(p<0.05)$. La degradación fue más rápida para las cápsulas con mayor contenido de polisacárido $(25 U>50 U>80 U)$ y aumentó con la temperatura $\left(4<20<30{ }^{\circ} \mathrm{C}\right)$. Este hecho se atribuyó a la degradación del alginato por parte de los microorganismos. Wu, Guo, Qin, and Li (2012) encontraron resultados similares al trabajar con sistemas de alginato, almidón y bentonita. Este parámetro alcanzó un $40 \%$ al final del ensayo a $4{ }^{\circ} \mathrm{C}$ (Fig. 6.2A), contra un $100 \%$ de degradación a $30{ }^{\circ} \mathrm{C}$ (Fig. 6.2C), observándose claramente el efecto de la temperatura en la degradación. En el análisis de varianza aplicado a este diseño experimental, se observó que la interacción (días*temperatura) fue la única significativa $(p<0.05)$, esto se explica al verificar que a 20 y $30{ }^{\circ} \mathrm{C}$, las cápsulas experimentaron una degradación total entre los 30 y 60 días de ensayo (Fig. $6.2 \mathrm{~B}$ y $\mathrm{C}$ ), mientras que a $4{ }^{\circ} \mathrm{C}$ este proceso de desintegración final se produjo entre los 60 y 90 días (Fig. 6.2A).

Con respecto a la liberación, también las cápsulas y las temperaturas fueron factores significativos $(p<0.05)$. Las cápsulas con $80 \mathrm{mg} / \mathrm{mL}$ liberaron menos urea, mientras que las de $25 \mathrm{U}$ y $50 \mathrm{U}$ se comportaron igual en cuanto a este parámetro (LSD test) (Fig. 5.2). 


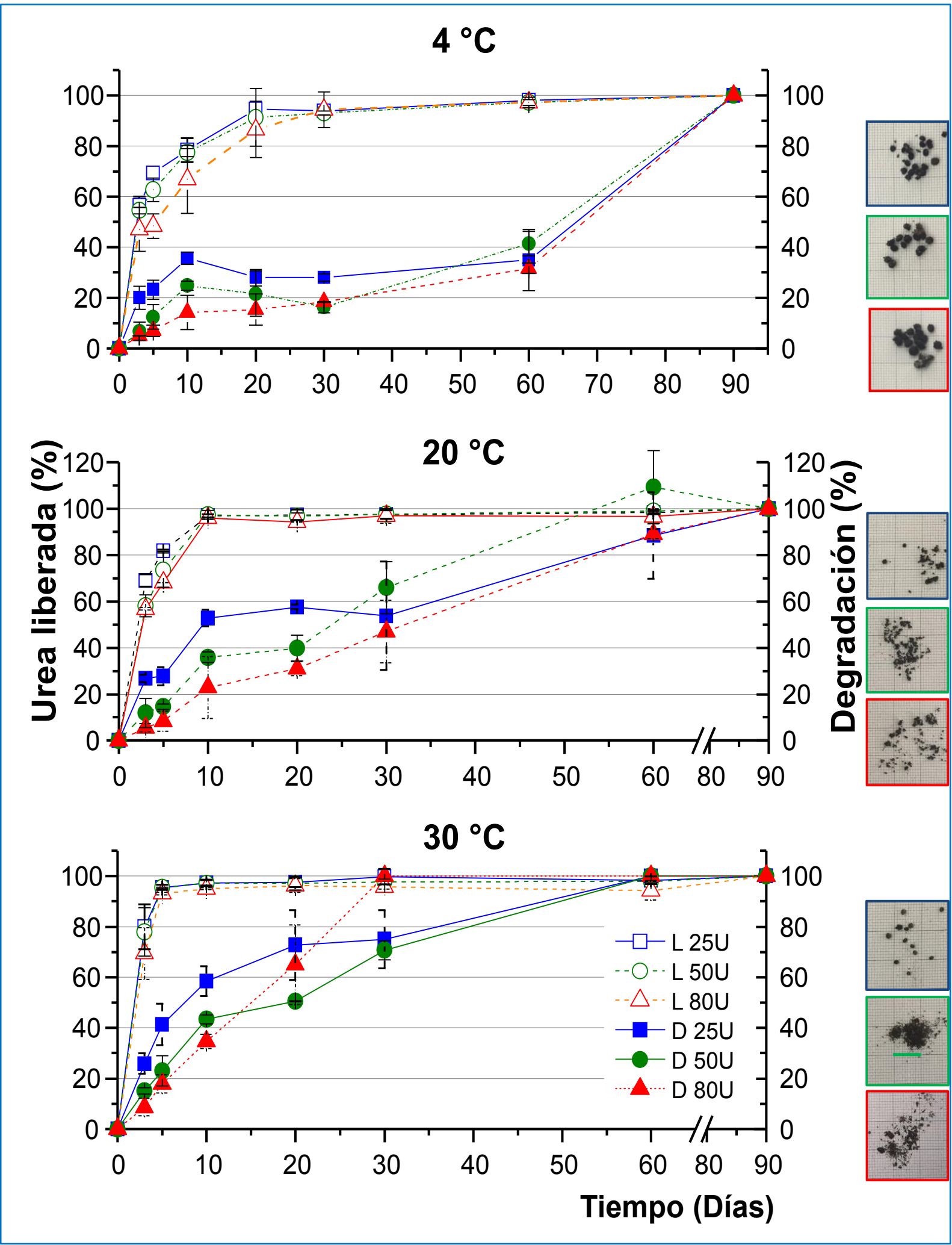

Figura 5.2. Liberación (L) de urea y degradación (D) de sistemas encapsulados en base a PYM con urea agregada (25U, $50 \mathrm{U}$ y $80 \mathrm{U})$, a diferentes temperaturas $\left(4,20\right.$ y $\left.30^{\circ} \mathrm{C}\right)$. Las fotografías a la derecha de la figura muestran las cápsulas degradadas luego de 60 días de ensayo. Para cada temperatura, las imágenes se muestran en el siguiente orden: arriba $=25 U$, medio $=50 U$ y $a b a j o=80 U$. Barra $=1 \mathrm{~cm}$. 
A $4{ }^{\circ} \mathrm{C}$, la liberación total de la urea se alcanzó entre los 30 y 60 días, sin embargo a 20 y $30{ }^{\circ} \mathrm{C}, 10$ días fueron suficientes para liberar toda la urea presente en las cápsulas (Fig. 6.2), esto coincidiría con lo mostrado por Jarrell and Boersma (1979), quienes encontraron un efecto de la temperatura en la liberación de urea en el suelo, a partir de gránulos recubiertos de urea azufrada, la liberación de urea a $25^{\circ} \mathrm{C}$ fue tres veces mayor que la alcanzada a $5{ }^{\circ} \mathrm{C}$.

Si bien los encapsulados cumplirían parcialmente los requisitos de un sistema de liberación "controlado", podrían tener otras propiedades deseables para los fertilizantes, como lo son, el aporte de materia orgánica y de micronutrientes provistos por el polvo de yerba mate que en los dispositivos de liberación controlada de nutrientes sintéticos no está contemplado. Además, de acuerdo a lo indicado por Chen et al. (2018), los encapsulados reunirían algunas características de "Fertilizantes amigables con el medio ambiente" (EFF), entre las cuales se destacan: la aplicación de materiales naturales degradables como materia prima o revestimiento, la reducción de la contaminación ambiental por pérdida de nutrientes por retardo, la prevención de la exposición a la urea en el agua y el suelo al servir como un barrera reduciendo la tasa de hidrólisis de urea y el aumento del contenido de materia orgánica del suelo.

En el caso de los encapsulados obtenidos en este trabajo, además del aporte orgánico del alginato de calcio como soporte de la matriz, se sumarán los efectos que aporta el PYM reforzando la matriz de los encapsulados y aumentando el contenido de minerales como magnesio y potasio en las cápsulas con mayor contenido de este subproducto.

El mecanismo de liberación de la urea se analizó utilizando modelos empíricos (Peppas \& Sahlin, 1989; Ritger \& Peppas, 1987):

La Ley de la Potencia (Ec. 5.4), el modelo de difusión-relajación (Ec. 5.5) y la expresión de Kopcha (Ec. 5.6) (Kopcha, Lordi, \& Tojo, 1991): 


$$
\frac{\mathrm{M}_{\mathrm{t}}}{\mathrm{M}_{\infty}}=\mathrm{kt}^{\mathrm{n}}
$$

Ec. 5.4

donde $\left(\mathrm{M}_{\mathrm{t}} / \mathrm{M}_{\infty}\right)$ representa la fracción de urea liberada al tiempo $t\left(\mathrm{M}_{\mathrm{t}}\right)$ con respecto a la máxima cantidad de urea que se liberaría a un tiempo $t=\infty$. La masa máxima de urea liberada $\left(\mathrm{M}_{\infty}\right)$ fue la masa cuantificada en las cápsulas, $k$ es una constante relacionada a cambios estructurales y características geométricas (porosidad, tortuosidad) de la matriz y los ingredientes activos, y $n$ es el exponente de transporte que indica el tipo de mecanismo de liberación involucrado.

$$
\frac{\mathrm{M}_{\mathrm{t}}}{\mathrm{M}_{\infty}}=\mathrm{k}_{\mathrm{d}} \mathrm{t}^{\mathrm{m}}+\mathrm{k}_{\mathrm{r}} \mathrm{t}^{2 \mathrm{~m}} \quad \text { Ec. } 5.5
$$

donde $\mathrm{k}_{\mathrm{d}}, \mathrm{k}_{\mathrm{r}}$ y $\mathrm{m}$ son constantes. El primer término representa la contribución difusional y el segundo representa la contribución de la relajación, teniendo en cuenta la posibilidad de dos mecanismos diferentes actuando juntos (Peppas \& Sahlin, 1989).

$$
\mathrm{M}=A \mathrm{t}^{1 / 2}+\mathrm{Bt}
$$

donde, $M$ es el porcentaje de urea liberado al tiempo $t$, mientras que $A$ y $B$ son los términos de difusión y erosión, respectivamente. De acuerdo a esta ecuación, si la relación de difusión a erosión es $A / B=1$, el mecanismo de liberación incluye ambos, la difusión y la erosión por igual; si $A / B>1$, entonces prevalece la difusión, mientras que si $A / B<1$, la erosión predomina. La Tabla 5.1 muestra los parámetros cinéticos obtenidos para los diferentes modelos; la bondad del ajuste se evaluó utilizando el coeficiente de correlación $\left(R^{2}\right)$ y el análisis de la distribución de los residuos. 
El mejor ajuste se obtuvo para el modelo de difusión-relajación (Ecuación 6.5), mientras que en el modelo de Kopcha (Ecuación 5.6) se observó una prevalencia del término difusional $(A)$ versus el término de erosión $(B)$, pero el ajuste del modelo no fue el mejor (Tabla 5.1).

Las constantes obtenidas para el modelo de difusión-relajación halladas para este trabajo, indicaron la prevalencia del mecanismo de difusión sobre el de relajación ( $\mathrm{kd} \gg \mathrm{kr}$ ). La superficie expuesta de las cápsulas se hincharía lentamente por el agua que contiene el suelo transformándose en hidrogel (Wu \& Liu, 2008).

Teniendo en cuenta que el $\mathrm{pH}$ en el suelo a lo largo del experimento se mantuvo alrededor de 7.5, los iones carboxilato a lo largo de las moléculas de alginato se repelerían mutuamente y produciría una relajación rápida en las cadenas poliméricas, facilitando la inclusión de moléculas de agua en la red de los encapsulados, como lo sugieren Wu et al. (2012).

Como la urea es altamente soluble en agua, la difusión sería el mecanismo de liberación que prevalece en estos sistemas. Sin embargo, bajo el efecto del agua, iones y microorganismos existentes en el suelo, la matriz de alginato se degradará lentamente en la última etapa y continuará disolviendo la urea. Un efecto similar fue reportado por Wu and Liu (2008) para la capa media de quitosano en su producto, ellos propusieron que en esta etapa, la tasa de degradación determina la tasa de liberación de nutrientes. 
Tabla 5.1 Parámetros obtenidos en los modelos empíricos para la liberación de urea de distintos sistemas a distintas temperaturas

\begin{tabular}{|c|c|c|c|c|c|c|c|c|c|c|}
\hline \multirow{3}{*}{ Modelos } & \multirow{3}{*}{ Parámetros } & \multicolumn{9}{|c|}{ Tratamientos } \\
\hline & & \multicolumn{3}{|c|}{$25 \mathrm{U}$} & \multicolumn{3}{|c|}{$50 \mathrm{U}$} & \multicolumn{3}{|c|}{$80 U$} \\
\hline & & $4^{\circ} \mathrm{C}$ & $20^{\circ} \mathrm{C}$ & $30^{\circ} \mathrm{C}$ & $4^{\circ} \mathrm{C}$ & $20^{\circ} \mathrm{C}$ & $30^{\circ} \mathrm{C}$ & $4^{\circ} \mathrm{C}$ & $20^{\circ} \mathrm{C}$ & $30^{\circ} \mathrm{C}$ \\
\hline \multirow[t]{5}{*}{ Ley de la Potencia } & $\mathrm{K}$ & 0.52364 & 0.69684 & 0.41179 & 0.48447 & 0.59754 & 0.40925 & 0.36595 & 0.56979 & 0.76334 \\
\hline & $\mathrm{n}$ & 0.16724 & 0.09760 & 0.27102 & 0.18467 & 0.14164 & 0.27025 & 0.25677 & 0.14946 & 0.06557 \\
\hline & MAE & 0.03780 & 0.04222 & 0.15956 & 0.03953 & 0.06615 & 0.15988 & 0.06356 & 0.06575 & 0.05231 \\
\hline & CME & 0.00290 & 0.00371 & 0.04690 & 0.00351 & 0.00810 & 0.04609 & 0.00724 & 0.00801 & 0.00618 \\
\hline & $\mathrm{R}^{2}$ & 0.97567 & 0.97105 & 0.64879 & 0.97001 & 0.93929 & 0.65031 & 0.94116 & 0.93782 & 0.95151 \\
\hline \multirow[t]{2}{*}{ Peppas y Sahlin } & $\mathrm{k}_{\mathrm{d}}$ & 0.45238 & 0.62034 & 0.77836 & 0.41366 & 0.50014 & 0.76958 & 0.28601 & 0.46819 & 0.68707 \\
\hline & $\mathrm{k}_{\mathrm{r}}$ & -0.00029 & -0.00039 & -0.00042 & -0.00028 & -0.00041 & -0.00041 & -0.00028 & -0.00041 & -0.00047 \\
\hline \multirow{4}{*}{$\frac{M_{t}}{M_{\infty}}=k_{d} t^{m}+k_{r} t^{2 m}$} & $\mathrm{~m}$ & 0.24446 & 0.16151 & 0.08683 & 0.26726 & 0.23739 & 0.08767 & 0.38014 & 0.25455 & 0.12450 \\
\hline & MAE & 0.02409 & 0.03010 & 0.02881 & 0.02581 & 0.04615 & 0.03171 & 0.04744 & 0.04211 & 0.04438 \\
\hline & CME & 0.00115 & 0.00206 & 0.00238 & 0.00176 & 0.00488 & 0.00296 & 0.00469 & 0.00430 & 0.00490 \\
\hline & $\mathrm{R}^{2}$ & 0.99117 & 0.98529 & 0.98368 & 0.98627 & 0.96648 & 0.97938 & 0.96503 & 0.96940 & 0.96477 \\
\hline \multirow[t]{2}{*}{ Kopcha } & $A$ & 34.30420 & 40.61900 & 43.89650 & 32.69520 & 38.21540 & 43.49490 & 27.93830 & 37.06900 & 42.08930 \\
\hline & $\mathrm{B}$ & -2.86120 & -3.73284 & -4.19379 & -2.65278 & -3.37381 & -4.15429 & -1.98039 & -3.24931 & -4.01037 \\
\hline \multirow{3}{*}{$M=A t^{1 / 2}+B t$} & MAE & 4.23457 & 7.95212 & 10.75100 & 3.97221 & 5.89100 & 10.76750 & 4.75839 & 4.94669 & 9.25055 \\
\hline & CME & 31.93430 & 92.63050 & 199.22800 & 29.49260 & 59.76240 & 199.09000 & 44.77030 & 46.90980 & 154.97700 \\
\hline & $\mathrm{R}^{2}$ & 0.97318 & 0.92778 & 0.85082 & 0.97484 & 0.95521 & 0.84896 & 0.96362 & 0.96358 & 0.87838 \\
\hline
\end{tabular}


Ritger and Peppas (1987) sugirieron que el valor del exponente $n$ para el mecanismo de liberación fickiana de un sistema polimérico con geometría esférica debería ser de alrededor de 0.43. Como se puede observar en la Tabla 5.1, los valores obtenidos en este trabajo fueron menores para cada condición de los encapsulados. Lupo, Maestro, Gutiérrez, \& González (2015) mientras estudiaban la liberación de extracto de cacao en cápsulas de alginato, sugirieron que este hecho indicaría que algo más está sucediendo además del proceso de difusión de Fick, y lo atribuyeron a la presencia de calcio en el medio de liberación. El catión continuaría su interacción con el alginato, por lo que la reticulación de la matriz se refuerza con el tiempo, que también se refleja en una constante de velocidad negativa $(k r)$ cuando se estudia el ajuste al modelo de Peppas-Sahlin. En nuestro caso, los iones de calcio permanecieron presentes en la superficie de las cápsulas ya que no se lavaron después de la gelificación y el polvo de yerba mate posee una gran cantidad de este catión, lo cual favorecería el endurecimiento posterior del encapsulado previo a la etapa de secado.

\subsubsection{Medición de la absorción de agua durante la degradación.}

La absorción de agua (WA) durante el proceso de degradación, es importante ya que en los polímeros hidrófilos la absorción de líquido aumenta la tasa de degradación de los encapsulados (Luzi et al., 2015).

En la Figura 5.3 se muestra la cinética de absorción de agua durante el ensayo de degradación. Tal como se observó en la sección anterior (5.4.1), que la temperatura afectó sensiblemente las condiciones de degradación, se detectó dicha influencia sobre el comportamiento de la absorción de agua en suelo. 


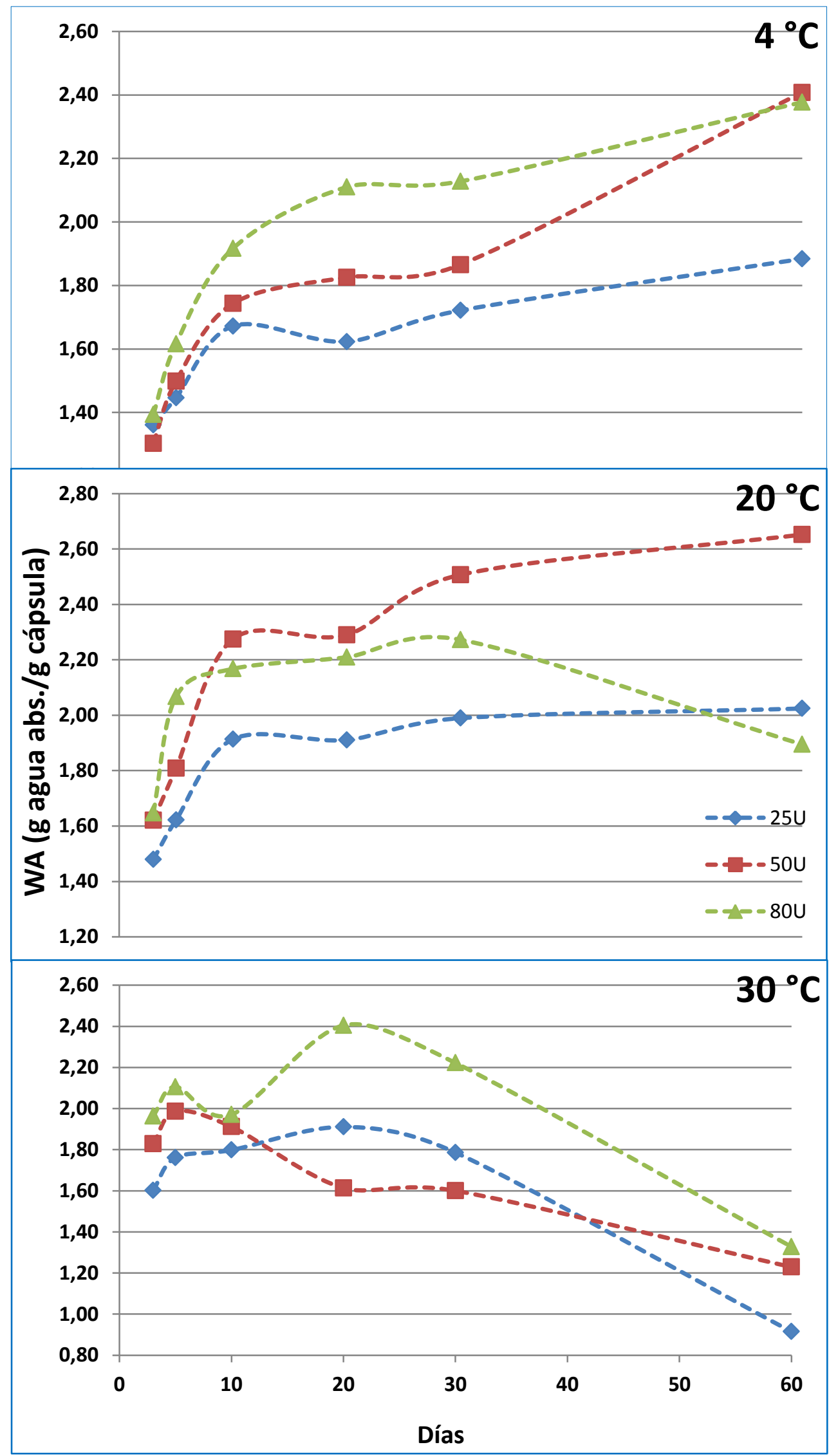

Figura 5.3. Absorción de agua (WA) en tierra durante el ensayo de degradación en cápsulas $(25 \mathrm{U}, 50 \mathrm{U}$ y $80 \mathrm{U})$, a temperaturas $\left(4,20\right.$ y $\left.30^{\circ} \mathrm{C}\right)$ en tiempos entre 3 y 60 días. 
A $4{ }^{\circ} \mathrm{C}$, Fig. 5.3A, se observa un comportamiento creciente de la absorción con el paso del tiempo, alcanzando valores máximos de hasta $2.40 \pm 0.06 \mathrm{~g}$ de agua absorbidos/g de cápsulas secas. Este comportamiento de absorción es favorecido a esta temperatura debido a que los procesos de degradación son más lentos y recién luego de 60 días bordean valores de 40 \% (Fig. 5.2), es decir la cápsula aún mantiene más de la mitad de su integridad, lo cual facilita la absorción. Las cápsulas con mayor contenido de PYM en la matriz (50U y 80U) son las que mayor cantidad de agua absorben, y esto puede ocurrir debido a que el polvo de yerba mate refuerza la matriz ayudando a mantener la estructura más compacta, lo cual no ocurre con las cápsulas de $25 U$, las cuales se degradan con más facilidad debido a que su contenido polimérico predomina sobre el del polvo de yerba mate, acelerando la degradación del alginato de calcio por la acción de los microorganismos que circundan el sistema.

En la Fig. 5.3B la absorción de agua aumenta hasta el día 30, donde tiende a estabilizarse o incluso descender como en el caso de $80 \mathrm{U}$. A $20^{\circ} \mathrm{C}$ y a 60 días los valores de degradación se encuentran cercanos al $100 \%$, lo cual impide que la cápsula siga acumulando agua en su interior, esto se puede observar más claramente a $30^{\circ} \mathrm{C}$ (Fig. 5.3C) donde la degradación a 20 días alcanza valores entre 50 y $70 \%$ para todas las cápsulas, a partir de este tiempo se empieza a observar un descenso de la absorción para todas las cápsulas, debido a la degradación, rupturas y desintegración que pudieron sufrir las cápsulas en estas condiciones.

La determinación de este parámetro confirmó que la relajación de la red que forma la matriz de los encapsulados no es el mecanismo principal de liberación de la urea, ya que las muestras siguieron absorbiendo agua, lo cual contribuye a la relajación de la matriz, luego de liberada la totalidad de la urea. 


\subsubsection{Determinación del contenido de minerales durante el ensayo de degradación.}

Se monitorearon los principales minerales del polvo de yerba mate ( $\mathrm{Ca}$, Mg y K) en las matrices a lo largo del ensayo de degradación. El contenido mineral inicial cuantificado en cada formulación se presenta en la Tabla 5.2. La relación PYM: alginato, se reflejó en el contenido de minerales detectados, así las cápsulas $25 \mathrm{U}$ mostraron un mayor contenido de calcio, atribuido a la mayor cantidad de alginato de calcio en la matriz (cerca del $48 \%$ en comparación con $32 \%$ y $18 \%$ para $50 U$ y $80 U$, respectivamente). Respecto a los contenidos de magnesio y potasio fueron más altos para las muestras de $80 U$, lo que está relacionado con una mayor cantidad de PYM en la matriz de estas cápsulas.

Tabla 5.2 Contenido de minerales ( $\mathrm{Ca}, \mathrm{Mg}$ y K), antes y después de la degradación.

\begin{tabular}{cccccc}
\hline \multirow{2}{*}{ Muestra } & $\begin{array}{c}\text { Tiempo } \\
\text { (días) }\end{array}$ & $\begin{array}{c}\text { Temperatura } \\
\left({ }^{\circ} \mathbf{C}\right)\end{array}$ & \multicolumn{2}{c}{ Contenido de Minerales (g/100g cápsula) } \\
\cline { 4 - 6 } & $\mathbf{0}$ & - & $\mathbf{M g}$ & $\mathbf{K}$ & $\mathbf{C a}$ \\
\hline \multirow{3}{*}{$\mathbf{2 5 U}$} & $\mathbf{3 0}$ & $\mathbf{4}$ & $0.147 \pm 0.011$ & $0.446 \pm 0.186$ & $6.789 \pm 0.234$ \\
& $\mathbf{3 0}$ & $\mathbf{2 0}$ & $0.183 \pm 0.008$ & $0.925 \pm 0.133$ & $7.955 \pm 0.007$ \\
& $\mathbf{3 0}$ & $\mathbf{3 0}$ & $0.190 \pm 0.014$ & $0.745 \pm 0.079$ & $8.268 \pm 0.439$ \\
\hline \multirow{4}{*}{$\mathbf{5 0 U}$} & $\mathbf{0}$ & - & $0.124 \pm 0.002$ & $0.705 \pm 0.007$ & $5.197 \pm 0.268$ \\
& $\mathbf{3 0}$ & $\mathbf{4}$ & $0.214 \pm 0.011$ & $0.631 \pm 0.024$ & $6.318 \pm 0.312$ \\
& $\mathbf{3 0}$ & $\mathbf{2 0}$ & $0.250 \pm 0.011$ & $1.020 \pm 0.024$ & $8.943 \pm 1.296$ \\
& $\mathbf{3 0}$ & $\mathbf{3 0}$ & $0.260 \pm 0.002$ & $0.881 \pm 0.080$ & $8.088 \pm 0.287$ \\
\hline \multirow{3}{*}{$\mathbf{8 0 U}$} & $\mathbf{0}$ & - & $0.274 \pm 0.007$ & $0.660 \pm 0.019$ & $5.609 \pm 0.253$ \\
& $\mathbf{3 0}$ & $\mathbf{4}$ & $0.221 \pm 0.007$ & $0.565 \pm 0.060$ & $6.357 \pm 0.901$ \\
& $\mathbf{3 0}$ & $\mathbf{2 0}$ & $0.228 \pm 0.052$ & $0.877 \pm 0.075$ & $6.503 \pm 0.929$ \\
& $\mathbf{3 0}$ & $\mathbf{3 0}$ & $0.326 \pm 0.020$ & $0.909 \pm 0.020$ & $7.939 \pm 0.020$ \\
\hline
\end{tabular}

A lo largo del período de almacenamiento no se detectó liberación de minerales, al contrario, se produjo un enriquecimiento de los mismos en algunas cápsulas en el tiempo final del ensayo (Tabla 5.2). Este hecho podría estar relacionado con la degradación del alginato de calcio y la materia orgánica en primer lugar, como se mencionó anteriormente en la sección 
(5.4.1). Entonces, con la disminución de la masa total de la cápsula debido a la degradación, los minerales se concentrarían en una matriz más pequeña.

Dado que el suelo empleado en el ensayo era fértil (35 \% materia orgánica), se cuantificaron por absorción/emisión atómica los minerales más representativos de su composición, el calcio ( $0.8 \mathrm{~g}$ de calcio/100 $\mathrm{g}$ de tierra) por ser el principal componente de la matriz de los encapsulados y el que mayor concentración se encuentra en el polvo de yerba mate, mientras que el potasio (0.15 g de potasio/100 $\mathrm{g}$ de tierra) es el segundo componente principal del PYM. Considerando que dadas las condiciones del ensayo, en la que toda la superficie de las cápsulas se encuentra en contacto con la tierra, la determinación del contenido de minerales en las cápsulas podría verse influenciado por el aporte de los minerales de la tierra adherida e incrustada a los encapsulados. Después de la degradación total, los minerales estarían disponibles para el suelo de los cultivos.

\subsubsection{Calorimetría Diferencial de Barrido (DSC)}

El polvo de yerba mate presenta un pico endotérmico ancho situado alrededor de $100-130{ }^{\circ} \mathrm{C}$ con valores de entalpías muy variados atribuidos al elevado número de constituyentes del residuo (antioxidantes, minerales, materia orgánica) y un pico endotérmico a $237^{\circ} \mathrm{C}$, también encontrado en trabajos previos (Schneider Teixeira et al., 2016) (Fig. 5.4). El polvo de yerba mate es el componente mayoritario en todas las formulaciones de cápsulas, constituyendo el 83, 67 y $52 \%$ de las formulaciones $80 \mathrm{U}, 50 \mathrm{U}$ y $25 \mathrm{U}$ respectivamente.

Mientras que la urea tiene un pico endotérmico, bien definido y estrecho a $137{ }^{\circ} \mathrm{C}$ (Schneider Teixeira et al., 2016), que no se observa en los termogramas (antes o después de la degradación) lo cual denota su encapsulación en la matriz. 
Las cápsulas de alginato de calcio (AlgCa) mostraron dos picos endotérmicos, el primero (entre 50 y $175^{\circ} \mathrm{C}$ ) se atribuyó a la deshidratación (Anbinder, Deladino, Navarro, Amalvy, \& Martino, 2011; Santagapita, Mazzobre, \& del Pilar Buera, 2012; Smitha, Sridhar, \& Khan, 2005). Sin embargo, este pico estuvo ausente en todas las cápsulas antes de la degradación (con y sin urea) (Figura 5.4). El segundo pico, a $200{ }^{\circ} \mathrm{C}$ estaría relacionado con las interacciones $\mathrm{COO}^{\circ} / \mathrm{Ca}^{2+}$ (Sankalia, Mashru, Sankalia, \& Sutariya, 2005; Santagapita et al., 2012). Por último presentaron un tercer pico exotérmico atribuido a la descomposición de las cápsulas de alginato de calcio alrededor de los $275^{\circ} \mathrm{C}$ (Santagapita et al., 2012). Este pico estuvo ausente o no era tan definido en las cápsulas con urea, siendo los resultados similares a los observados por Sankalia et al. (2005) quienes tampoco observaron este pico en cápsulas de alginato de calcio y papaína.

Los encapsulados de yerba mate control (sin urea) mostraron el pico alrededor de $200{ }^{\circ} \mathrm{C}$ asociado anteriormente al alginato de calcio y otro pico endotérmico situado a $260{ }^{\circ} \mathrm{C}$, atribuido al polvo de yerba mate por comparación con los termogramas aislados para este material. Cuando se incorporó la urea estos valores disminuyeron a alrededor de $196{ }^{\circ} \mathrm{C}$ y $240{ }^{\circ} \mathrm{C}$ (Figura 5.4). 


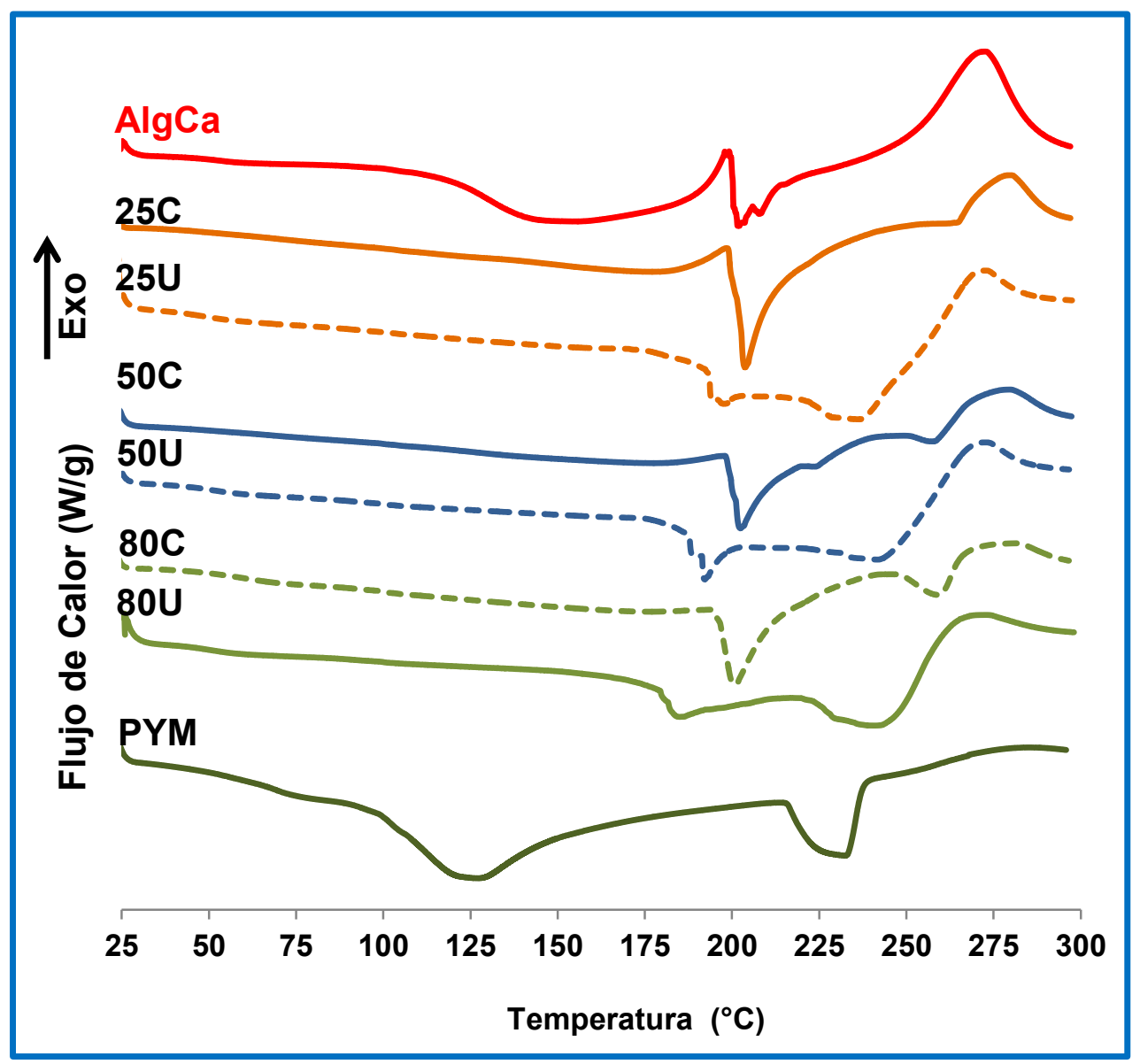

Figura. 5.4 Termogramas de cápsulas sin degradar con diferentes proporciones de PYM/alginato (25, 50 y 80), con urea (U) y sin urea (C).; Alginato de calcio (AlgCa), y polvo de yerba mate (PYM),

Con respecto a la determinación de la temperatura de transición vítrea (Tg) para las cápsulas control (antes de la degradación), esta reveló dos eventos; la $\mathrm{Tg}_{1}$ estuvo cerca de $53{ }^{\circ} \mathrm{C}$ en las cápsulas de 25 y 50 (PYM/alginato) con y sin urea incorporada, sin embargo para las cápsulas de 80 , este valor disminuyó de $65{ }^{\circ} \mathrm{C}$ a $49{ }^{\circ} \mathrm{C}$ para cápsulas sin y con urea, respectivamente (Tabla 5.3). 
Tabla 5.3 Parámetros térmicos (media \pm desviación standard) obtenidos de los termogramas de DSC para las cápsulas de alginato y cápsulas de PYM con y sin urea.

\begin{tabular}{ccccccc}
\hline Cápsula & $\mathbf{T}_{\text {inicio1 }}\left({ }^{\circ} \mathbf{C}\right)$ & $\mathbf{T}_{\text {pico1 }}\left({ }^{\circ} \mathbf{C}\right)$ & $\operatorname{Tg}_{1}\left({ }^{\circ} \mathbf{C}\right)$ & $\mathbf{T}_{\text {inicio2 }}\left({ }^{\circ} \mathbf{C}\right)$ & $\mathbf{T}_{\text {pico2 }}\left({ }^{\circ} \mathbf{C}\right)$ & $\operatorname{Tg}_{2}\left({ }^{\circ} \mathbf{C}\right)$ \\
\hline AlgCa & $199.8 \pm 0.38$ & $204.60 \pm 4.21$ & $*$ & $*$ & $*$ & $*$ \\
\hline $\mathbf{2 5 C}$ & $200.56 \pm 1.31$ & $203.11 \pm 0.84$ & $53.03 \pm 0.29$ & $*$ & $*$ & $104.11 \pm 0.38$ \\
$\mathbf{2 5 U}$ & $196.12 \pm 3.73$ & $196.76 \pm 4.02$ & $53.45 \pm 4.92$ & $222.74 \pm 0.05$ & $234.49 \pm 3.77$ & $96.46 \pm 4.83$ \\
\hline $\mathbf{5 0 C}$ & $199.72 \pm 0.64$ & $202.71 \pm 0.53$ & $54.13 \pm 2.81$ & $250.74 \pm 1.25$ & $260.44 \pm 1.94$ & $99.96 \pm 0.20$ \\
$\mathbf{5 0 U}$ & $190.96 \pm 0.22$ & $192.55 \pm 0.76$ & $52.42 \pm 2.57$ & $226.02 \pm 4.31$ & $246.57 \pm 2.77$ & $99.83 \pm 0.12$ \\
\hline $\mathbf{8 0 C}$ & $196.37 \pm 0.47$ & $200.19 \pm 0.55$ & $65.27 \pm 4.36$ & $248.51 \pm 0.45$ & $258.88 \pm 1.71$ & $100.09 \pm 0.19$ \\
$\mathbf{8 0 U}$ & $184.74 \pm 6.17$ & $187.74 \pm 5.44$ & $49.99 \pm 0.43$ & $228.85 \pm 6.78$ & $248.44 \pm 2.03$ & $100.13 \pm 0.26$ \\
\hline
\end{tabular}

* No detectable

Este cambio se atribuyó al efecto plastificante de la urea favorecida por el alto contenido de polvo de yerba mate. Sin embargo, la segunda temperatura de transición vítrea $\left(\mathrm{Tg}_{2}\right)$ se encontró alrededor de $100{ }^{\circ} \mathrm{C}$ para todas las cápsulas. En una investigación anterior, realizada en cápsulas de alginato de calcio que contienen extractos antioxidantes de yerba mate, también se encontraron dos valores de $\mathrm{Tg}$ (alrededor de 50 y $100^{\circ} \mathrm{C}$ ) (Anbinder et al., 2011). El primero se atribuyó a zonas amorfas de la matriz, con mayor movilidad. El segundo valor encontrado alrededor de $100^{\circ} \mathrm{C}$, podría asociarse con la estructura de caja de huevos del alginato de calcio, una estructura ordenada con más enlaces de hidrógeno dentro del gel. Lupo et al. (2015), encontraron valores similares de $\mathrm{Tg}_{1}$ entre $45^{\circ} \mathrm{C}$ y $50{ }^{\circ} \mathrm{C}$ para cápsulas de alginato sin y con extracto de cacao, respectivamente.

En la Figura 5.5 se presentan los termogramas de los encapsulados al día 30 del ensayo de degradación/liberación. A este tiempo, en algunas de las cápsulas almacenadas a 4 y $20{ }^{\circ} \mathrm{C}$ se observó un pico amplio centrado en 120 ${ }^{\circ} \mathrm{C}$ similar al observado en la Figura 5.4 para el PYM. Sin embargo, todas las muestras almacenadas a $30^{\circ} \mathrm{C}$ lo exhibieron, independientemente del tiempo de ensayo. Este hecho se asoció al avance de la degradación en las matrices, en donde lo primero en degradarse es el alginato de calcio, mientras que el 
polvo de yerba mate se convierte en el material principal de las matrices hasta su degradación total.

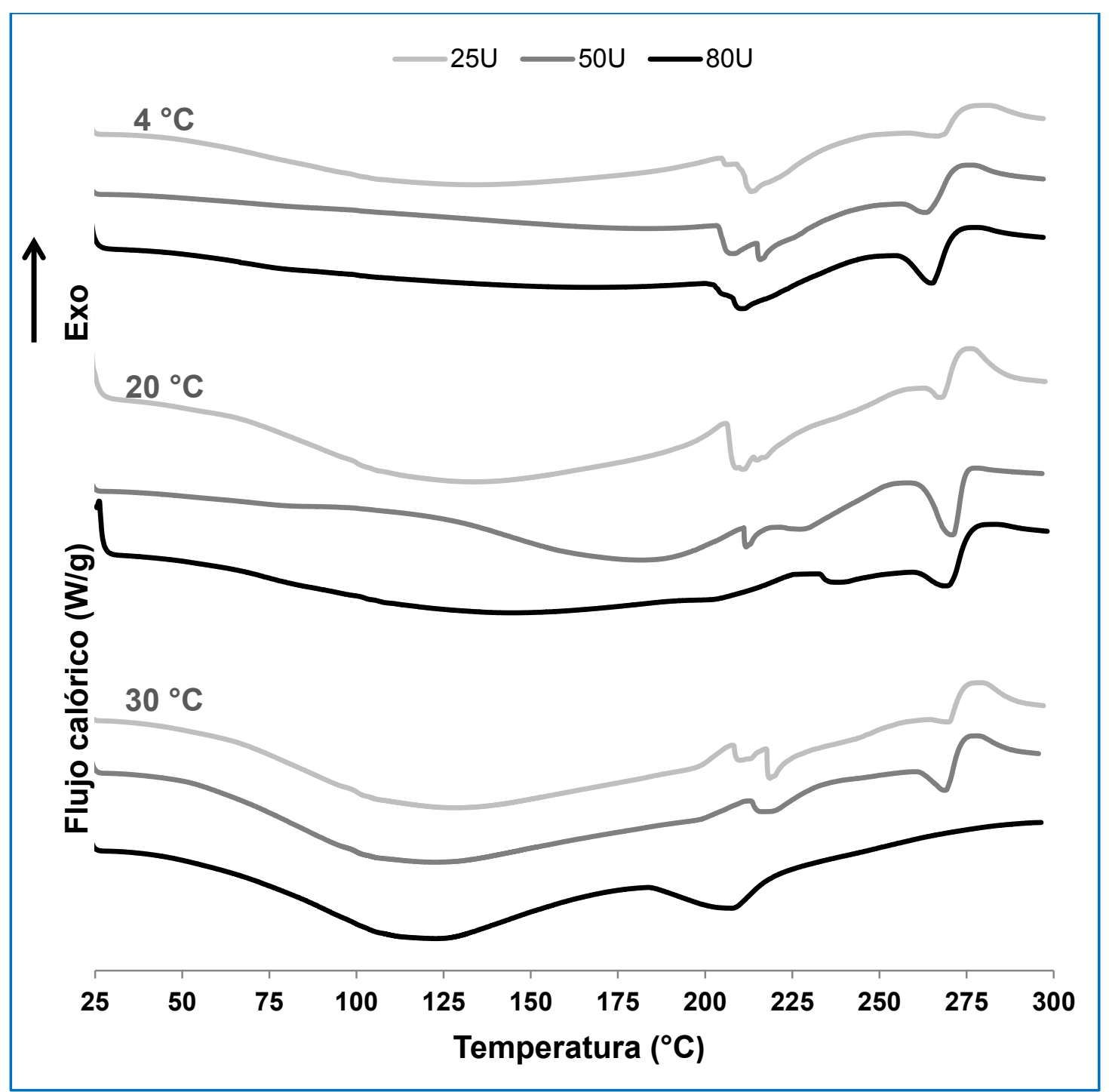

Figura. 5.5 Termogramas de cápsulas con Urea degradadas 30 días; a diferentes temperaturas.

El polvo de yerba mate está en exceso con respecto a la proporción de alginato de calcio, el efecto de esto, se puede observar claramente en el almacenamiento $30{ }^{\circ} \mathrm{C}$ ya que las cápsulas están más degradadas, lo que significa que la presencia de alginato es casi inexistente y el PYM es el componente principal de las cápsulas. 
El monitoreo del proceso de degradación por DSC ayudó a dilucidar la importancia del tiempo y la temperatura del ensayo (Tabla 5.4). A $4{ }^{\circ} \mathrm{C}$, la temperatura de pico $\left(\mathrm{T}_{\text {pico1 }}\right)$ aumenta con el tiempo de ensayo ( $\sim 16$ grados de 5 a 30 días para $25 \mathrm{U}$ y $50 \mathrm{U}$ y 25 grados para $80 \mathrm{U})$. A $20{ }^{\circ} \mathrm{C}$ el comportamiento dependía también del tiempo, a los 30 días, la temperatura de pico en el ensayo de degradación aumentó entre 10 y 14 grados centígrados para muestras de $25 \mathrm{U}$ y $50 \mathrm{U}$, respectivamente, y $40{ }^{\circ} \mathrm{C}$ en el caso de $80 \mathrm{U}$ (Tabla 5.4). Finalmente a $30{ }^{\circ} \mathrm{C}$ se observaron temperaturas de pico más altas, independientemente del tiempo de ensayo, alcanzando los $222{ }^{\circ} \mathrm{C}$. Este comportamiento podría atribuirse al hecho de que la condición de almacenamiento a $30{ }^{\circ} \mathrm{C}$ actúa como un tratamiento de "annealing" para los sistemas estudiados.

Con respecto al segundo pico, las cápsulas control sin urea mostraron el pico a $260{ }^{\circ} \mathrm{C}$, cuando se incorporó el mineral este pico se desplazó a $245{ }^{\circ} \mathrm{C}$ (Tabla 5.3) lo cual denota la interacción entre la urea y grupos específicos donde el PYM estaba previamente situado. En el ensayo de degradación, este pico se observó en todas las muestras almacenadas a $30{ }^{\circ} \mathrm{C}$, con excepción de las cápsulas $80 \mathrm{U}$ almacenadas por 30 días. Mientras que su aparición en las muestras almacenadas a $4{ }^{\circ} \mathrm{C}$ y $20{ }^{\circ} \mathrm{C}$ fue aleatoria (inexistente en algunos casos), y muchas veces no se midió debido a su pequeño tamaño (Tabla 5.4). 
Tabla 5.4 Parámetros térmicos (media \pm desviación standard) en el ensayo de degradación, obtenidos en los termogramas de DSC para las cápsulas con fertilizante (25U, $50 \mathrm{U}$ y $80 \mathrm{U}$ ) a diferentes temperaturas $\left(4,20\right.$ y $\left.30^{\circ} \mathrm{C}\right)$ y tiempo de almacenamiento $(5,10$ y 30 días).

\begin{tabular}{|c|c|c|c|c|c|c|}
\hline $\begin{array}{l}\text { Temperatura } \\
\left({ }^{\circ} \mathrm{C}\right)\end{array}$ & Cápsula & $\begin{array}{c}\text { Tiempo } \\
\text { (días) }\end{array}$ & $\mathrm{T}_{\text {inicio1 }}\left({ }^{\circ} \mathrm{C}\right)$ & $\mathrm{T}_{\text {pico1 } 1}\left({ }^{\circ} \mathrm{C}\right)$ & $\mathrm{T}_{\text {inicio2 }}\left({ }^{\circ} \mathrm{C}\right)$ & $\mathrm{T}_{\text {pico2 }}\left({ }^{\circ} \mathrm{C}\right)$ \\
\hline 4 & $25 \mathrm{U}$ & 5 & $191.04 \pm 0.27$ & $196.37 \pm 4.05$ & ** & $* *$ \\
\hline 4 & $25 \mathrm{U}$ & 10 & $194.98 \pm 0.13$ & $199.22 \pm 0.13$ & $* *$ & $* *$ \\
\hline 4 & $25 \mathrm{U}$ & 30 & $209.41 \pm 1.54$ & $212.33 \pm 1.44$ & $* *$ & $* *$ \\
\hline 4 & $50 U$ & 5 & $186.82 \pm 3.30$ & $191.65 \pm 0.11$ & $* *$ & $* *$ \\
\hline 4 & $50 U$ & 10 & $194.41 \pm 4.09$ & $198.49 \pm 7.52$ & * & * \\
\hline 4 & $50 \mathrm{U}$ & 30 & $205.88 \pm 2.41$ & $214.46 \pm 0.38$ & $258.77 \pm 1.12$ & $265.47 \pm 2.55$ \\
\hline 4 & $80 U$ & 5 & $185.55 \pm 1.36$ & $193.07 \pm 0.83$ & $* *$ & $* *$ \\
\hline 4 & $80 U$ & 10 & $190.47 \pm 7.10$ & $193.15 \pm 6.41$ & $259.15 \pm 0.27$ & $264.41 \pm 2.03$ \\
\hline 4 & $80 U$ & 30 & $215.25 \pm 11.96$ & $219.35 \pm 13.04$ & $257.57 \pm 0.33$ & $265.51 \pm 1.76$ \\
\hline 20 & $25 \mathrm{U}$ & 5 & $195.78 \pm 7.75$ & $199.16 \pm 5.6$ & $263.23 \pm 1.41$ & $269.33 \pm 2.09$ \\
\hline 20 & $25 U$ & 10 & $206.82 \pm 1.88$ & $211.46 \pm 0.48$ & * & * \\
\hline 20 & $25 \mathrm{U}$ & 30 & $207.62 \pm 1.56$ & $213.86 \pm 4.11$ & * & * \\
\hline 20 & $50 U$ & 5 & $191.33 \pm 1.54$ & $196.59 \pm 0.27$ & * & * \\
\hline 20 & $50 U$ & 10 & $213.02 \pm 6.94$ & $214.74 \pm 6.55$ & * & * \\
\hline 20 & $50 U$ & 30 & $213.20 \pm 2.89$ & $215.47 \pm 5.17$ & $258.77 \pm 1.12$ & $265.47 \pm 2.55$ \\
\hline 20 & $80 U$ & 5 & $187.07 \pm 1.14$ & $193.26 \pm 0.16$ & * & * \\
\hline 20 & $80 U$ & 10 & $203.13 \pm 0.0$ & $207.15 \pm 0.0$ & $254.86 \pm 3.87$ & $263.91 \pm 2.99$ \\
\hline 20 & $80 U$ & 30 & $225.87 \pm 7.42$ & $233.68 \pm 4.92$ & $259.59 \pm 0.0$ & $267.49 \pm 0.21$ \\
\hline 30 & $25 \mathrm{U}$ & 5 & $206.40 \pm 3.22$ & $208.14 \pm 4.45$ & $262.97 \pm 3.85$ & $270.36 \pm 3.27$ \\
\hline 30 & $25 U$ & 10 & $211.85 \pm 4.61$ & $213.05 \pm 4.89$ & $261.98 \pm 4.65$ & $268.05 \pm 2.67$ \\
\hline 30 & $25 U$ & 30 & $208.25 \pm 0.04$ & $209.44 \pm 0.16$ & $266.53 \pm 1.56$ & $273.56 \pm 3.58$ \\
\hline 30 & $50 U$ & 5 & $202.89 \pm 3.01$ & $204.73 \pm 4.01$ & $257.79 \pm 1.58$ & $265.42 \pm 1.32$ \\
\hline 30 & $50 U$ & 10 & $221.23 \pm 0.58$ & $222.34 \pm 0.04$ & $258.07 \pm 0.63$ & $266.28 \pm 1.57$ \\
\hline 30 & $50 U$ & 30 & $214.84 \pm 1.92$ & $217.04 \pm 0.05$ & $263.04 \pm 0.25$ & $268.44 \pm 0.27$ \\
\hline 30 & $80 U$ & 5 & $214.97 \pm 6.43$ & $222.31 \pm 3.44$ & $257.15 \pm 0.40$ & $265.82 \pm 0.11$ \\
\hline 30 & $80 U$ & 10 & $54.05 \pm 0.12$ & $115.06 \pm 5.84$ & $258.32 \pm 0.60$ & $265.99 \pm 0.12$ \\
\hline 30 & $80 U$ & 30 & $185.63 \pm 0.44$ & $206.72 \pm 2.18$ & $* *$ & $* *$ \\
\hline
\end{tabular}

* Picos muy pequeños

** No detectable 
En las muestras durante el ensayo de degradación, la $\operatorname{Tg}_{1}$ se encontró en cápsulas con un corto tiempo de almacenamiento (5 días), y principalmente para $25 \mathrm{U}$, con valores entre $50{ }^{\circ} \mathrm{C}$ y $70{ }^{\circ} \mathrm{C}$. Considerando que, la $\mathrm{Tg}_{2}$ está situada alrededor de $100{ }^{\circ} \mathrm{C}$ estaba presente en todas las muestras y no cambió con la temperatura ni el tiempo de ensayo (datos no presentados).

\subsubsection{Espectroscopía Infrarroja con Transformada de Fourier (FT-IR)}

El espectro de PYM (Fig. 6.4) mostró una banda ancha ubicada alrededor de $3400 \mathrm{~cm}^{-1}$ asignada a los modos de estiramiento de los grupos $\mathrm{O}-\mathrm{H}$. Además, picos a $1520 \mathrm{~cm}^{-1}$ atribuidos a la vibración $\mathrm{C}=\mathrm{C}$ de un anillo aromático y la banda de estiramiento $\mathrm{C}-\mathrm{O}$ a $1266 \mathrm{~cm}^{-1}$ también fueron observados. Se detectaron otras bandas relacionadas con hidroxilo entre 1160 y $1070 \mathrm{~cm}^{-1}$ (Schneider Teixeira et al., 2016).

La urea mostró picos típicos en 1618 y $1453 \mathrm{~cm}^{-1}$ (Fig. 6.4) atribuidos a la flexión de la amida II y las vibraciones de estiramiento C-N (Guo, Liu, Hu, Zhan, \& Wu, 2005; Hussain, Devi, \& Maji, 2012; Ni et al., 2009; Schneider Teixeira et al., 2016).

Las cápsulas simples de alginato de calcio (AlgCa) ya se han caracterizado (Bajpai \& Sharma, 2004; Sankalia et al., 2005; Sartori, Finch, Ralph, \& Gilding, 1997). En este trabajo, cuando se formaron cápsulas control de alginato de calcio, el pico de estiramiento $\mathrm{O}-\mathrm{H}$ se situó a $3420 \mathrm{~cm}^{-1}$ asociado a unión intramolecular, mientras que el hombro $\mathrm{O}-\mathrm{H}$ se muestra a $3254 \mathrm{~cm}^{-1}$, que corresponde a la unión intermolecular (Sartori et al., 1997). También se identificaron los picos de alginato de sodio COO- $a \approx 1610$ y $1415 \mathrm{~cm}^{-1}$ estiramiento asimétrico y simétrico, respectivamente (Sarmento, Ferreira, Veiga, \& Ribeiro, 2006; Sartori et al., 1997) así como la banda de estiramiento COO a $1027 \mathrm{~cm}^{-1}$ (Bajpai \& Sharma, 2004) (Fig. 5.6). Al incorporarse urea a esta formulación $(\mathrm{AlgCa}+U$ ) se observaron los picos de la primera zona a $3451 \mathrm{~cm}^{-1}$ y $3351 \mathrm{~cm}^{-1}$. Además, se observó un nuevo pico a $1461 \mathrm{~cm}^{-1}$ el cual también fue encontrado en cápsulas de quitosano cargadas con urea por 
Hussain et al. (2012), quienes lo atribuyeron a la vibración del estiramiento C$\mathrm{N}$.

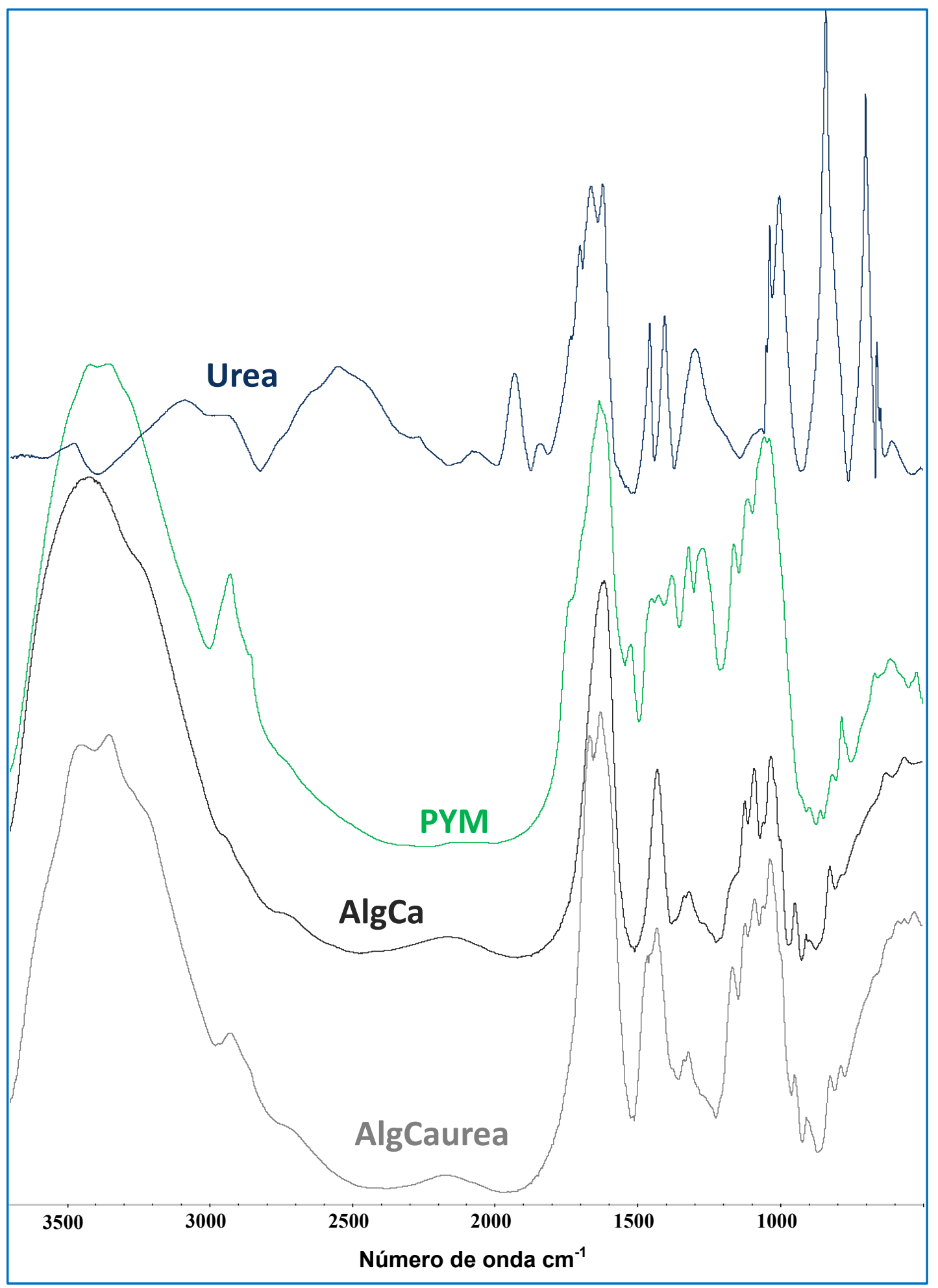

Figura. 5.6 Espectros FT-IR de materiales control (PYM, AlgCa, AlgCaUrea y Urea). 


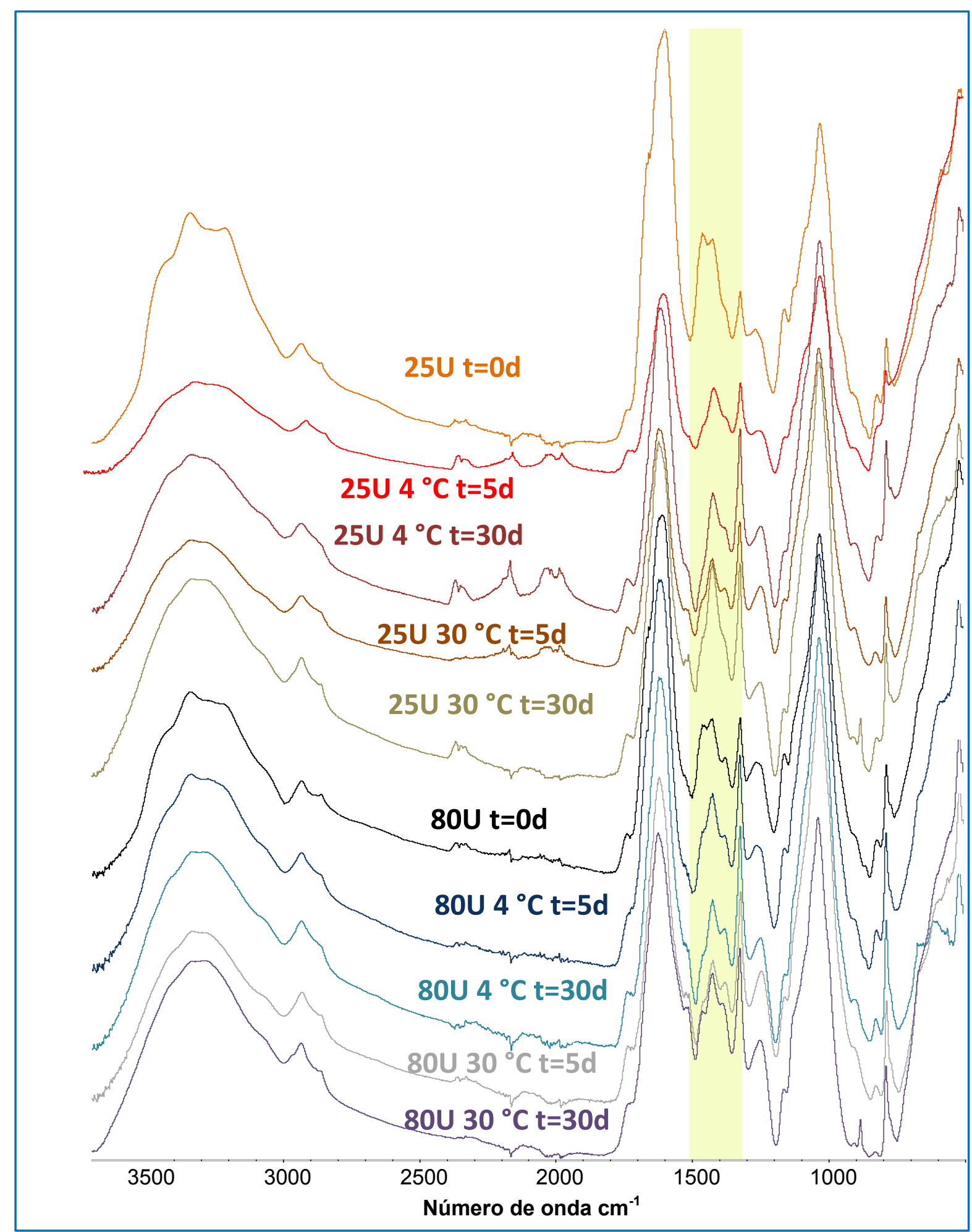

Figura. 5.7. Espectros FT-IR de cápsulas con urea (25U y $80 \mathrm{U})$ a diferentes temperaturas $\left(4\right.$ y $30^{\circ} \mathrm{C}$ ) y tiempos de degradación (5 y 30 días). La columna coloreada identifica los cambios en las bandas entre 1300 y $1500 \mathrm{~cm}^{-1}$. 
En los sistemas $25 \mathrm{U}, 50 \mathrm{U}$ y $80 \mathrm{U}$, estando todos los componentes juntos, se observó en la primera zona de los espectros: un hombro alrededor de 3400 $\mathrm{cm}^{-1}$ atribuido al PYM, mientras que el pico a 3330 y el hombro a $3209 \mathrm{~cm}^{-1}$ están asociados a la estructura del alginato de calcio (Figura 5.7).

Durante el ensayo de degradación (hasta 30 días), el pico de la matriz de alginato de calcio $\left(3420 \mathrm{~cm}^{-1}\right)$, permaneció constante para todas las muestras, disminuyendo su intensidad a lo largo del almacenamiento independientemente de la temperatura ensayada (Figura 6.5). Sin embargo, el hombro solo se observó en las muestras $25 \mathrm{U}$ almacenadas a $4{ }^{\circ} \mathrm{C}$ durante 3 días. Este comportamiento se asoció a la degradación del alginato de calcio, específicamente, el primer pico es más resistente porque está relacionado con el enlace intramolecular, mientras que el hombro detectado es más débil, atribuido a la unión intermolecular (Sartori et al., 1997). Estos hallazgos concuerdan con el hecho de que el alginato es el primero en degradarse en las cápsulas (Sección 5.4.1).

Con respecto a la segunda zona de los espectros $25 \mathrm{U}, 50 \mathrm{U}$ y $80 \mathrm{U}$, el pico situado a $1600 \mathrm{~cm}^{-1}$ permaneció sin cambios a lo largo del ensayo de degradación a todas las temperaturas estudiadas. Respecto del pico a $1461 \mathrm{~cm}^{-1}$ se observó claramente en las cápsulas antes del ensayo de degradación (25U, $50 \mathrm{U}$ y $80 \mathrm{U}$ ) (Figura 6.5), mientras que en las cápsulas almacenadas durante 5 días aún se detectó un pico de baja intensidad, el cual desapareció a tiempos mayores conforme la urea fue liberada.

\subsubsection{Crecimiento microbiano durante el almacenamiento}

El crecimiento microbiano en las placas analizadas para bacterias y mohos se puede observar en la Figura 5.8, mientras que la observación microscópica del desarrollo microbiano durante la degradación de los sistemas con fertilizantes encapsulados se puede observar en la Figura 5.9. 
Luego de 10 días de ensayo, las cápsulas enterradas a $4{ }^{\circ} \mathrm{C}$ mostraron un crecimiento moderado de microorganismos, pudiéndose aún observar la estructura de la cápsula. Sin embargo a $20 \circ 30^{\circ} \mathrm{C}, 10$ días fueron suficientes para alcanzar una fase log de crecimiento y como se observa en las fotos de la Figura 5.9, la superficie está cubierta de microorganismos. Estas observaciones concuerdan con la cuantificación realizada para mohos y levaduras (Tabla 5.5 y Tabla 5.6).

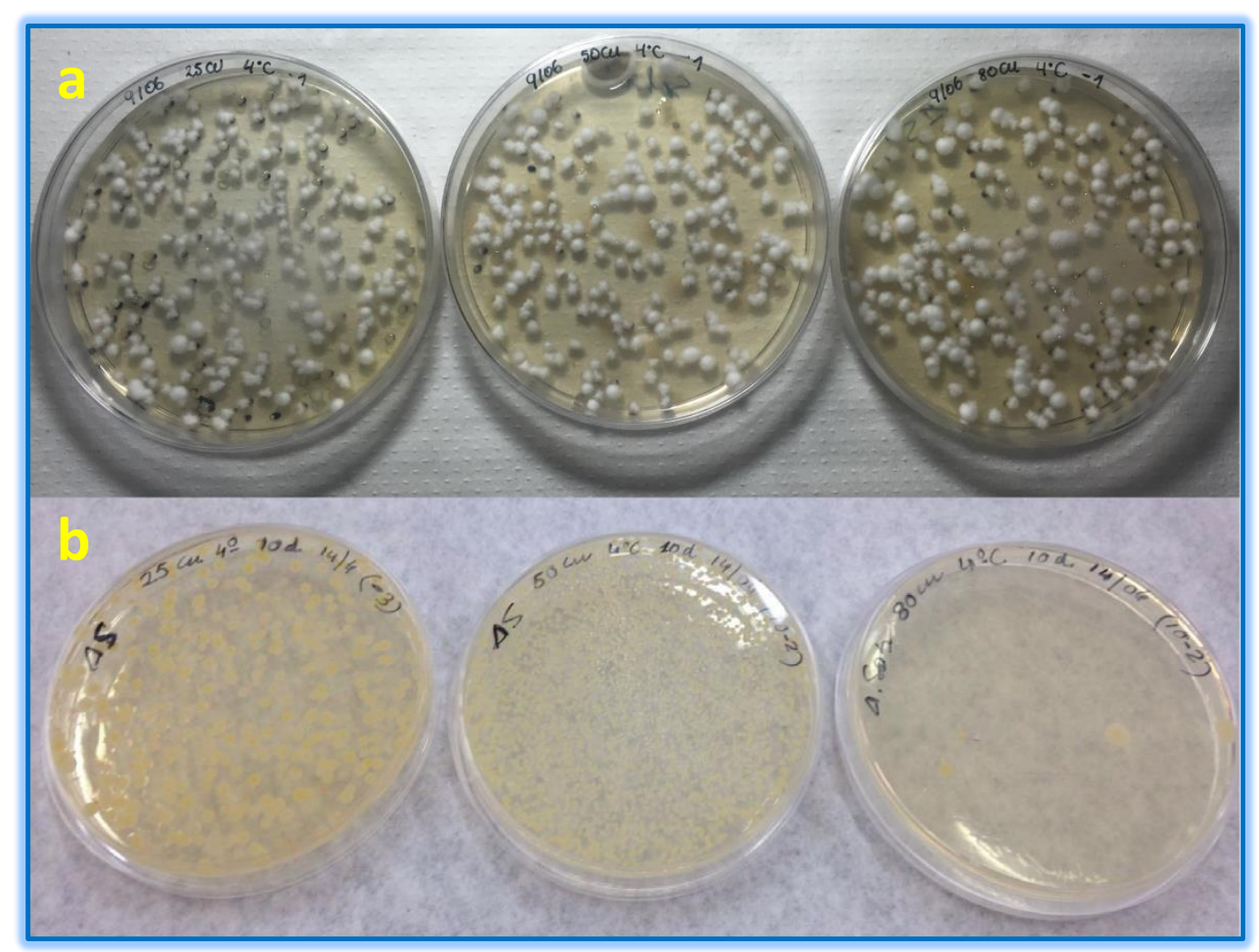

Figura. 5.8. Fotografías del crecimiento microbiano en las cápsulas almacenadas a $4{ }^{\circ} \mathrm{C}$, realizado en placas Petri:

a) Agar Nutrivo (Bacterias) b) Agar Saboraud Glucosa (Mohos).

Columnas: tipo de cápsulas izq.: 25U, medio: $50 \mathrm{U}$ y derecha: $80 \mathrm{U}$.

En general el desarrollo de bacterias fue mayor que el crecimiento de mohos para todas las condiciones (formulaciones y temperaturas), el crecimiento bacteriano aumentó de la siguiente manera: $25 \mathrm{U}<50 \mathrm{U}<80 \mathrm{U}$. 
Tabla 5.5 Recuento de bacterias para las cápsulas con fertilizante ( $25 \mathrm{U}, 50 \mathrm{U}$ y $80 \mathrm{U}$ ) a diferentes temperaturas $\left(4,20\right.$ y $\left.30^{\circ} \mathrm{C}\right)$ y tiempo de almacenamiento bajo tierra $(3,5,10$ y 30 días).

\begin{tabular}{cccccc}
\hline Muestra & $\begin{array}{c}\text { Temperatura } \\
\left({ }^{\circ} \mathbf{C}\right)\end{array}$ & $\begin{array}{c}\text { Recuento de } \\
\text { Bacterias, } \\
\text { muestras } \\
\text { inoculadas t=3 días }\end{array}$ & $\begin{array}{c}\text { Recuento de } \\
\text { Bacterias, } \\
\text { muestras }\end{array}$ & $\begin{array}{c}\text { Recuento de } \\
\text { Bacterias, } \\
\text { muestras } \\
\text { inoculadas t=5 días } \\
\text { inoculadas t=10 } \\
\text { días }\end{array}$ & $\begin{array}{c}\text { Recuento de } \\
\text { Bacterias, } \\
\text { muestras } \\
\text { inoculadas t=30 } \\
\text { días }\end{array}$ \\
\hline \multirow{2}{*}{$\mathbf{2 5 U}$} & 4 & $2.4 \times 10^{4}$ & $22.6 \times 10^{5}$ & $8.0 \times 10^{6}$ & $8.0 \times 10^{6}$ \\
& 20 & $2.4 \times 10^{4}$ & $12.5 \times 10^{5}$ & $5.8 \times 10^{6}$ & $5.8 \times 10^{6}$ \\
\hline \hline \multirow{2}{*}{$\mathbf{5 0 U}$} & 30 & $2.0 \times 10^{4}$ & $11.1 \times 10^{5}$ & $1.2 \times 10^{7}$ & $1.0 \times 10^{7}$ \\
\hline & 4 & $1.0 \times 10^{4}$ & $22.6 \times 10^{5}$ & $2.0 \times 10^{8}$ & $36.4 \times 10^{9}$ \\
& 20 & $1.7 \times 10^{5}$ & $2.0 \times 10^{9}$ & $13.2 \times 10^{10}$ & $5.2 \times 10^{10}$ \\
\hline \multirow{2}{*}{$\mathbf{8 0 U}$} & 30 & $2.4 \times 10^{4}$ & $22.6 \times 10^{5}$ & $72.8 \times 10^{10}$ & $6.8 \times 10^{8}$ \\
\hline & 4 & $2.0 \times 10^{4}$ & $1.1 \times 10^{6}$ & $2.9 \times 10^{9}$ & $26.6 \times 10^{9}$ \\
& 20 & $2.4 \times 10^{4}$ & $10.6 \times 10^{10}$ & $10.6 \times 10^{10}$ & $6.0 \times 10^{10}$ \\
& 30 & $2.4 \times 10^{4}$ & $1.1 \times 10^{11}$ & $1.1 \times 10^{11}$ & $9.4 \times 10^{10}$ \\
\hline
\end{tabular}

Tabla 5.6 Recuento de Mohos para las cápsulas con fertilizante (25U, $50 \mathrm{U}$ y $80 \mathrm{U})$ a diferentes temperaturas $\left(4,20\right.$ y $\left.30^{\circ} \mathrm{C}\right)$ y tiempo de almacenamiento bajo tierra $(3,5,10$ y 30 días).

\begin{tabular}{|c|c|c|c|c|c|}
\hline Muestra & $\begin{array}{c}\text { Temperatura } \\
\left({ }^{\circ} \mathrm{C}\right)\end{array}$ & $\begin{array}{c}\text { Recuento de } \\
\text { Mohos, muestras } \\
\text { inoculadas } t=3 \\
\text { días }\end{array}$ & $\begin{array}{c}\text { Recuento de } \\
\text { Mohos, muestras } \\
\text { inoculadas } t=5 \\
\text { días }\end{array}$ & $\begin{array}{c}\text { Recuento de } \\
\text { Mohos, muestras } \\
\text { inoculadas } t=10 \\
\text { días }\end{array}$ & $\begin{array}{c}\text { Recuento de } \\
\text { Mohos, muestras } \\
\text { inoculadas } t=30 \\
\text { días }\end{array}$ \\
\hline & & \multicolumn{4}{|c|}{ UFC/mL } \\
\hline \multirow{3}{*}{$25 \mathrm{U}$} & 4 & 90 & 255 & $1.25 \times 10^{7}$ & $1.9 \times 10^{6}$ \\
\hline & 20 & 100 & 500 & $1.3 \times 10^{5}$ & $5.2 \times 10^{4}$ \\
\hline & 30 & 700 & $1.2 \times 10^{4}$ & $1.5 \times 10^{4}$ & 1100 \\
\hline \multirow{3}{*}{$50 U$} & 4 & 190 & $1.98 \times 10^{4}$ & $1.0 \times 10^{5}$ & $1.1 \times 10^{5}$ \\
\hline & 20 & 8200 & $1.16 \times 10^{4}$ & $8.4 \times 10^{4}$ & 2000 \\
\hline & 30 & $2.13 \times 10^{4}$ & $1.91 \times 10^{7}$ & $1.33 \times 10^{9}$ & $1.0 \times 10^{6}$ \\
\hline \multirow{3}{*}{$80 U$} & 4 & 80 & $1.96 \times 10^{4}$ & $1.5 \times 10^{4}$ & $1.35 \times 10^{5}$ \\
\hline & 20 & 100 & 6000 & $10.5 \times 10^{4}$ & 1000 \\
\hline & 30 & 4000 & $2.35 \times 10^{7}$ & $1.0 \times 10^{7}$ & $2.0 \times 10^{7}$ \\
\hline
\end{tabular}

Para los mohos, el patrón no fue tan claro pero se observó su desarrollo en todas las condiciones ensayadas (Fig. 5.9). 


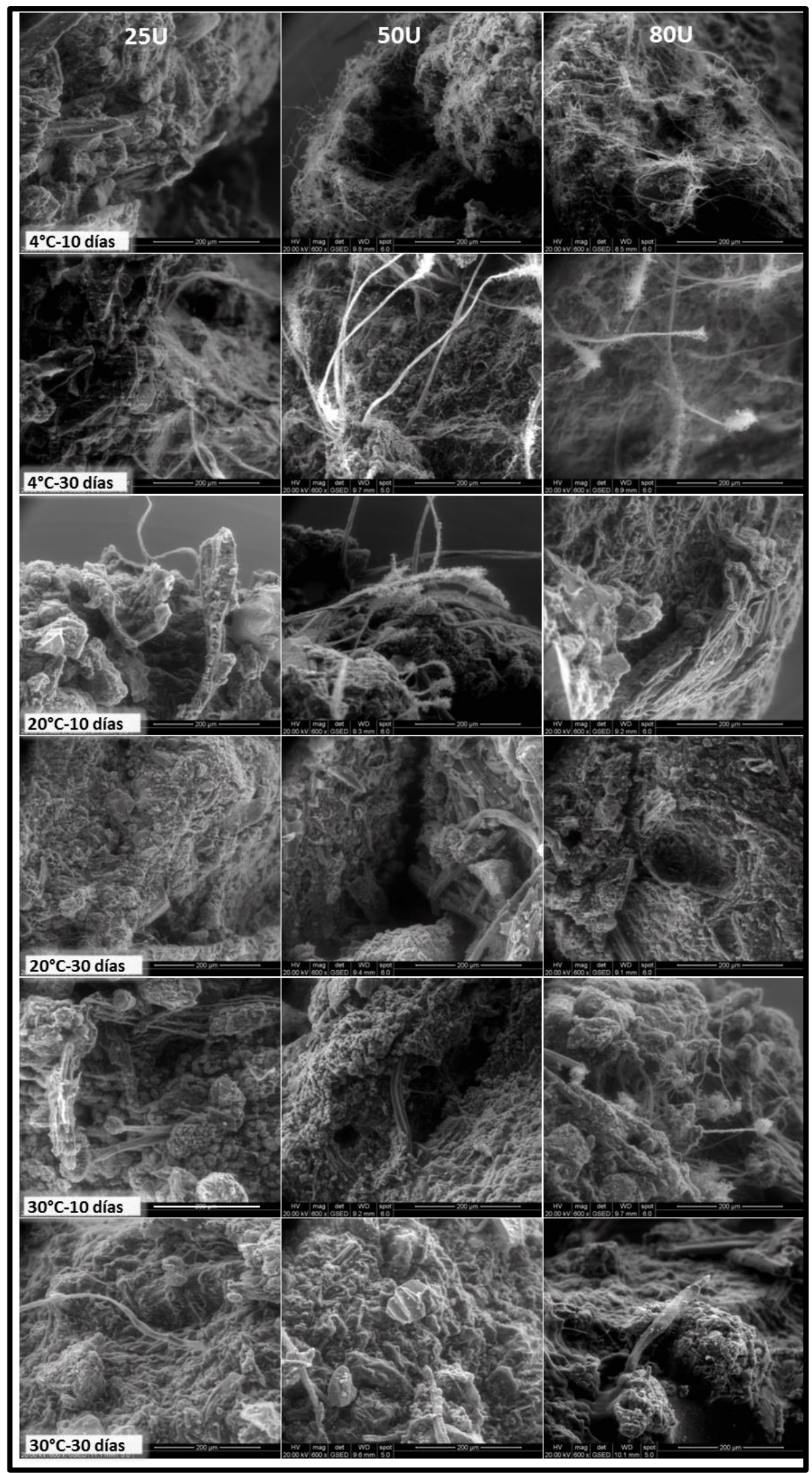

Figura. 5.9. Micrografías ESEM de cápsulas degradadas. Columnas: tipo de cápsulas izq.: 25U, medio: $50 \mathrm{U}$ y derecha: $80 \mathrm{U}$ ). Filas: condición de temperatura y tiempo de ensayo. Barra $=200 \mu \mathrm{m}$. 


\subsection{Conclusiones parciales}

- La temperatura de ensayo afectó tanto la cinética de liberación de la urea como la de degradación de los encapsulados.

- La liberación de la urea fue total a los 10 días de ensayo para las cápsulas almacenadas a 20 y $30^{\circ}$, mientras que a $4^{\circ} \mathrm{C}$ el total de la urea encapsulada se liberó en tierra a los 30 días de ensayo.

- La degradación de los encapsulados se vio acelerada por la temperatura de ensayo, las cápsulas almacenadas a 20 y $30^{\circ} \mathrm{C}$ se degradaron por completo a los 60 días, mientras que las almacenadas a $4^{\circ} \mathrm{C}$ lo hicieron a los 90 días de almacenamiento.

- La liberación de la urea encapsulada en suelo estuvo gobernada principalmente por fenómenos difusivos.

- Las cápsulas $50 \mathrm{U}$ y $80 \mathrm{U}$ absorbieron más cantidad de agua en suelo. La determinación de este parámetro confirmó el mecanismo de liberación difusivo, ya que las muestras siguieron absorbiendo agua a tiempos mayores luego de liberada la totalidad de la urea.

- El análisis calorimétrico permitió confirmar los supuestos de que el alginato de calcio se degrada primero durante el almacenamiento en tierra, así como el efecto de la temperatura sobre la velocidad de degradación de la matriz.

- El estudio de los espectros FT-IR permitió evidenciar la degradación del alginato de calcio en primer lugar, la encapsulación y posterior liberación de la urea de las matrices.

- La población microbiana de mohos y bacterias presentes en el suelo se desarrollaron normalmente en la superficie de los encapsulados, lo cual contribuyó a la degradación de las matrices. 
- Los encapsulados con $80 \mathrm{mg} / \mathrm{mL}$ (polvo de yerba mate/alginato de calcio), mostraron una degradación más lenta, una tasa de liberación de urea menor, mayor resistencia a la compresión, menor adsorción de agua y al tener más cantidad de PYM aportaría mayor cantidad de minerales como calcio, magnesio y potasio, por lo cual este tratamiento fue elegido como el mejor, para compararlo en el próximo capítulo contra un sistema de encapsulación que contiene fósforo y potasio. 


\section{CAPÍTULO VI}

Comparación con sistemas

encapsulados que contienen otros

fertilizantes (Fósforo y Potasio) 


\subsection{Sistemas con otros tipos de fertilizantes (Fósforo y Potasio)}

El consumo anual de nutrientes totales $\left(\mathrm{N}+\mathrm{P}_{2} \mathrm{O}_{5}+\mathrm{K}_{2} \mathrm{O}\right)$, para fertilizantes fue de 184.700.000 toneladas en 2014 y se estimó que alcanzaría 186.600.000 toneladas en 2015. Con un crecimiento sucesivo del 1.6 por ciento anual, se espera que alcance 199.000.000 toneladas para finales de 2019. La Figura 6.1 indica las previsiones de la demanda mundial de nutrientes totales de fertilizantes de 2015 a 2019 , contra el consumo real en los seis años anteriores (FAO, 2016).

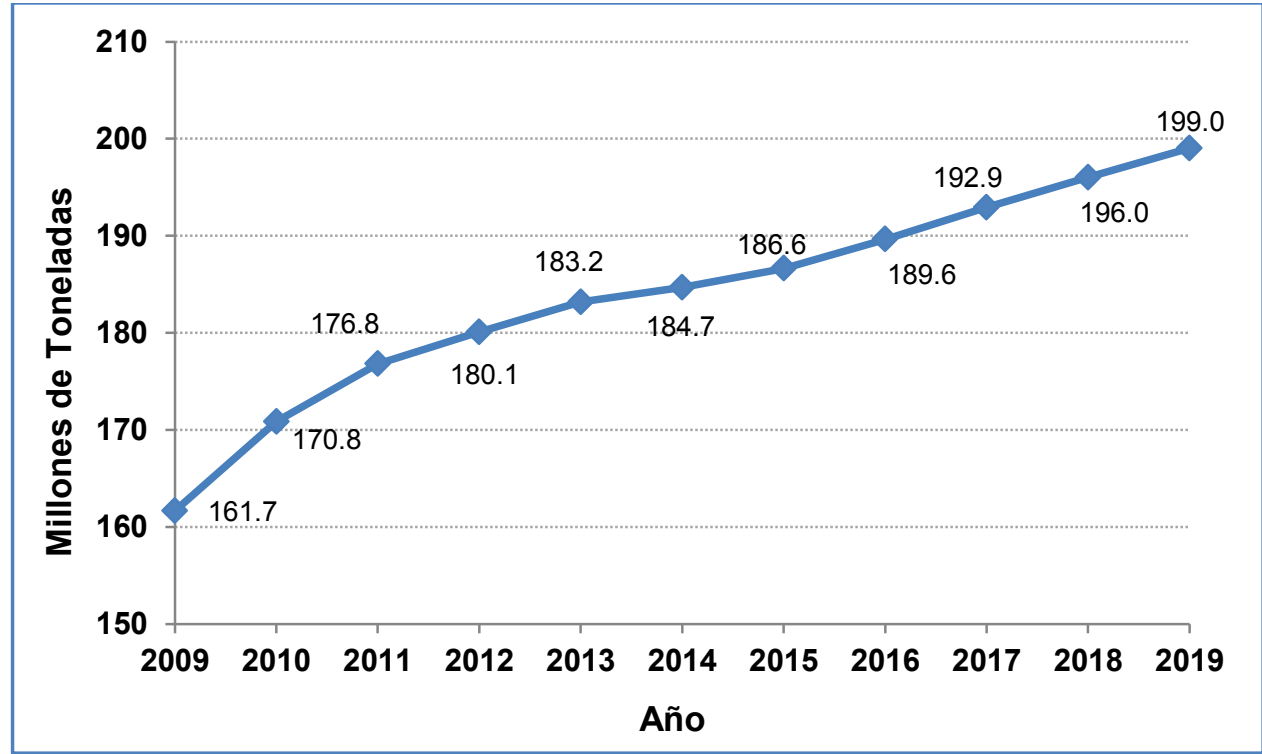

Figura 6.1 Consumo Global de Nutrientes $\left(\mathrm{N}+\mathrm{P}_{2} \mathrm{O}_{5}+\mathrm{K}_{2} \mathrm{O}\right)$. Fuente: FAO (2016)

Se estima que hasta un $90 \%$ de los fertilizantes convencionales aplicados en los cultivos, pueden llegar a perderse sin llegar a cumplir su objetivo, dependiendo del método de aplicación (dosificación) y de las condiciones climáticas y del suelo (Nakamatsu, 2017).

Acorde a este panorama, varias son las investigaciones que han estudiado y comparado diversos tipos de sistemas de estos fertilizantes. 
Basu, Kumar, y Srivastava (2010), en el estudio del modelado de liberación de NPK a partir de gránulos recubiertos esféricamente, encontraron que la liberación de nutrientes se puede mejorar controlando el ancho del material de recubrimiento y señalan incluso que se pueden usar revestimientos de zinc para satisfacer las necesidades de este micronutriente en el suelo.

\subsubsection{Fósforo (P)}

El fósforo es un macroelemento esencial necesario para el crecimiento y desarrollo de las plantas. Los requisitos de fósforo varían según el contenido de nutrientes del suelo. Su escasez restringe el crecimiento de las plantas y retarda su madurez. (Hossain, 1990; Sadia, Mahasen, Shahrin, Roni, \& Uddin, 2013).

Existen varias formas en las que el fósforo es utilizado, entre los que se destacan los fertilizantes a base de ácido fosfórico (al cual pertenece el fosfato monopotásico), fosfatos simples $\left(\mathrm{P}_{2} \mathrm{O}_{5}\right)$, rocas de fosfato de aplicación directa, fertilizantes de fosfato a base de ácido nítrico, etc. (FAO, 2016).

\subsubsection{Potasio (K)}

La importancia del potasio en los cultivos, radica en estimular el crecimiento de la planta, incluyendo sus órganos de almacenamiento por su efectividad en diferentes procesos como la fotosíntesis, extensión celular, translocación de nutrientes y formación de proteínas (Baloch, Uddin, Nizamani, Solangi, \& Siddiqui, 2014; Inam, Sahay, \& Mohammad, 2010).

El fosfato monopotásico es una sal altamente soluble y se forma por la reacción estequiométrica del ácido fosfórico $\mathrm{H}_{3} \mathrm{PO}_{4}$ con dos equivalentes de hidróxido de potasio $(\mathrm{KOH})$ y es aplicado como fertilizante por ser una fuente común de fósforo y potasio (Kamburova \& Kirilov, 2008). 
Se estima que la demanda de fertilizantes de potasio será de 34.5 millones toneladas en 2018 , con un crecimiento anual del 2.6 por ciento con respecto a 2014. Del aumento mundial proyectado en la demanda, se estima que el $27 \%$ será requerido por el continente americano (FAO, 2016). 


\subsection{Materiales y métodos}

En este capítulo, se evaluará el comportamiento del mejor tratamiento (80U) obtenido en las cápsulas analizadas anteriormente, frente a sistemas con otro tipo de fertilizantes (Fósforo y Potasio), denominadas como cápsulas (80PK) como se describió en la sección 4.3.1.

Para las comparaciones entre estos sistemas se siguieron algunos métodos ya empleados durante esta investigación y otros empleados específicamente para esta sección, entre los cuales están:

- Cinética de liberación en agua y en tierra (Sección 6.2.1)

- Determinación del contenido de fósforo (Sección 6.2.2)

- Determinación del contenido de potasio (Sección 6.2.3)

- Determinación del contenido de minerales (Sección 3.2.3)

- Porosimetría con intrusión de mercurio (Sección 6.2.4)

- Observación en microscopio electrónico (SEM) (Sección 5.2.1)

- Calorimetría Diferencial de Barrido (DSC) (Sección 5.3.4)

- Espectroscopía Infrarroja con Transformada de Fourier (FT-IR) (Sección 5.3.5).

\subsubsection{Cinética de liberación de Fertilizantes (urea, fósforo y potasio)}

Para la comparación de los sistemas encapsulados con los distintos fertilizantes, se estudiaron cinéticas de liberación, en agua y en tierra. Para el análisis de la urea, se utilizaron las cápsulas 80U, mientras que para el fósforo y potasio se emplearon las cápsulas denominadas 80PK.

\subsubsection{Cinética de liberación de Urea, Fósforo y Potasio en tierra.}

De acuerdo al estudio de liberación de urea realizado previamente (Sección 5.3.4), se emuló un experimento similar para analizar la 
liberación de fósforo y potasio en tierra, para lo cual, se colocó una masa $(0.1 \mathrm{~g})$ de cápsulas secas en bolsas de nylon de malla fina $(1 \mathrm{~mm})$ (Gasatex, Argentina) y se enterraron $5 \mathrm{~cm}$ por debajo de la superficie del suelo (Terrafertil, Argentina) en macetas de polietileno de alta densidad de $240 \mathrm{~mL}$. El tipo de cápsula utilizado fue el 80PK, a una temperatura de almacenamiento de $20^{\circ} \mathrm{C}$ y durante distintos períodos de incubación $(3,5$, 10,20 y 30 días). Para cada fertilizante, se preparó un recipiente individual y se replicó dos veces. A lo largo de los experimentos, la muestra de suelo (tierra) se mantuvo con un contenido de humedad de $35-40 \%$ mediante pesada periódica y agregado de agua del grifo cuando era necesario.

\subsubsection{Cinética de liberación de Urea, Fósforo y Potasio en agua.}

Se realizó un ensayo dinámico para analizar la liberación de urea, fósforo y potasio en agua, para lo cual se armó un dispositivo (Figura 6.2) con dos canastillas esféricas de acero inoxidable que contenían una masa $(1 \mathrm{~g})$ de cápsulas secas y se sumergieron completamente en $50 \mathrm{~mL}$ de agua desionizada ultrapura en vasos de precipitado de $100 \mathrm{~mL}$. Los tipos de cápsulas utilizadas fueron $80 \mathrm{U}$ y $80 \mathrm{PK}$, a temperatura ambiente $\left(\sim 20^{\circ} \mathrm{C}\right)$. Se tomaron muestras a diferentes tiempos $(10,20,30,40,50,60,90,120$ y 150 minutos) para ser analizadas.

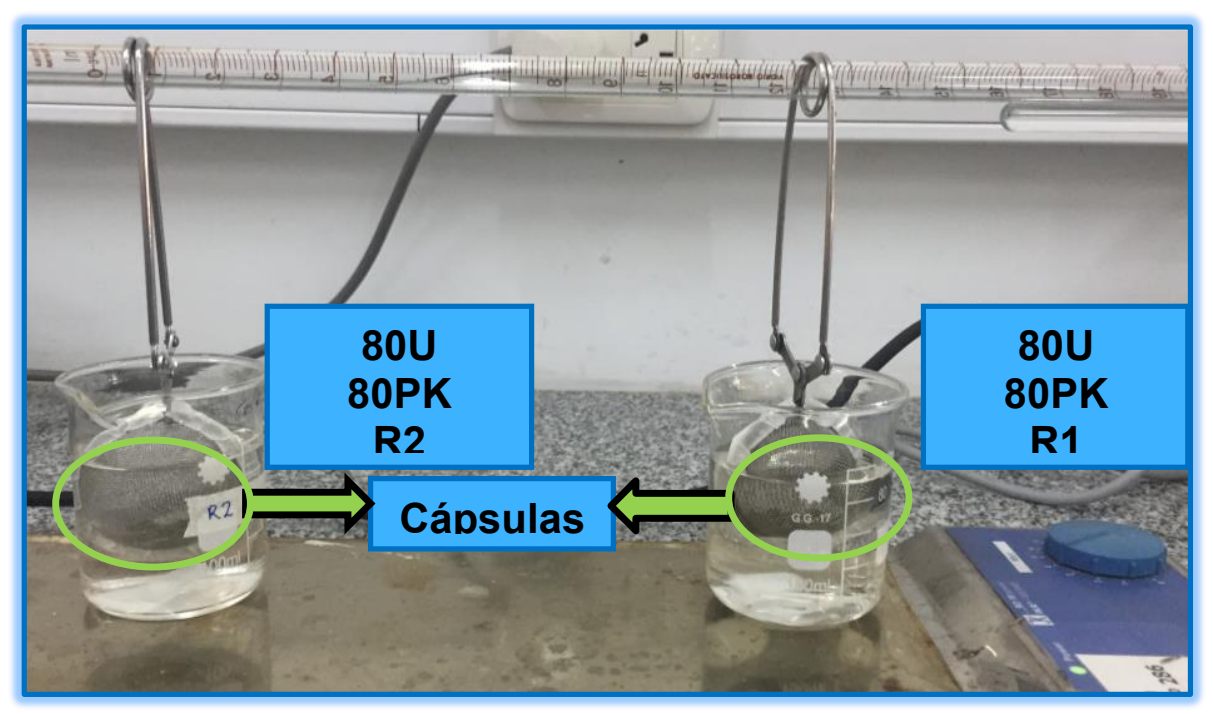

Figura 6.2 Montaje del experimento dinámico para determinación de liberación de Urea, Fósforo y Potasio en agua. 
Para cada mineral, se preparó un recipiente individual y se replicó dos veces. A lo largo de los experimentos, el agua se mantuvo en agitación continua a 300 RPM mediante un agitador magnético (RO 10 power IKAMAG ${ }^{\circledR}$, IKA LABORTECHNIK, Selangor, Malasia) para garantizar la homogeneidad de las muestras tomadas.

\subsubsection{Determinación del contenido de fósforo.}

El contenido de fósforo tanto en el ensayo en tierra como en el ensayo en agua, fue cuantificado por el método fosfomolibdato/UV, BioSystems, S.A. (Barcelona, España).

Para el ensayo en tierra, 0.15 gramos de cápsulas secas fueron molidas en un mortero y se disolvieron en $50 \mathrm{~mL}$ de agua, mientras que para el ensayo en agua desionizada ultrapura, se tomó una alícuota $(10 \mu \mathrm{L})$ del agua en que sumergieron las cápsulas en cada tiempo. En este método el fosfato inorgánico presente en la muestra reacciona con el molibdato en medio ácido, originando un complejo que se cuantificó espectrofotométricamente en un equipo Shimadzu UV mini 1240 UV-VIS (Kyoto, Japón) a una longitud de onda de $340 \mathrm{~nm}$.

\subsubsection{Determinación del contenido de potasio.}

El contenido de potasio, fue cuantificado por conductividad con un doble medidor de pH/conductividad (S47, SevenMulti, Mettler-Toledo, EEUU) y las tasas de liberación acumulativas se determinaron como una función del tiempo utilizando una curva de calibración (Figura 6.3) realizada con fosfato monopotásico entre 0.0625 y $2.0 \mathrm{mg} / \mathrm{mL}$ de concentración y a $20{ }^{\circ} \mathrm{C}$ de temperatura. Luego los valores fueron ajustados a la contribución de la conductividad del potasio en la sal y expresado en moles de potasio. Se realizaron dos réplicas para cada experimento. 


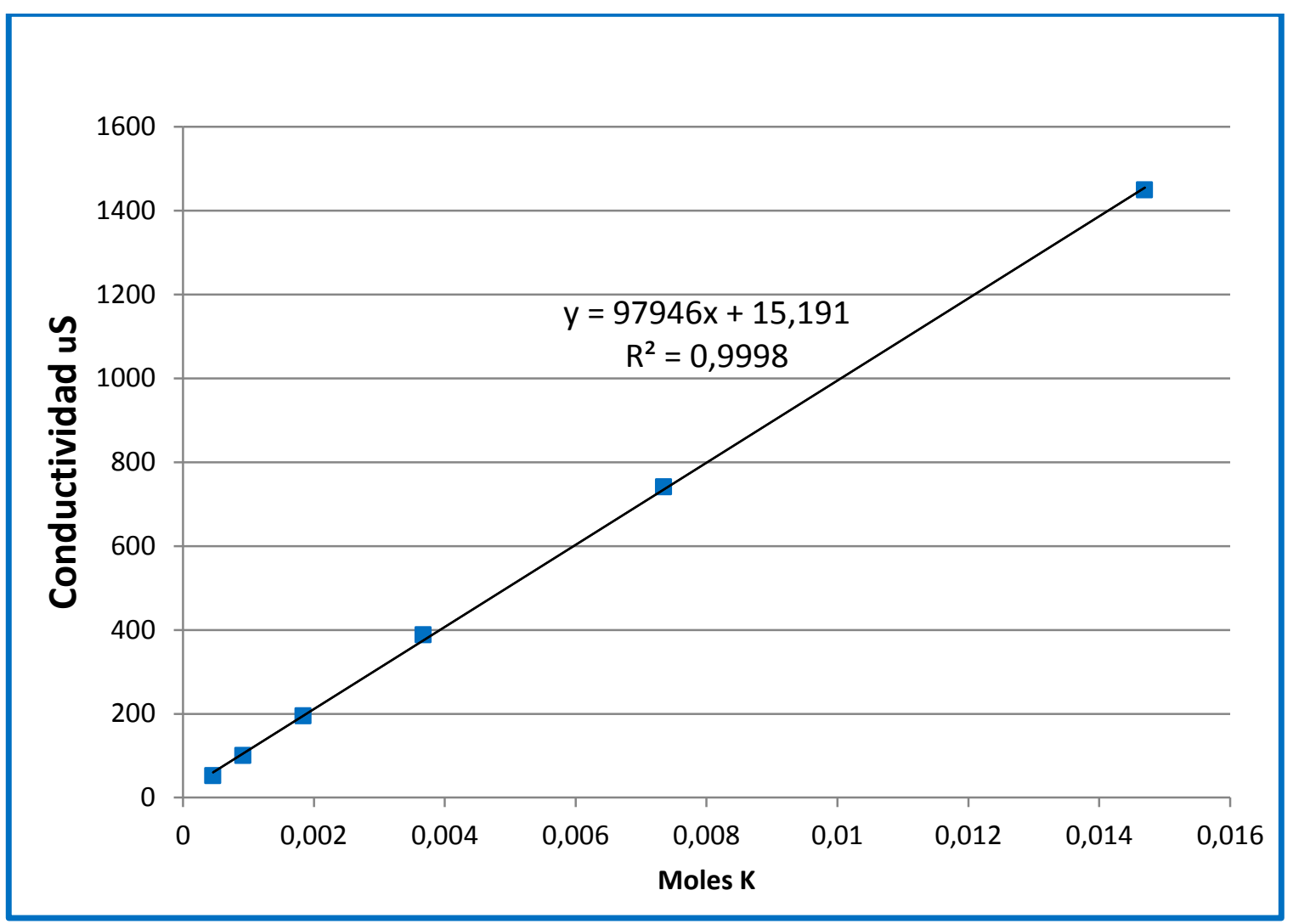

Figura 6.3 Curva de calibración para el fosfato monopotásico $\left(\mathrm{KH}_{2} \mathrm{PO}_{4}\right)$

Las muestras tomadas para el ensayo en tierra fueron tratadas de igual forma que para la determinación del contenido de fósforo (sección 6.2.2), mientras que las mediciones para determinar la cinética de liberación en agua se tomaron directamente de los vasos de precipitados a los tiempos establecidos.

\subsubsection{Porosimetría con intrusión de mercurio}

La porosidad es la relación entre los huecos o el volumen intersticial de un material y su masa. En el caso de sistemas como los obtenidos en este trabajo, los poros pueden quedar cerrados o abiertos, estos últimos poseen un canal por el cual se conectan a la superficie. Como la fracción de intersticios pueden ser penetrados por un líquido, se puede determinar el tamaño del poro promedio y la distribución del tamaño de poros. También es 
importante la forma general de los poros (cilíndricos, esféricos, chatos), el área superficial y la tortuosidad.

La distribución del diámetro de tamaño de los poros de las cápsulas de fertilizantes seleccionadas se estimó mediante porosimetría de intrusión de mercurio usando equipos Pascal 140 y 440 (Thermo Fisher Scientific, EE. UU.). Lo que permitió determinar un diámetro de poro mayor a $7.3 \mathrm{~nm}$ (meso y macroporos) con presiones desde 0 a $200 \mathrm{MPa}$.

El tratamiento de datos experimentales se basó en la ecuación de Washburn (Washburn, 1921);

$$
r=2 \sigma \cos \alpha / p \quad \text { Ec. } 6.1
$$

donde $p$ es la presión aplicada, $r$ es el radio del poro, $\sigma$ es la tensión superficial de $\mathrm{Hg}$ y $\alpha$ es el ángulo de contacto entre el mercurio y la muestra analizada. 


\subsection{Resultados}

\subsubsection{Cinética de liberación de Urea, Fósforo y Potasio en tierra.}

La cinética de liberación de la urea y del fosfato monopotásico para evaluar el fósforo y potasio, además de la degradación de los sistemas a diferentes tiempos bajo tierra se muestran en la Fig. 6.4.

Respecto a la degradación, el análisis estadístico refleja que el tipo de cápsula y el tiempo inciden significativamente $(p<0.05)$, siendo mayor para las cápsulas con el fosfato monopotásico (80PK>80U) y aumentó conforme transcurrió el ensayo. Una hipótesis de esta diferencia en la degradación es que, en presencia de la humedad del ensayo, algunos iones calcio serían desplazados de la matriz para formar fosfato de calcio con el fosfato proveniente del fertilizante.

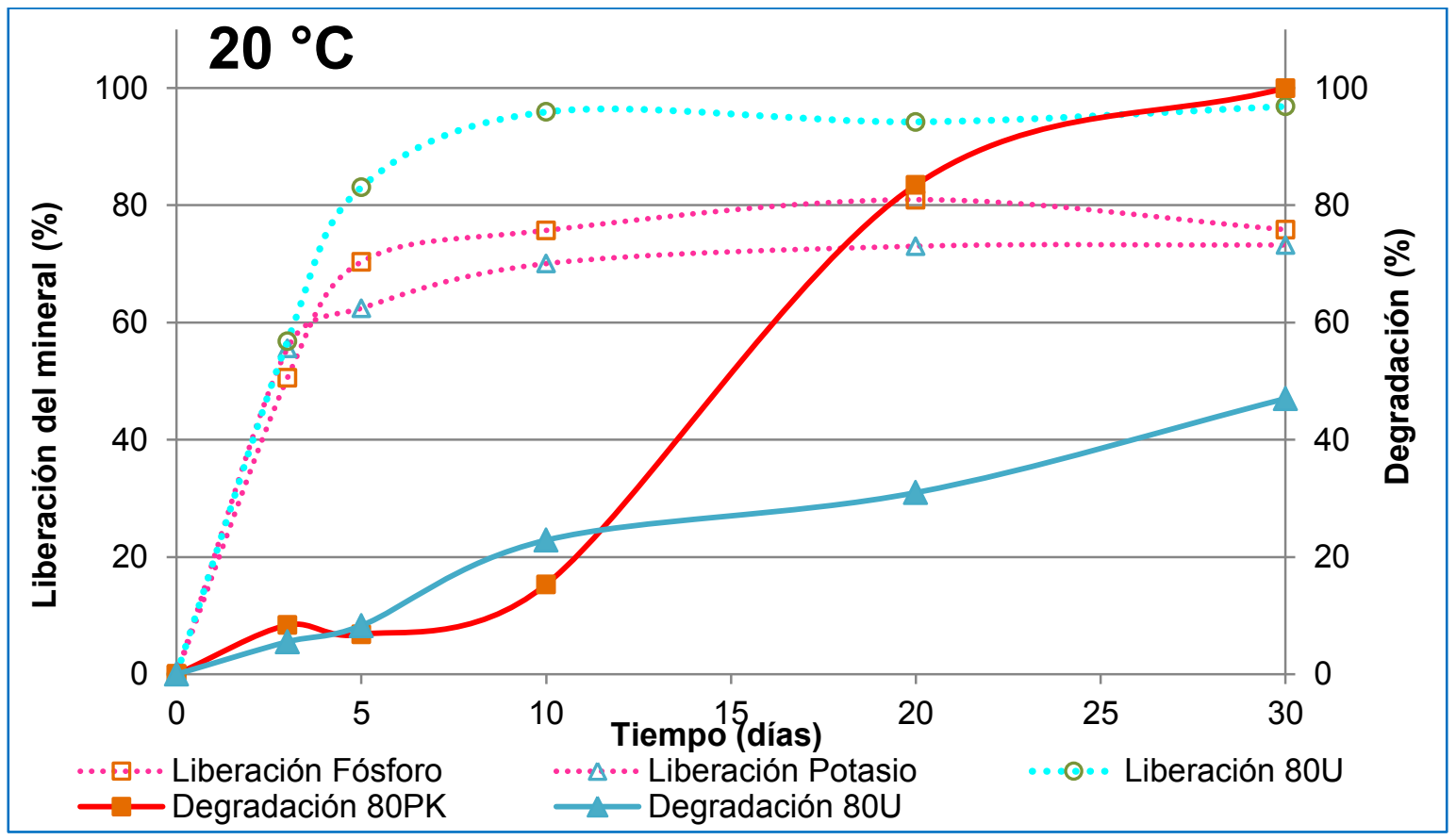

Figura 6.4 Cinética de Liberación de minerales y degradación de sistemas encapsulados en base a polvo de yerba mate con urea, sodio y potasio. 
El análisis de varianza también revela el efecto de la interacción (tipo de cápsula*días) para $p<0.05$, mostrando una clara diferencia para las cápsulas de $80 \mathrm{PK}$ que entre los días 20 y 30 se han degradado completamente frente al $30.98 \%$ y $47.01 \%$ para el tratamiento con urea (80U) a los mismos tiempos.

Para la liberación, se observó que tanto la muestra analizada como el tiempo tuvieron efecto significativo $(p<0.05)$. La liberación de los fertilizantes utilizados mostraron el siguiente comportamiento: (Potasio<Fósforo<Urea), siendo estadísticamente diferentes entre sí.

La interacción muestra*tiempo refleja su efecto al observar que la cápsula con urea agregada (80U) a partir del día 10 ya ha liberado más del $95 \%$ sin aumentar significativamente para los días 20 y 30 ensayados en esta cápsula, mientras que para fósforo y potasio se reportan valores de liberación de 75.72 $\%$ y $70.05 \%$ respectivamente, los cuales difieren significativamente a tiempos mayores con respecto a las cápsulas $80 U$ (LSD test).

El ensayo realizado a una temperatura de $20^{\circ} \mathrm{C}$, se evalúo hasta el día 30 , debido a la fractura observada en las cápsulas 80PK, como se muestra en la Figura 6.7, se consideró una degradación del $100 \%$ a este tiempo, lo cual impidió la continuidad del experimento a tiempos mayores a los evaluados para las cápsulas con urea (80U) detallado en la sección 6.3.1, donde se observó que a 30 días la degradación de estas cápsulas bordeaba el $47 \%$. Teniendo en cuenta que las cápsulas $80 \mathrm{PK}$ dan un salto abrupto en la curva de degradación entre el día 10 y 20 del ensayo, la medición real del contenido remanente de la sal agregada en la matriz estaría influenciada por el aporte de los minerales presentes en la tierra, como se mencionó anteriormente en la sección 5.4.3.

La Tabla 6.1 muestra los parámetros cinéticos de ajuste para los diferentes sistema de encapsulados, los cuales fueron evaluados por el coeficiente de correlación $\left(\mathrm{R}^{2}\right)$ y la distribución de los residuos. 
Tabla 6.1 Parámetros obtenidos en los modelos empíricos para la liberación en tierra de urea (80U), fósforo (80PK $(\mathrm{P}))$ y potasio $(80 \mathrm{PK}(\mathrm{K}))$.

\begin{tabular}{ccccc}
\hline \multirow{2}{*}{ Modelos } & \multirow{2}{*}{ Parámetros } & \multicolumn{3}{c}{ Tratamientos } \\
& & $\mathbf{8 0 U}$ & $\mathbf{8 0 P K}(\mathbf{P})$ & $\mathbf{8 0 P K}(\mathbf{K})$ \\
\hline Ley de la & $\mathrm{K}$ & 0.50479 & 0.51217 & 0.51420 \\
Potencia & $\mathrm{N}$ & 0.20823 & 0.13837 & 0.11314 \\
& $\mathrm{MAE}$ & 0.04872 & 0.05049 & 0.01643 \\
& $\mathrm{CME}$ & 0.00589 & 0.00561 & 0.00062 \\
& $\mathrm{R}^{2}$ & 0.95824 & 0.94168 & 0.99222 \\
\hline Peppas y Sahlin & $\mathrm{kd}$ & 0.38662 & 0.39761 & 0.46152 \\
& $\mathrm{kr}$ & -0.00137 & -0.00136 & -0.00083 \\
& $\mathrm{~m}$ & 0.38244 & 0.30626 & 0.18503 \\
& $\mathrm{MAE}$ & 0.03372 & 0.03462 & 0.00930 \\
& $\mathrm{CME}$ & 0.00266 & 0.00326 & 0.00022 \\
& $\mathrm{R}^{2}$ & 0.98304 & 0.96952 & 0.99753 \\
\hline Kopcha & $\mathrm{A}$ & 41.87470 & 39.32470 & 37.17150 \\
& $\mathrm{~B}$ & -4.44602 & -4.68006 & -4.44939 \\
& $\mathrm{MAE}$ & 3.33425 & 3.39819 & 2.74669 \\
& $\mathrm{CME}$ & 20.62140 & 26.40970 & 13.25370 \\
& $\mathrm{R}^{2}$ & 0.98538 & 0.97253 & 0.98329 \\
\hline
\end{tabular}

MAE: Error Absoluto Medio (Valor Promedio de los residuos)

CME: Cuadrado Medio del Error

De igual forma que en el análisis para los encapsulados del capítulo $\mathrm{V}$, el mejor ajuste fue encontrado para el modelo de Peppas y Sahlin (Ecuación 5.5), el cual ratifica la prevalencia del mecanismo de difusión sobre la relajación $(k d>>k r)$.

\subsubsection{Cinética de liberación de Urea, Fósforo y Potasio en agua.}

La cinética de liberación de los fertilizantes modelos en los respectivos sistemas se muestra en la Figura 6.5.

El ensayo fue realizado a temperatura ambiente $\left(\sim 20^{\circ} \mathrm{C}\right)$ y fue evaluado hasta los 150 minutos de inmersión, debido al porcentaje de liberación del potasio el cual, medido por conductividad mostró porcentajes muy cercanos al $100 \%$ y estables a partir de 120 minutos. Dicha estabilidad también fue 
alcanzada a este tiempo tanto para la urea como para el fósforo, pero con valores de liberación mucho menores, alrededor de $72 \quad \%$ y $45 \%$ respectivamente. El hecho de que el porcentaje de fósforo liberado se haya estabilizado en valores considerablemente menores, se atribuyó a que parte del fósforo agregado esté asociado a los iones calcio de la matriz que a estos tiempos de ensayo no pudieron ser detectados en la solución.

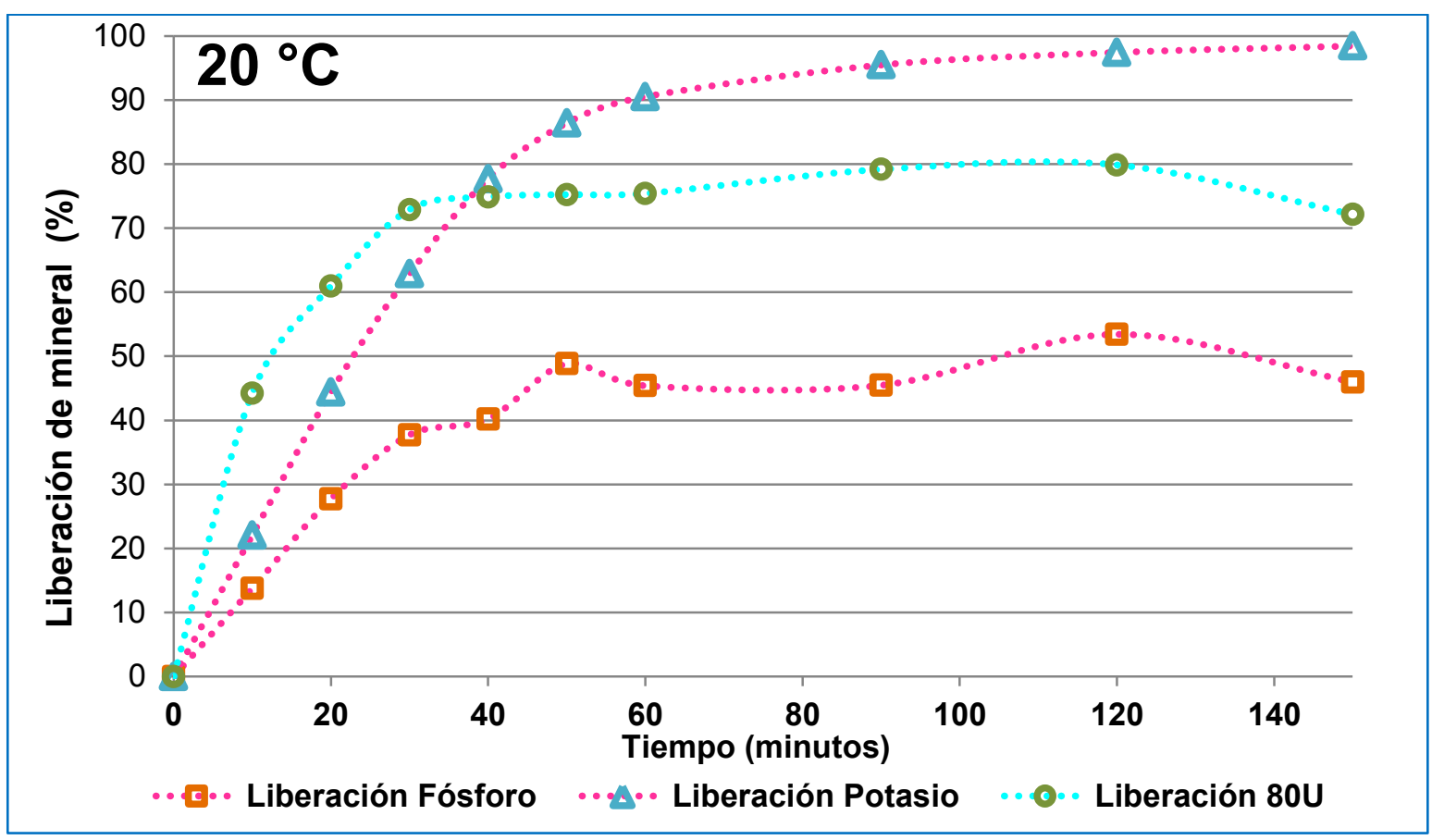

Figura 6.5 Cinética de Liberación de urea, fósforo y potasio en agua.

La liberación de urea, fósforo y potasio fue medida en la solución que contenía las cápsulas, por lo cual se estarían utilizando las mismas muestras en cada análisis, a diferencia de los ensayos en tierra donde se medía el remanente contenido en cápsulas ensayadas en recipientes independientes. Teniendo en cuenta la naturaleza de este ensayo, un análisis de similitud detallado por Costa y Sousa Lobo (2001), fue aplicado para comparar el comportamiento de liberación de las tres curvas.

El factor de similitud es un criterio para la evaluación de semejanzas entre dos perfiles de liberación de principios activos en la industria farmacéutica. Este factor $\left(f_{2}\right)$ es definido como la transformación de la suma de errores al cuadrado; que considera la media de la suma de cuadrados de la diferencia, 
para cada punto, entre los perfiles de las dos curvas a comparar y ajusta los resultados entre 0 y 100. Para diferencias iguales o superiores a 100 la ecuación tiene que ser reajustada o los datos normalizados para que no se obtengan valores de $f_{2}$ negativos. Cuando los dos perfiles son idénticos, $f_{2}$ es igual a 100 y decrece conforme aumentan las diferencias (Costa \& Sousa Lobo, 2001).

En la Tabla 6.2 se reportan los valores de $f_{2}$ calculados para las comparaciones entre las diferentes cinéticas de liberación.

Tabla 6.2 Valores de $f_{2}$ calculados para cinéticas de liberación en agua entre diferentes tipos de fertilizantes, Potasio-Fósforo (K-P), PotasioUrea (K-U) y Fósforo-Urea (P-U).

\begin{tabular}{lccc}
\hline Comparaciones & K-P & K-U & P-U \\
\hline $\mathbf{f}_{2}$ & 20.95 & 40.42 & 22.23 \\
\hline
\end{tabular}

Frutos \& Ocaña (2011) indicaron que de acuerdo a experiencias de análisis de datos de disoluciones, se considera aceptable una diferencia media de no más de un $10 \%$ en cualquier punto de las muestras comparadas y reportaron una equivalencia de los valores de $f_{2}$ respecto del porcentaje de diferencia entre perfiles de disolución (Tabla 6.3)

Tabla 6.3 Valores de $\mathrm{f}_{2}$ para diferencias medias entre perfiles de disolución.

\begin{tabular}{lllllllllllllll}
\hline Dif. (\%) & 0 & 2 & 5 & 10 & 15 & 20 & 30 & 40 & 50 & 60 & 70 & 80 & 90 & 100 \\
\hline $\mathbf{f}_{2}$ & 100 & 82.5 & 64.6 & 50.0 & 41.1 & 34.9 & 26.1 & 19.9 & 15.0 & 11.1 & 7.7 & 4.8 & 2.3 & 0 \\
\hline
\end{tabular}

Fuente: Frutos \& Ocaña (2011)

Los valores de $\mathrm{f}_{2}$ calculados para las comparaciones entre los diferentes tipos de fertilizantes (Tabla 6.2), muestran que la mayor similaridad se encontró entre el potasio y la urea $\left(f_{2}=40.42\right)$ y que de acuerdo a la Tabla 6.3, indicarían una diferencia de alrededor del $15 \%$ entre estas cinéticas, mientras 
que las otras comparaciones fósforo-potasio y fósforo-urea, con valores de $\mathrm{f}_{2}$ alrededor de 20, indicarían una diferencia cercana al $40 \%$.

En la Tabla 6.4 se presentan los parámetros cinéticos para el ajuste de liberación en agua, los cuales fueron evaluados por el coeficiente de correlación $\left(\mathrm{R}^{2}\right)$ y la distribución de los residuos al igual que en los ensayos realizados en tierra.

Tabla 6.4 Parámetros obtenidos en los modelos empíricos para la liberación en tierra de urea (80U), fósforo $(80 \mathrm{PK}(\mathrm{P}))$ y potasio $(80 \mathrm{PK}(\mathrm{K}))$.

\begin{tabular}{ccccc}
\hline \multirow{2}{*}{ Modelos } & Parámetros & \multicolumn{3}{c}{ Tratamientos } \\
& & $\mathbf{8 0 U}$ & $\mathbf{8 0 P K}(\mathbf{P})$ & $\mathbf{8 0 P K}(\mathbf{K})$ \\
\hline \multirow{2}{*}{ Ley de la } & $\mathbf{K}$ & 0.40578 & 0.12637 & 0.17611 \\
Potencia & $\mathbf{n}$ & 0.14183 & 0.29166 & 0.36626 \\
& $\mathbf{M A E}$ & 0.05613 & 0.04561 & 0.08296 \\
& $\mathbf{C M E}$ & 0.00534 & 0.00405 & 0.01109 \\
& $\mathbf{R}^{\mathbf{2}}$ & 0.91404 & 0.86281 & 0.90763 \\
\hline \multirow{3}{*}{ Peppas y Sahlin } & $\mathbf{k d}$ & 0.23850 & 0.04830 & 0.06072 \\
& $\mathbf{k r}$ & -0.00006 & -0.00004 & -0.00007 \\
& $\mathbf{m}$ & 0.31155 & 0.59265 & 0.69704 \\
& $\mathbf{M A E}$ & 0.03653 & 0.02560 & 0.04228 \\
& $\mathbf{C M E}$ & 0.00210 & 0.00174 & 0.00277 \\
& $\mathbf{R}^{2}$ & 0.96805 & 0.94443 & 0.97821 \\
\hline \multirow{3}{*}{ Kopcha } & $\mathbf{A}$ & 17.71490 & 8.52165 & 14.25970 \\
& $\mathbf{B}$ & -0.96730 & -0.36412 & -0.47256 \\
& $\mathbf{M A E}$ & 3.33505 & 3.44981 & 6.35423 \\
& $\mathbf{C M E}$ & 17.18120 & 24.76770 & 75.22190 \\
& $\mathbf{R}$ & 0.97236 & 0.91618 & 0.93735 \\
\hline
\end{tabular}

De igual forma que en el ensayo de liberación en tierra, el modelo de Peppas y Sahlin (Ecuación 5.5), fue el que presentó el mejor ajuste, indicando que el mecanismo de difusión es el que predomina sobre la relajación ( $k d>>k r)$. 


\subsubsection{Determinación del contenido de minerales}

Se analizó el contenido de minerales de los encapsulados 80PK al inicio y durante el ensayo de degradación (0, 10 y 30 días).

El contenido de los minerales ( $\mathrm{Mg}, \mathrm{K}$ y $\mathrm{Ca}$ ), a diferentes tiempos fueron cuantificados y se presentan en la Tabla 6.5. Al comparar el contenido de minerales de las cápsulas $80 \mathrm{PK}$ con las $80 \mathrm{U}$ (valores reportados en la sección 5.4.3) detalladas en la Tabla 6.5, se observa la similitud en los valores de magnesio y calcio, lo cual puede estar asociado al contenido de PYM que es igual en ambas cápsulas, mientras que para el potasio, como era de esperarse en las cápsulas $80 \mathrm{PK}$, presenta un valor de seis veces más que lo contenido en las $80 \mathrm{U}$, debido a la contribución del fosfato monopotásico.

Tabla 6.5 Contenido de minerales ( $\mathrm{Mg}, \mathrm{K}$ y Ca), antes y después de la degradación.

\begin{tabular}{ccccc}
\hline \multirow{2}{*}{ Muestra } & $\begin{array}{c}\text { Tiempo } \\
\text { (días) }\end{array}$ & \multicolumn{3}{c}{ Contenido de Minerales (g/100g cápsula) } \\
\cline { 3 - 5 } & $\mathbf{0}$ & $\mathbf{M g}$ & $\mathbf{K}$ & $\mathbf{C a}$ \\
\hline $\mathbf{8 0 P K}$ & $\mathbf{1 0}$ & $0.1803 \pm 0.0044$ & $1.5389 \pm 0.0307$ & $5.2095 \pm 0.1430$ \\
& $\mathbf{3 0}$ & $0.2810 \pm 0.0095$ & $0.9209 \pm 0.1777$ & $5.4577 \pm 0.2741$ \\
\hline \multirow{2}{*}{$\mathbf{8 0 U}$} & $\mathbf{0}$ & $0.2737 \pm 0.0067$ & $0.6594 \pm 0.0186$ & $5.6087 \pm 0.2534$ \\
& $\mathbf{3 0}$ & $0.2275 \pm 0.0517$ & $0.8765 \pm 0.0748$ & $6.5033 \pm 0.9291$ \\
\hline
\end{tabular}

En el ensayo de degradación de las cápsulas 80PK, se observó el mismo comportamiento ocurrido en los encapsulados 80U, con excepción del contenido de potasio que disminuyó de 3.99 en cápsulas sin degradar a 0.92 (g/100 g de cápsula) a 30 días de degradación, esta diferencia se atribuyó a la liberación del $\mathrm{K}$ agregado como fosfato monopotásico, mientras que el potasio proveniente del PYM podría mantenerse ligado a la matriz del mismo modo 
que el magnesio, el cual presentó una cantidad inicial y final en el mismo orden, tal como ocurrió al evaluar las cápsulas $80 U$.

\subsubsection{Porosimetría con intrusión de mercurio}

Según la IUPAC, los poros se pueden clasificar en tres categorías: macroporos, con diámetros mayores a $50 \mathrm{~nm}$; mesoporos, con diámetros entre 2 y $50 \mathrm{~nm}$; y microporos, con diámetros menores a 2 nm (Landry, 2005; Sujka \& Jamroz, 2007)

El análisis de porosidad se realizó para cápsulas con $80 \mathrm{mg}$ de PYM/mL de alginato, sin fertilizante, con urea y con fosfato monopotásico. Los tres tipos de cápsulas presentaron mesoporos y macroporos (Figura 6.6). Las cápsulas control (sin urea) mostraron una distribución bimodal con un máximo de diámetro de poro de 100 y 1000 nm, las cápsulas con urea mostraron una distribución normal con un diámetro de poro máximo centrado en $100 \mathrm{~nm}$, mientras que las cápsulas con $\mathrm{KH}_{2} \mathrm{PO}_{4}$ mostraron al igual que las cápsulas control una distribución bimodal y un máximo de tamaño de poro de 100 y 1000 nm (George \& Abraham, 2006; Klein, Stock, \& Vorlop, 1983).

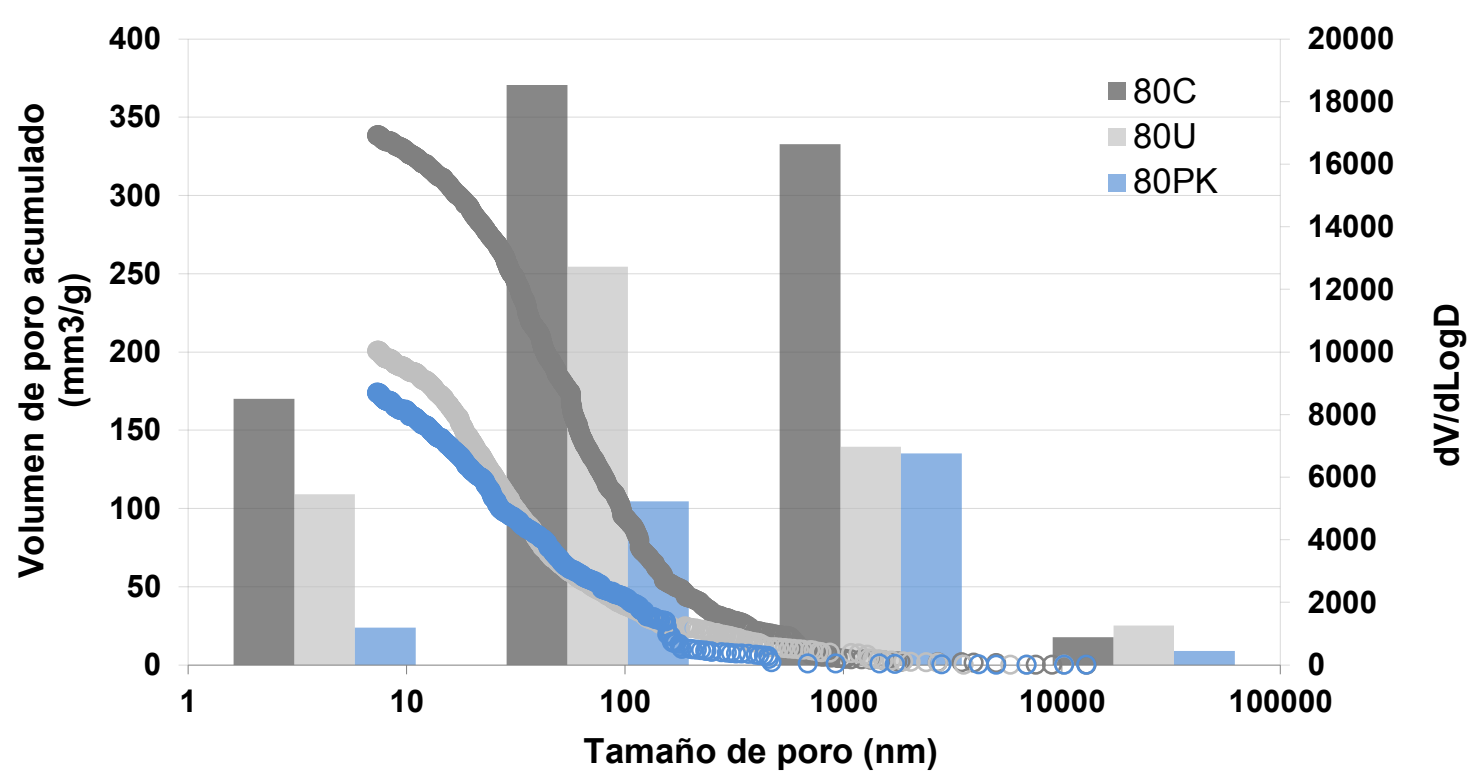

Figura 6.6. Distribución del diámetro de poros para las cápsulas de $80 \mathrm{mg}$ de polvo/mL de alginato, sin urea (80C) y cápsula cargada de urea (80U). Eje principal: volumen acumulativo de poros (gráfico de líneas), eje secundario: $\mathrm{dV} / \mathrm{d} \log \mathrm{D}$ (gráfico de barras). 
Como se puede observar en la Fig. 6.6, en general, las cápsulas cargadas de urea y fosfato monopotásico mostraron una porosidad menor, la cual se atribuiría a que las moléculas la urea y del fosfato monopotásico estarían situadas en lugares específicos de la matriz.

\subsubsection{Observación en microscopio electrónico}

En las micrografías SEM se pueden observar diferencias en la superficie de la cápsula al comparar las cápsulas 80U y 80PK (Figura 6.7).

Estas diferencias pueden estar relacionadas con el contenido de fertilizante en la cápsula y en la forma en que los iones del fosfato monopotásico intervienen en la reticulación de la matriz. Como se observó en el análisis de porosidad, las cápsulas $80 \mathrm{U}$ tienen la mayor cantidad de poros en tamaño de $100 \mathrm{~nm}$, mientras que los encapsulados 80PK muestran una mayor proporción de poros en un tamaño de $1000 \mathrm{~nm}$.

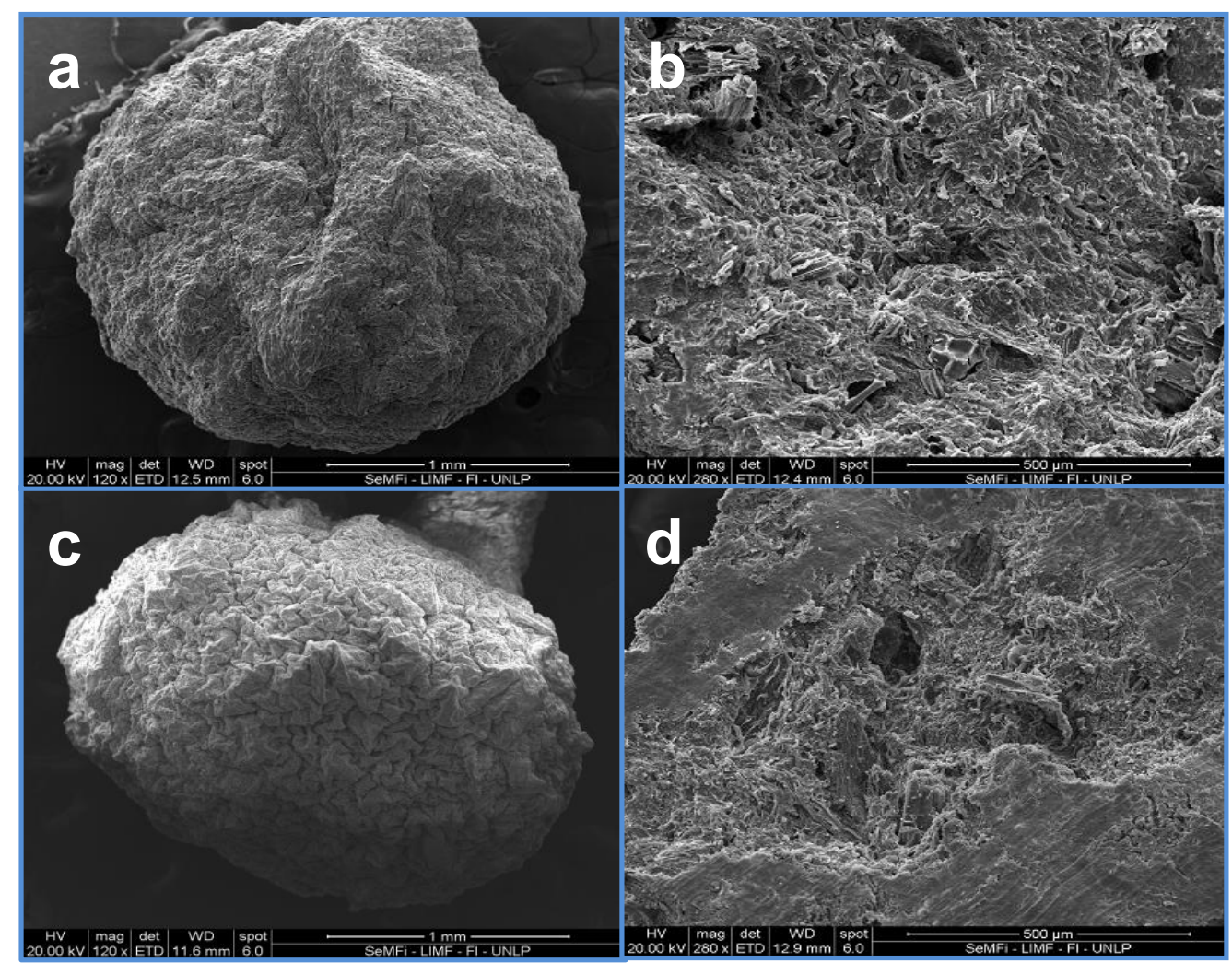

Figura 6.7 Micrografías SEM de cápsulas secas a) $80 U$ entera, b) $80 U$ corte transversal, c) $80 \mathrm{PK}$ entera y d) $80 \mathrm{PK}$ corte transversal. 
Esta prevalencia de poros más grandes para el tratamiento 80PK puede favorecer el ingreso de agua a la matriz de los encapsulados dando lugar a las reacciones biológicas, por ende su liberación y degradación fueron más rápidas que para las cápsulas $80 U$, como se verificó en el ensayo realizado en tierra (Sección 6.3.1).

\subsubsection{Calorimetría Diferencial de Barrido (DSC)}

Con respecto a los termogramas obtenidos para cápsulas con fosfato monopotásico, se observó una gran similitud con los obtenidos para cápsulas con urea descritos en la sección 5.4.4, aunque a temperaturas menores. El primer pico endotérmico se situó a $173^{\circ} \mathrm{C}$ y el segundo a $247^{\circ} \mathrm{C}$ (Fig. 6.8). La sal empleada mostró dos eventos endotérmicos alrededor de $225{ }^{\circ} \mathrm{C}$ y 275 ${ }^{\circ} \mathrm{C}$.

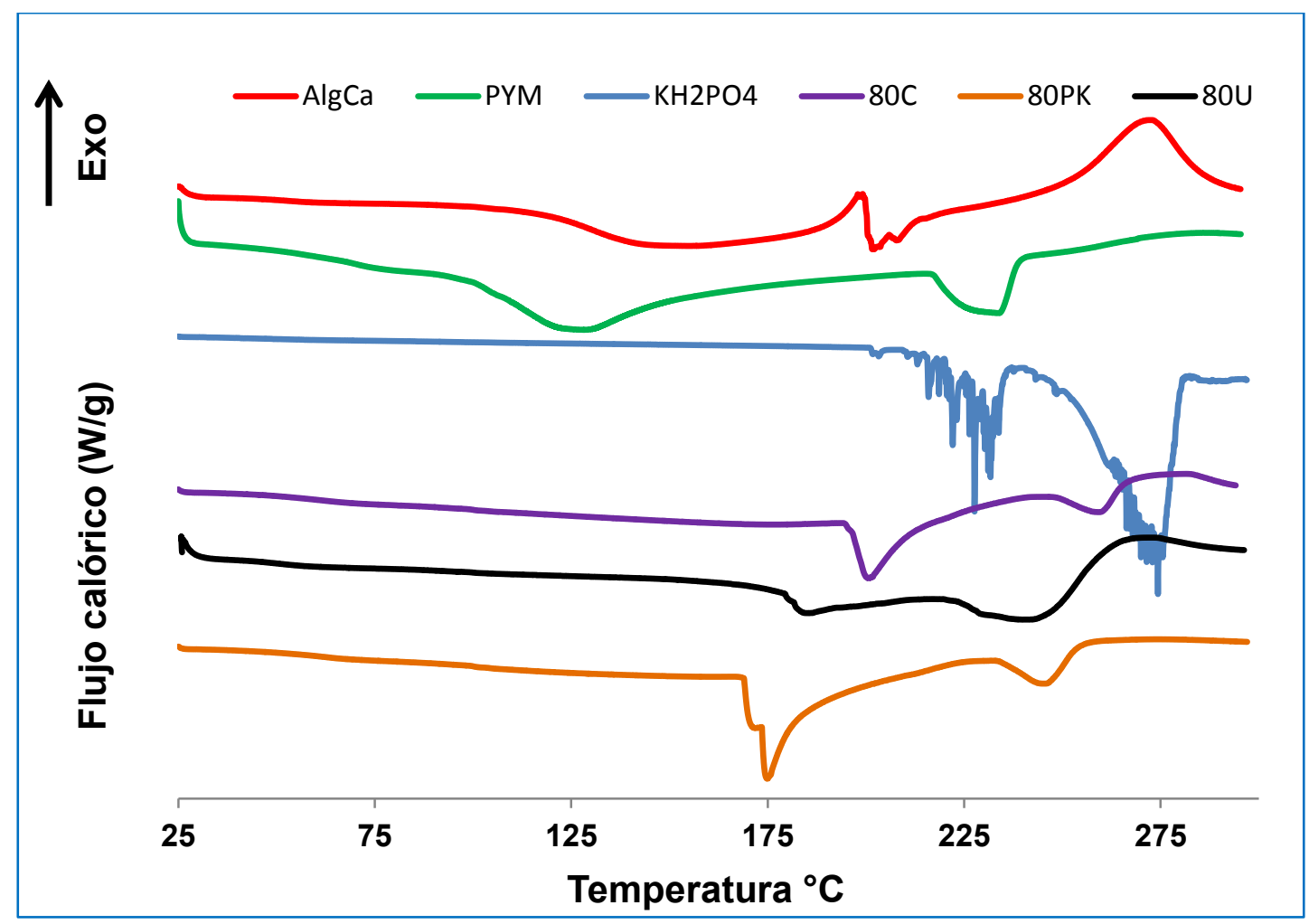

Figura 6.8 Termogramas control de Alginato de calcio (AlgCa), polvo de yerba mate (PYM), Fosfato monopotásico $\left(\mathrm{KH}_{2} \mathrm{PO}_{4}\right)$, cápsulas de PYM/alginato de calcio $(80 \mathrm{mg} / \mathrm{mL})$ sin fertilizante $(80 \mathrm{C})$, con urea $(80 \mathrm{U})$ y con fosfato monopotásico (80PK). 
El efecto de la degradación de las muestras sobre las propiedades térmicas se puede observar en la Fig. 6.9. El primer pico, atribuido al alginato de calcio se corre a temperaturas mayores con el avance de la degradación hasta desaparecer en las muestras de 20 y 30 días, denotando la degradación del alginato de calcio en primer lugar como se mencionó para las cápsulas con urea. En el mismo sentido, también se observó la aparición del pico de yerba mate alrededor de $100{ }^{\circ} \mathrm{C}$ en muestras almacenadas a mayor tiempo.

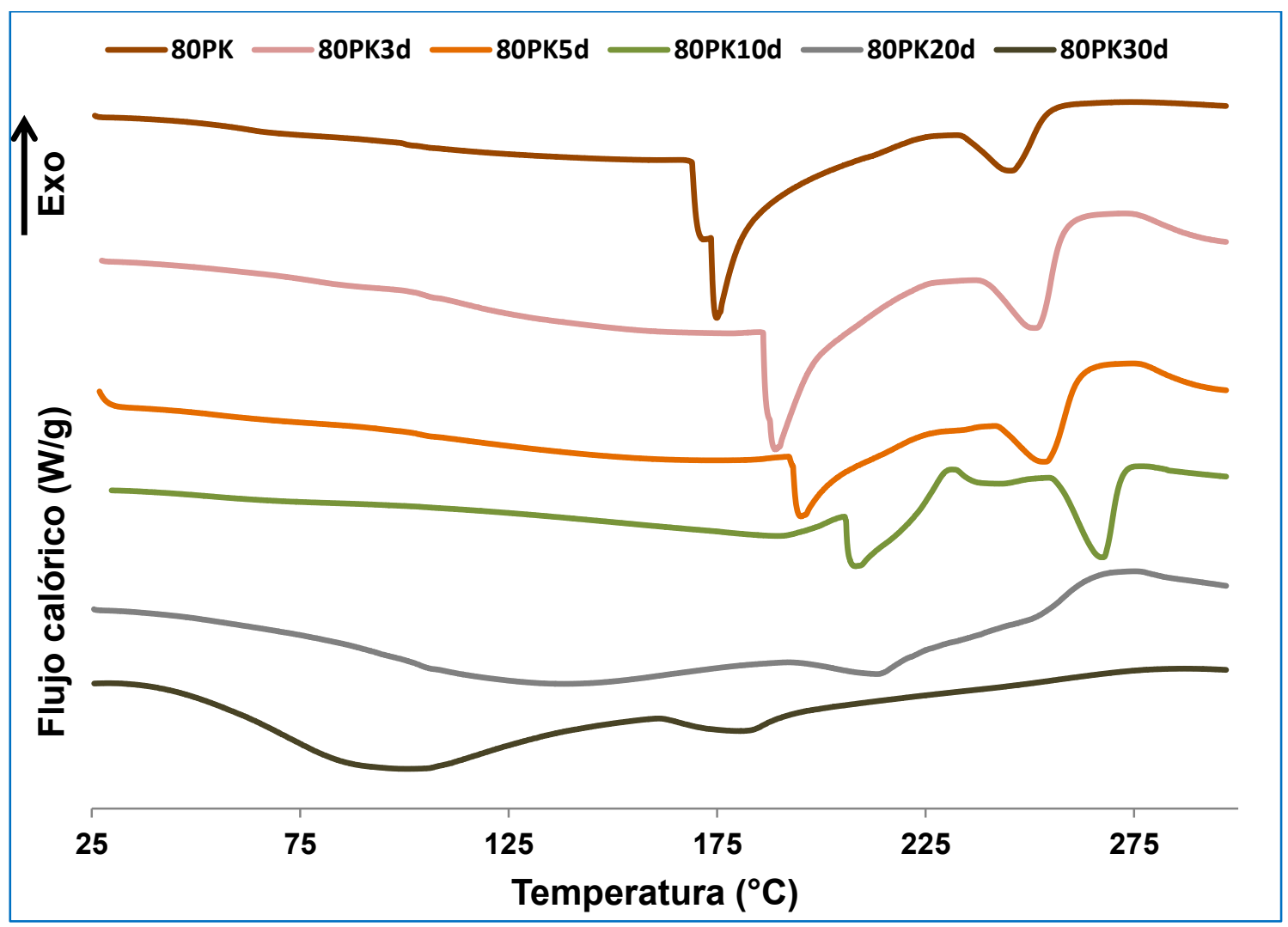

Figura 6.9 Termogramas de cápsulas con fosfato monopotásico (80PK) durante el ensayo de degradación, en tiempos entre 3 y 30 días, almacenadas a $20^{\circ} \mathrm{C}$. 
Tabla 6.6 Parámetros térmicos (media \pm desviación standard) en el ensayo de degradación, obtenidos en los termogramas de DSC para las cápsulas con fertilizante (80PK) a $20^{\circ} \mathrm{C}$ y tiempos de almacenamiento $(3,5,10,20$ y 30 días $)$.

\begin{tabular}{|c|c|c|c|c|c|c|}
\hline Cápsula & $\mathrm{T}_{\text {inicio1 }}\left({ }^{\circ} \mathrm{C}\right)$ & $\mathrm{T}_{\text {pico1 } 1}\left({ }^{\circ} \mathrm{C}\right)$ & $\operatorname{Tg}_{1}\left({ }^{\circ} \mathrm{C}\right)$ & $\mathrm{T}_{\text {inicio2 }}\left({ }^{\circ} \mathrm{C}\right)$ & $\mathrm{T}_{\text {pico2 }}\left({ }^{\circ} \mathrm{C}\right)$ & $\mathrm{Tg}_{2}\left({ }^{\circ} \mathrm{C}\right)$ \\
\hline 80PK Control & $170.78 \pm 3.11$ & $172.99 \pm 2.50$ & $63.59 \pm 0.70$ & $235.49 \pm 0.74$ & $246.92 \pm 0.92$ & $100.19 \pm 0.13$ \\
\hline $80 U^{*}$ Control & $184.74 \pm 6.17$ & $187.74 \pm 5.44$ & $49.99 \pm 0.43$ & $228.85 \pm 6.78$ & $248.44 \pm 2.03$ & $100.13 \pm 0.26$ \\
\hline $80 \mathrm{PK} 3 d$ & $187.53 \pm 3.05$ & $197.77 \pm 12.12$ & $* *$ & $249.07 \pm 13.82$ & $260.89 \pm 13.02$ & $104.46 \pm 0.43$ \\
\hline $80 P K 5 d$ & $198.66 \pm 7.93$ & $200.18 \pm 7.16$ & $* *$ & $241.44 \pm 2.06$ & $253.99 \pm 0.88$ & $103.23 \pm 0.51$ \\
\hline $80 P K 10 d$ & $208.65 \pm 3.92$ & $211.15 \pm 2.11$ & $* *$ & $251.88 \pm 7,16$ & $262.24 \pm 7.79$ & $104.76 \pm 0.94$ \\
\hline $80 P K ~ 20 d$ & $183.81 \pm 17.29$ & $201.78 \pm 17.51$ & $* *$ & ** & $* *$ & $102.68 \pm 0.98$ \\
\hline $80 \mathrm{PK} \mathrm{30d}$ & $171.71 \pm 13.28$ & $191.88 \pm 14.79$ & $* *$ & ** & $* *$ & $90.73 \pm 4.07$ \\
\hline $80 U * 30 d$ & $225.87 \pm 7.42$ & $233.68 \pm 4.92$ & ** & ** & ** & $99.87 \pm 3.64$ \\
\hline
\end{tabular}

Con respecto las transiciones vitreas en las cápsulas con fósforo y potasio, la $\mathrm{Tg}_{1}$ solo se observó en muestras sin degradar a una temperatura de $63^{\circ} \mathrm{C}$, mientras que se identificó la $\mathrm{Tg}_{2}$ en todos los casos, corriéndose a una temperatura menor $\left(90^{\circ} \mathrm{C}\right)$ en las muestras almacenadas a 30 días, denotando la fragilidad de la porción de alginato de calcio en estas muestras que es más marcada que para las muestras de 80U. (Tabla 6.6)

\subsubsection{Espectroscopía Infrarroja con Transformada de Fourier (FT-IR)}

Las cápsulas $80 \mathrm{PK}$ antes del ensayo de degradación mostraron un espectro de FT-IR similar al que presentó el tratamiento $80 \mathrm{U}$ a excepción del hombro de $3200 \mathrm{~cm}^{-1}$, reforzando la hipótesis planteada en la sección 6.3.2, estaría asociada a la formación del fosfato de calcio, la cual reduciría la disponibilidad de iones de calcio presentes en uniones intermoleculares. Un nuevo pico se observó cercano a $820 \mathrm{~cm}^{-1}$ el cual fue atribuido al fosfato monopotásico, que presentó un amplio pico centrado en esta longitud de onda (Figura 6.10). 
Varios estudios (Baran, Lis, \& Ratajczak, 1989; Syed, Pang, Zhang, \& Zhang, 2013) han atribuido las vibraciones de estiramiento de los grupos fosfatos en las regiones entre $800-1400 \mathrm{~cm}^{-1}$.

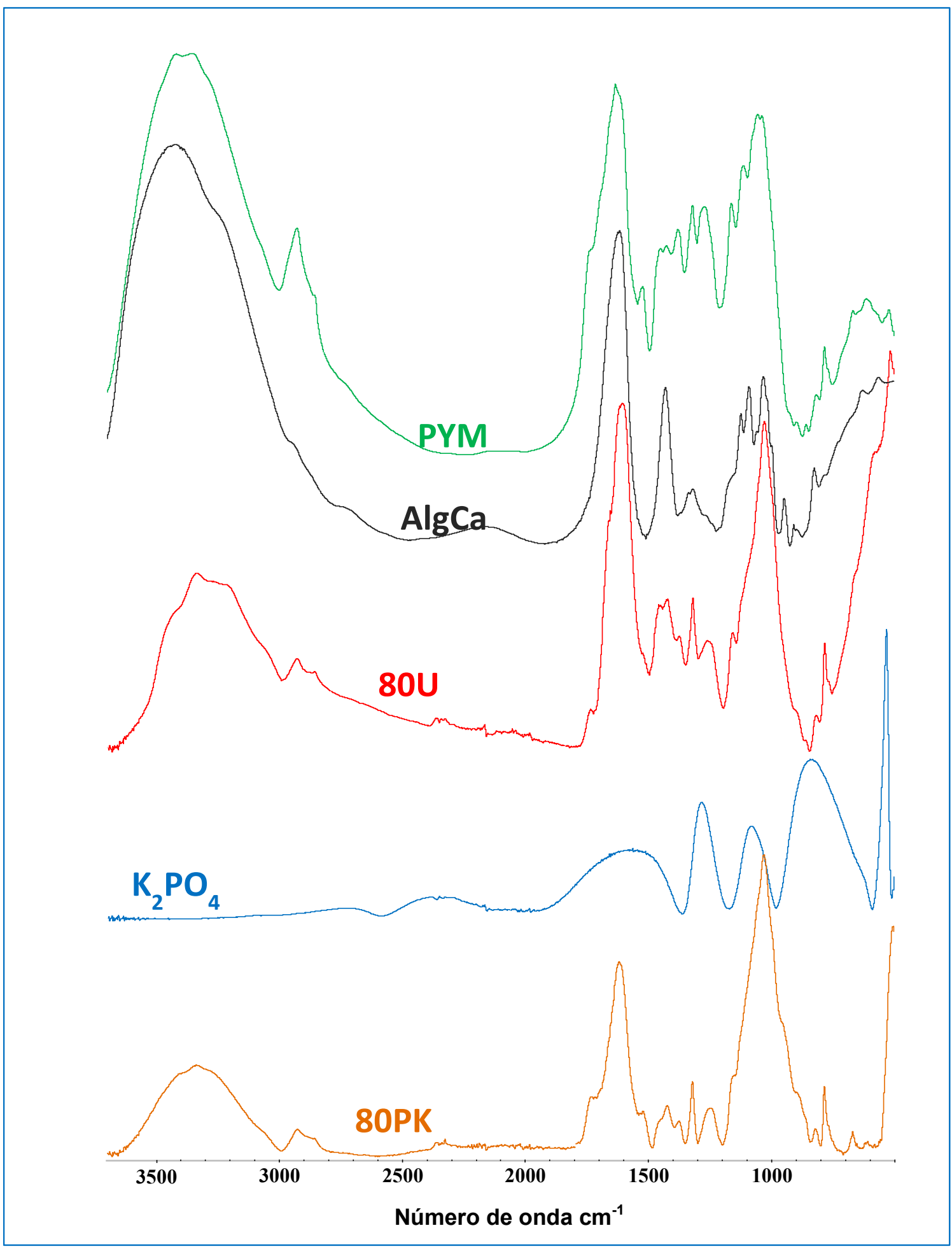

Figura. 6.10 Espectros FT-IR de materiales control (PYM, AlgCa, Fosfato monopotásico $\left(\mathrm{KH}_{2} \mathrm{PO}_{4}\right), 80 \mathrm{U}$ y $\left.80 \mathrm{PK}\right)$. 
Durante el ensayo de degradación se observaron similitudes respecto de las cápsulas que contenían agregados de urea (la disminución de la intensidad de los picos de $3300 \mathrm{~cm}^{-1}$ atribuido a la degradación de la matriz de alginato de calcio) y la reducción de pico a hombro situado a $1370 \mathrm{~cm}^{-1}$.

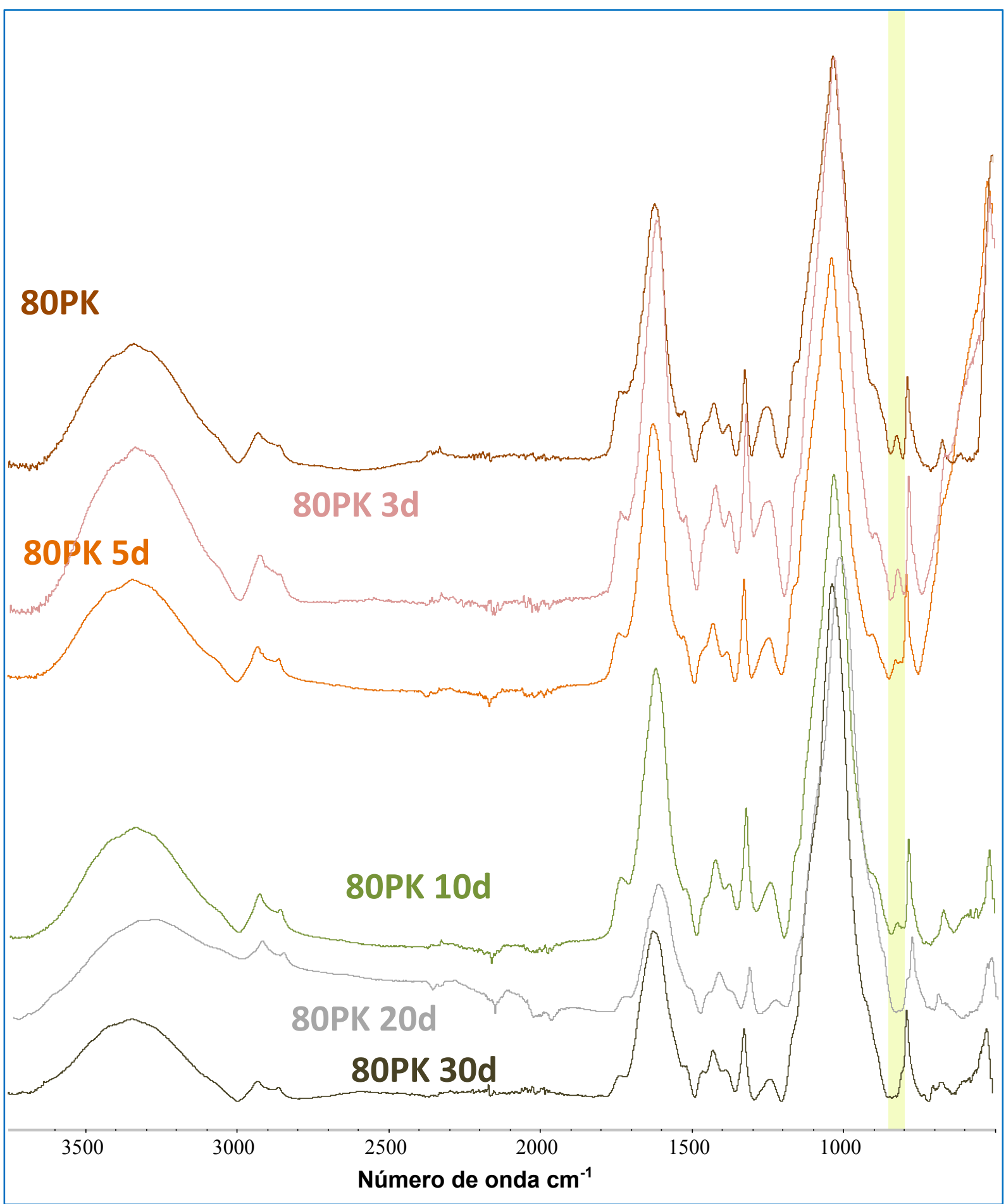

Figura. 6.11. Espectros FT-IR de cápsulas con fosfato monopotásico (80PK) a $20^{\circ} \mathrm{C}$ y tiempos de degradación $(3,5,10,20$ y 30 días). La columna coloreada identifica los cambios en las bandas entre 800 y $850 \mathrm{~cm}^{-1}$. 
Respecto al pico característico del fosfato monopotásico situado en la zona de $820 \mathrm{~cm}^{-1}$, se observó su disminución hasta su desaparición a los 20 días de ensayo que coincide con la cinética de liberación relacionada a los ensayos de fósforo y potasio que a este tiempo alcanzó una liberación de alrededor del $75 \%$ para ambos minerales. 


\subsection{Conclusiones parciales}

- El fosfato monopotásico incluido en los sistemas (80PK), afectó la estructura de las cápsulas, mostrando una porosidad menor en comparación con los encapsulados 80U. Sin embargo las cápsulas PK mostraron mayor proporción de poros de mayor tamaño Esta modificación en la matriz, incidió en una degradación más rápida del tratamiento (80PK) que la ocurrida en los sistemas de urea agregada (80U).

- El mecanismo de liberación difusivo resultó predominante sobre el de relajación para los dos sistemas evaluados tanto en medio sólido (tierra), como en medio líquido (agua).

- El contenido de minerales analizado para calcio, magnesio y potasio, mostró un comportamiento similar en el ensayo de degradación para los dos sistemas, manteniendo en el mismo orden el contenido aportado por el polvo de yerba mate ligado a la matriz de los encapsulados.

- El análisis calorimétrico y el estudio de los espectros de FT-IR, confirmaron que la degradación del alginato de calcio ocurrió en primer lugar y de forma similar para los dos sistemas estudiados. 
Conclusiones 
Se obtuvieron fertilizantes amigables con el medio ambiente empleando polvo de yerba mate en diferentes proporciones, como componente principal de la matriz, en sistemas de encapsulación con alginato de calcio para la liberación controlada de fertilizantes. La adición de elevadas cantidades de polvo de yerba mate, aumentó la eficiencia de encapsulación de fertilizantes, por el refuerzo que éste proporcionó a la matriz, disminuyó la adsorción de agua y mejoró propiedades físicas como la resistencia a la compresión, otorgando a los encapsulados características importantes para el procesamiento, almacenamiento y aplicación en la industria del agro.

Adicionalmente, el elevado contenido de polvo de yerba mate cumplió con el doble efecto que se esperaba por su incorporación, funcionó como material de relleno de los sistemas encapsulados, disminuyendo la velocidad de liberación de la urea y actúo como abono orgánico, aportando minerales requeridos para el desarrollo de cultivos. El mecanismo de liberación por difusión fue el que prevaleció en los sistemas desarrollados, junto a un aporte menor del mecanismo de relajación.

El procedimiento desarrollado para la obtención de encapsulados demostró ser versátil para su aplicación en diferentes sistemas, uno de urea y otro de aporte conjunto (fósforo y potasio) mediante el fosfato monopotásico, que permitieron evaluar sus mecanismos de liberación, así como las interacciones ocurridas en los mismos. Al compararlos entre sí, se pudo observar que el agregado de fosfato monopotásico influyó en la estructura de los encapsulados, aumentando el tamaño de los poros y acelerando la degradación de la matriz, pero manteniendo el mecanismo de liberación de difusión sobre el de relajación, tanto en tierra como en agua.

La obtención de fertilizantes encapsulados en matrices obtenidas a partir de polvo de yerba mate, resulta una prometedora estrategia, al emplear un subproducto de la industria y desarrollar tecnologías amigables con el medio ambiente en el marco de una agricultura sustentable. 
1. Aguilar, I. (2014). Preparación y evaluación en suelo de fertilizantes de liberación controlada cubiertos con polímeros biodegradables. Universidad Nacional de Colombia.

2. Aguirre Calvo, T., \& Santagapita, P. (2016). Physicochemical characterization of alginate beads containing sugars and biopolymers. Journal of Quality and Reliability Engineering, 2016.

3. Ajibola, O., Aviara, N., \& Ajetumobi, O. (2003). Sorption equilibrium and thermodynamic properties of cowpea (Vigna unguiculata). Journal of Food Engineering, 58(4), 317-324.

4. Akelah, A. (1996). Novel utilizations of conventional agrochemicals by controlled release formulations. Mater Science Engeneering, C4, 83-98.

5. Al-Zahrani, S. (2000). Utilization of polyethylene and paraffin waxes as controlled delivery systems for different fertilizers. Industrial \& Engineering Chemistry Research, 39(2), 367-371.

6. Anbinder, P. S., Deladino, L., Navarro, A. S., Amalvy, J. I., \& Martino, M. N. (2011). Yerba Mate Extract Encapsulation with Alginate and Chitosan Systems: Interactions between Active Compound Encapsulation Polymers. Journal of Encapsulation and Adsorption Sciences, 1, 80-87.

7. AOAC. (1984). OFFICIAL METHODS OF ANALYSIS. .

8. Arifin, D. Y., Lee, L. Y., \& Wang, C.-H. (2006). Mathematical modeling and simulation of drug release from microspheres: Implications to drug delivery systems. Advanced Drug Delivery Reviews, 58(12-13), 1274-1325.

9. Association of American Plant Food Control Officials (AAPFCO). (1995). Official Publication No. 48.

10. Association of American Plant Food Control Officials (AAPFCO). (1997). Official Publication No. 50.

11. Astolfi-Filho, Z., Souza, A. C., Reipert, É. C., \& Telis, V. (2005). Encapsulação de suco de maracujá por co-cristalização com sacarose: cinética de 
cristalização e propriedades físicas. Food Science and Technology (Campinas), 795-801.

12. Azeem, B., KuShaari, K., Man, Z. B., Basit, A., \& Thanh, T. H. (2014). Review on materials \& methods to produce controlled release coated urea fertilizer. Journal of Controlled Release, 181, 11-21.

13. Bajpai, S., \& Sharma, S. (2004). Investigation of swelling/degradation behaviour of alginate beads crosslinked with $\mathrm{Ca} 2+$ and $\mathrm{Ba} 2+$ ions. Reactive and Functional Polymers, 59(2), 129-140.

14. Ballester Olmos, J. F. (1994). Abonos nitrogenados de liberación lenta: Ministerio de Agricultura, Pesca y Alimentación, Madrid (España).

15. Baloch, P. A., Uddin, R., Nizamani, F. K., Solangi, A. H., \& Siddiqui, A. A. (2014). Effect of nitrogen, phosphorus and potassium fertilizers on growth and yield characteristics of radish (Raphinus sativus L.). American-Eurasian Journal of Agricultural \& Environmental Sciences, 14(6), 565-569.

16. Baran, J., Lis, T., \& Ratajczak, H. (1989). Structure and polarized IR spectra of the K2HPO4 - 3H2O crystal. Journal of Molecular Structure, 195, 159-174.

17. Barchuk, R. (1998). Aporte nutricional de la yerba mate. M. Sc. Thesis. Facultad de Medicina, Universidad Nacional del Nordeste, Argentina.

18. Basu, S., Kumar, N., \& Srivastava, J. (2010). Modeling NPK release from spherically coated fertilizer granules. Simulation Modelling Practice and Theory, 18(6), 820-835.

19. Boente, G., González, H., Martinez, E., Pollio, M., \& Resnik, S. (1996). Sorption isotherms of corn-Study of mathematical models. Journal of Food Engineering, 29(1), 115-128.

20. Borgogna, M., Bellich, B., Zorzin, L., Lapasin, R., \& Cesàro, A. (2010). Food microencapsulation of bioactive compounds: Rheological and thermal characterisation of non-conventional gelling system. Food Chemistry, 122(2), 416-423. 
21. Bucalá, V. (2013). Procesamiento de sólidos. Procesamiento de alimentos II (Cap. 2 "Propiedades de una partícula"). Universidad Nacional del Sur, Dpto. de Ingeniería Química.

Dirección URL : < http://www.criba.edu.ar/cinetica/solidos/Programa.pdf>

22. Burtnik, O. J. (2006). Yerba mate: Manual de producción. INTA, AER Santo Tomé, Corrientes, Argentina. 52p.

23. Ceballos, A., Giraldo, G., \& Orrego, C. (2009). Evaluación de varios modelos de isotermas de adsorción de agua de un polvo de fruta deshidratada. Vector, 4, 107-116.

24. Champagne, C. P., \& Fustier, P. (2007). Microencapsulation for the improved delivery of bioactive compounds into foods. Current Opinion in Biotechnology, 18(2), 184-190.

25. Chávez, F., Olvera, B. I., Ganem, A., \& Quintanar, D. (2002). Liberación de sustancias lipofílicas a partir de nanocápsulas poliméricas. Revista de la Sociedad Química de México, 46(4), 349-356.

26. Chen, J., Lü, S., Zhang, Z., Zhao, X., Li, X., Ning, P., \& Liu, M. (2018). Environmentally friendly fertilizers: A review of materials used and their effects on the environment. Science of the Total Environment, 613, 829-839.

27. Chirife, J., \& Iglesias, H. A. (1978). Equations for fitting water sorption isotherms of foods: Part 1-a review. International Journal of Food Science \& Technology, 13(3), 159-174.

28. Código Alimentario Argentino (CAA). (2002). Capítulo XV: Productos estimulantes o fruitivos.

29. Córdoba, A. L., Deladino, L., \& Martino, M. (2013). Effect of starch filler on calcium-alginate hydrogels loaded with yerba mate antioxidants. Carbohydrate Polymers, 95(1), 315-323.

30. Costa, P., \& Sousa Lobo, J. M. (2001). Modeling and comparison of dissolution profiles. European Journal of Pharmaceutical Sciences, 13(2), 123133. 
31. Dai, J.-J., Fan, X.-L., Yu, J.-G., Fang, L., \& Zhang, Q. (2008). Study on the rapid method to predict longevity of controlled release fertilizer coated by water soluble resin. Agricultural Sciences in China, 7(9), 1127-1132.

32. Dave, A., Mehta, M., Aminabhavi, T., Kulkarni, A., \& Soppimath, K. (1999). A review on controlled release of nitrogen fertilizers through polymeric membrane devices. Polymer-Plastics Technology and Engineering, 38(4), $675-711$.

33. Deladino, L., Navarro, A., \& Martino, M. N. (2007). Encapsulation of active compounds: Ionic gelation and cocrystallization as case studies. In C. E. Lupano (Ed.), Functional properties of food components (pp. 125-157).

34. Deladino, L., Navarro, A. S., \& Martino, M. N. (2013). Carrier systems for yerba mate extract (llex paraguariensis) to enrich instant soups. Release mechanisms under different $\mathrm{pH}$ conditions. LWT - Food Science and Technology, 53(1), 163-169.

35. Dellacassa, E., \& Bandoni, A. L. (2001). El mate. Revista de Fitoterapia, 1(4), 269-278.

36. Devassine, M., Henry, F., Guerin, P., \& Briand, X. (2002). Coating of fertilizers by degradable polymers. International Journal of Pharmaceutics, 242(1-2), 399-404.

37. Donati, I., Holtan, S., Mørch, Y. A., Borgogna, M., Dentini, M., \& Skjåk-Bræk, G. (2005). New hypothesis on the role of alternating sequences in calciumalginate gels. Biomacromolecules, 6(2), 1031-1040.

38. Draget, K. I., Smidsrød, O., \& Skjåk-Bræk, G. (2005). Alginates from algae. Biopolymers Online.

39. Esmelindro, M. C., Toniazzo, G., Waczuk, A., Dariva, C., \& Oliveira, D. d. (2002). Effects of industrial processing steps on the physico-chemical characteristics of mate tea leaves. Food Science and Technology (Campinas), 22(2), 199-204. 
40. FAO. (2016). World fertilizer trends and outlook to 2019. Food and Agriculture organization of the United Nations (FAO), Rome, Summary Report.

41. FAO, I., \& IFA, A. (2002). Los Fertilizantes y su Uso. Organización de las Naciones Unidas para la Agricultura y la Alimentación, Asociación Internacional de la Industria de los Fertilizantes.

42. Farmacopea Argentina. (2012). Octava Edición. Buenos Aires, Argentina: Imprenta del Congreso de la Nación.

43. Fertilizer, M. (1998). Ed. United Nations Industrial Development Organization (UNIDO) and International Fertilizer Development Center (IFDC): Norwell, MA: Kluwer Academic.

44. Fontan, C. F., Chirife, J., Sancho, E., \& Iglesias, H. (1982). Analysis of a model for water sorption phenomena in foods. Journal of Food Science, 47(5), 1590-1594.

45. Frutos, G., \& Ocaña, J. (2011). Técnicas de remuestreo en la comparación de curvas de disolución de fármacos. Paper presented at the Anales de la Real Academia Nacional de Farmacia.

46. Fulton, J., \& Port, K. (2016). Physical properties of granular fertilizers and impact on spreading.

47. Gabas, A., Telis, V., Sobral, P., \& Telis-Romero, J. (2007). Effect of maltodextrin and arabic gum in water vapor sorption thermodynamic properties of vacuum dried pineapple pulp powder. Journal of Food Engineering, 82(2), 246-252.

48. Garrido, J. L. (2017). Estudio de la cinética de secado en cápsulas de alginato.

49. George, M., \& Abraham, T. E. (2006). Polyionic hydrocolloids for the intestinal delivery of protein drugs: Alginate and chitosan: a review. Journal of Controlled Release, 114(1), 1-14. 
50. Ginés, I., \& Mariscal Sancho, I. d. L. (2002). Incidencia de los fertilizantes sobre el $\mathrm{pH}$ del suelo.

51. Giulian, R., lochims dos Santos, C. E., de Moraes Shubeita, S., da Silva, L. M., Dias, J. F., \& Yoneama, M. L. (2007). Elemental characterization of commercial mate tea leaves (Ilex paraguariensis A. St.-Hil.) before and after hot water infusion using ion beam techniques. Journal of Agricultural and Food Chemistry, 55(3), 741-746.

52. González, M., Rodríguez García, M., Hernández, M. I., Rodríguez, C., Rieumont, J., Cuesta, E., Morales, A. (2005). Obtención de un fertilizante de liberación lenta y controlada enriquecido con diferentes plantas marinas. Revista Cubana de Química, 17(3).

53. Guo, M., Liu, M., Hu, Z., Zhan, F., \& Wu, L. (2005). Preparation and properties of a slow release NP compound fertilizer with superabsorbent and moisture preservation. Journal of Applied Polymer Science, 96(6), 2132-2138.

54. Han, X., Chen, S., \& Hu, X. (2009). Controlled-release fertilizer encapsulated by starch/polyvinyl alcohol coating. Desalination, 240(1-3), 21-26.

55. Hanafi, M., Eltaib, S., \& Ahmad, M. (2000). Physical and chemical characteristics of controlled release compound fertiliser. European Polymer Journal, 36(10), 2081-2088.

56. He, X, Liao, Z., Huang, P., Duan, J., Ge, R., Li, H., \& Geng, Z., (2007). Characteristics and performance of novel water-absorbent slow release nitrogen fertilizers. Agricultural Sciences in China, 6(3), 338-346.

57. Heinrichs, R., \& Malavolta, E. (2001). Mineral composition of a commercial product from mate-herb (Ilex paraguariensis St. Hil.). Ciência Rural, 31(5), 781-785.

58. Hossain, M. (1990). Effect of different sources of nutrients and mulching on the growth and yield of amaranth. MS Thesis, Dept. Hort., Bangladesh Agri Univ., Mymensingh, Bangladesh. 
59. Huertas, R. A. P. (2010). Revisión: Microencapsulación de Alimentos. Revista Facultad Nacional de Agronomía, 63(2), 5669-5684.

60. Hurtado, M. G., Díaz, M. I. H., Martell, D. D., Briones, J. R., Acosta, C. R., Cuesta, E., \& Sardiña, C. (2007). Síntesis y comportamiento de un material polimérico aplicado como recubrimiento en un fertilizante de liberación controlada. Revista Iberoamericana de Polímeros, 8(4), 275-286.

61. Hussain, M. R., Devi, R., \& Maji, T. (2012). Controlled release of urea from chitosan microspheres prepared by emulsification and cross-linking method. Iranian Polymer Journal, 21(8), 473-479.

62. Inam, A., Sahay, S., \& Mohammad, F. (2010). Studies on Potassium content in two root crops under Nitrogen fertilization.

63. INYM. Instituto Nacional de la Yerba Mate. Retrieved from http://www.inym.org.ar/.

64. IRAM. (1996). Instituto Argentino de Racionalización de Materiales. Yerba Mate: Determinación de cenizas totales.

65. Jarrell, W., \& Boersma, L. (1979). Model for the Release of Urea by Granules of Sulfur-Coated Urea Applied to Soil 1. Soil Science Society of America Journal, 43(5), 1044-1050.

66. Jaya, S., \& Das, H. (2004). Effect of maltodextrin, glycerol monostearate and tricalcium phosphate on vacuum dried mango powder properties. Journal of Food Engineering, 63(2), 125-134.

67. Jiménez Gómez, S. (1992). Fertilizantes de liberación lenta: Introducción. Fertilizantes de liberación lenta. Jiménez Gómez, S. Ed., Mundi-Prensa. Madrid, 1-7.

68. Kamburova, K., \& Kirilov, P. (2008). Calculating the salt index of pK and NPK liquid fertilizers from potassium phosphates. J. Chem. Technol. Metal, 43, 227230. 
69. Klein, J., Stock, J., \& Vorlop, K. D. (1983). Pore size and properties of spherical Ca-alginate biocatalysts. Applied Microbiology and Biotechnology, 18(2), 86-91.

70. Kloth, B. (1996). Aglukon Spezialdünger $\mathrm{GmbH}$ : Reply to the request on controlled-release fertilizers. Personal communication.

71. Kopcha, M., Lordi, N. G., \& Tojo, K. J. (1991). Evaluation of release from selected thermosoftening vehicles. Journal of pharmacy and pharmacology, 43(6), 382-387.

72. Landry, M. R. (2005). Thermoporometry by differential scanning calorimetry: experimental considerations and applications. Thermochimica Acta, 433(1-2), $27-50$.

73. Lee, B. B., Ravindra, P., \& Chan, E. S. (2013). Size and shape of calcium alginate beads produced by extrusion dripping. Chemical Engineering \& Technology, 36(10), 1627-1642.

74. Liang, X., Zhang, Y., Liu, L., \& Yao, J. (2012). Synthesis and urea-loading of an eco-friendly superabsorbent composite based on mulberry branches. BioResources, 8(1), 130-144.

75. Liu, G., Zotarelli, L., Li, Y., Dinkins, D., Wang, Q., \& Ozores-Hampton, M. (2014). Controlled-Release and Slow-Release Fertilizers as Nutrient Management Tools1. Horticultural Sciences Department, HS1255, 1-7.

76. Liu, L., Kost, J., Fishman, M. L., \& Hicks, K. B. (2008). A review: controlled release systems for agricultural and food applications: ACS Publications.

77. López, A., Deladino, L., Navarro, A., \& Martino, M. (2011). Encapsulación de compuestos bioactivos con alginatos para la industria de alimentos. @ limentech, Ciencia y Tecnología Alimentaria, 10(1).

78. Lupo, B., Maestro, A., Gutiérrez, J. M., \& González, C. (2015). Characterization of alginate beads with encapsulated cocoa extract to prepare functional food: comparison of two gelation mechanisms. Food Hydrocolloids, $49,25-34$. 
79. Luzi, F., Fortunati, E., Puglia, D., Petrucci, R., Kenny, J., \& Torre, L. (2015). Study of disintegrability in compost and enzymatic degradation of PLA and PLA nanocomposites reinforced with cellulose nanocrystals extracted from Posidonia oceanica. Polymer Degradation and Stability, 121, 105-115.

80. Madene, A., Jacquot, M., Scher, J., \& Desobry, S. (2006). Flavour encapsulation and controlled release-a review. International Journal of Food Science \& Technology, 41(1), 1-21.

81. Maiocchi, M. G., Del Vitto, L. A., Petenatti, M. E., Marchevsky, E. J., Avanza, M. V., Pellerano, R. G., \& Petenatti, E. M. (2016). Composición multielemental y valor nutricional de" dumosa"(Ilex dumosa)," yerba mate"(I. paraguariensis) y su mezcla comercial en diferentes formas de uso. Revista de la Facultad de Ciencias Agrarias. Universidad Nacional de Cuyo, 48(1), 145-159.

82. Marschner, H. (2012). Marschner's mineral nutrition of higher plants. Vol. 89: Academic press.

83. Mathlouthi, M. (2001). Water content, water activity, water structure and the stability of foodstuffs. Food Control, 12(7), 409-417.

84. Moreno, J. J. (2016). Innovative Processing Technologies for Foods with Bioactive Compounds: CRC Press.

85. Mulder, W., Gosselink, R., Vingerhoeds, M., Harmsen, P., \& Eastham, D. (2011). Lignin based controlled release coatings. Industrial Crops and Products, 34(1), 915-920.

86. Nakamatsu, J. (2017). Matrices Poliméricas para Liberación Controlada de Sustancias Activas. Revista de Química, 16(1-2), 13-23.

87. Ni, B., Liu, M., \& Lü, S. (2009). Multifunctional slow-release urea fertilizer from ethylcellulose and superabsorbent coated formulations. Chemical Engineering Journal, 155(3), 892-898.

88. Ni, B., Liu, M., Lü, S., Xie, L., \& Wang, Y. (2011). Environmentally friendly slow-release nitrogen fertilizer. Journal of Agricultural and Food Chemistry, 59(18), 10169-10175. 
89. Ni, B., Liu, M., Lü, S., Xie, L., Zhang, X., \& Wang, Y. (2010). Novel SlowRelease Multielement Compound Fertilizer with Hydroscopicity and Moisture Preservation. Industrial \& Engineering Chemistry Research, 49(10), 45464552.

90. Ni, B., Lü, S., \& Liu, M. (2012). Novel Multinutrient Fertilizer and Its Effect on Slow Release, Water Holding, and Soil Amending. Industrial \& Engineering Chemistry Research, 51(40), 12993-13000.

91. Niu, Y., \& Li, H. (2012). Controlled Release of Urea Encapsulated by Starch-gpoly(vinyl acetate). Industrial \& Engineering Chemistry Research, 51(38), 12173-12177.

92. Nutralene, A. (1993). Nitroform, AZOLON-Biologically. Controlled Nitrogen Release.

93. Orcutt, D. M., \& Nilsen, E. T. (2000). The physiology of plants under stress: soil and biotic factors (J. W. Sons Ed. Vol. 2).

94. Pedroza-Islas, R. (2002). Alimentos Microencapsulados: Particularidades de los procesos para la microencapsulación de alimentos para larvas de especies acuícolas. Avances en Nutrición Acuícola VI. Memorias del VI Simposium Internacional de Nutrición Acuícola, 3.

95. Peleg, M. (1977). Flowability of food powders and methods for its evaluationa review. Journal of Food Process Engineering, 1(4), 303-328.

96. Peppas, N. A., \& Sahlin, J. J. (1989). A simple equation for the description of solute release. III. Coupling of diffusion and relaxation. International Journal of Pharmaceutics, 57(2), 169-172.

97. Poncelet, D., Lencki, R., Beaulieu, C., Halle, J., Neufeld, R., \& Fournier, A. (1992). Production of alginate beads by emulsification/internal gelation. I. Methodology. Applied Microbiology and Biotechnology, 38(1), 39-45.

98. Pothakamury, U. R., \& Barbosa-Cánovas, G. V. (1995). Fundamental aspects of controlled release in foods. Trends in Food Science \&amp; Technology, 6(12), 397-406. 
99. Rassis, D., Saguy, I., \& Nussinovitch, A. (2002). Collapse, shrinkage and structural changes in dried alginate gels containing fillers. Food Hydrocolloids, 16(2), 139-151.

100. Rendón García, D., Vargas Taborda, J. F., \& Castrillón Zuluaga, P. (2016). Encapsulación de DHA/EPA mediante secado por aspersión: identificación de metodologías de proceso y agentes encapsulantes compatibles. Corporación Universitaria Lasallista.

101. Risch, S. J. (1995). Encapsulation: overview of uses and techniques: ACS Publications.

102. Ritger, P. L., \& Peppas, N. A. (1987). A simple equation for description of solute release.I: Fickian and non-Fickian release from non-swellable devices in the form of slabs, spheres, cylinders or discs. . Journal of Controlled Release, 5 23-36.

103. Rodríguez-Llimos, A., Chiappetta, D., Szeliga, M., Fernández, A., \& Bregni, C. (2003). Micropartículas de alginato conteniendo paracetamol.

104. Rodríguez, O. (1993). Evaluaciones de cobertura, barreras vivas y otras medidas de conservación de suelos en laderas. U.C.V., Maracay, Venezuela.

105. Sadia, A., Mahasen, M., Shahrin, S., Roni, M., \& Uddin, A. J. (2013). Phosphorus levels on growth and yield of turnip (Brassica campestris var. Rapifera). Bangladesh Research Publications Journal, 8(1), 29-33.

106. Salman, O. A. (1989). Polyethylene-coated urea. 1. Improved storage and handling properties. Industrial \& Engineering Chemistry Research, 28(5), 630632.

107. Sankalia, M. G., Mashru, R. C., Sankalia, J. M., \& Sutariya, V. B. (2005). Papain entrapment in alginate beads for stability improvement and sitespecific delivery: physicochemical characterization and factorial optimization using neural network modeling. Aaps pharmscitech, 6(2), E209-E222. 
108. Santagapita, P. R., Mazzobre, M. F., \& del Pilar Buera, M. (2012). Invertase stability in alginate beads: Effect of trehalose and chitosan inclusion and of drying methods. Food Research International, 47(2), 321-330.

109. Sarmento, B., Ferreira, D., Veiga, F., \& Ribeiro, A. n. (2006). Characterization of insulin-loaded alginate nanoparticles produced by ionotropic pre-gelation through DSC and FTIR studies. Carbohydrate Polymers, 66(1), 1-7.

110. Sartori, C., Finch, D. S., Ralph, B., \& Gilding, K. (1997). Determination of the cation content of alginate thin films by FTi.r. spectroscopy. Polymer, 38(1), 4351.

111. Schneider Teixeira, A., Deladino, L., \& Zaritzky, N. (2016). Yerba mate (Ilex paraguariensis) waste and alginate as a matrix for the encapsulation of $\mathrm{N}$ fertilizer. ACS Sustainable Chemistry \& Engineering, 4(4), 2449-2458.

112. Serrano, L. A. L., Silva, C. M. M., J.Ogliari, Carvalho, A. J. C., Marinho, C. S., \& Detmann, E. (2006). Utilização de substrato composto por resíduos da agroindústria canavieira para produção de mudas de maracujazeiro-amarelo. Revista Brasileira de Fruticultura, 3, 487-491.

113. Shavit, V., Reiss, M., \& Shaviv, A. (2002). Wetting mechanisms of gel- based controlled-release fertilizers. Journal of Controlled Release, 88, 71-83.

114. Shaviv, A. (2001). Advances in controlled-release fertilizers. Advances in Agronomy, 71, 1-49.

115. Siegel, R. A., \& Rathbone, M. J. (2012). Overview of controlled release mechanisms Fundamentals and applications of controlled release drug delivery (pp. 19-43): Springer.

116. Siepmann, J., \& Siepmann, F. (2008). Mathematical modeling of drug delivery. International Journal of Pharmaceutics, 364(2), 328-343.

117. Sikorski, P., Mo, F., Skjåk-Bræk, G., \& Stokke, B. T. (2007). Evidence for eggbox-compatible interactions in calcium- alginate gels from fiber X-ray diffraction. Biomacromolecules, 8(7), 2098-2103. 
118. Silva, R. D. A., Bueno, A. L. S., Gallon, C. W., Gomes, L. F., Kaiser, S., Pavei, C., Jahn, M. P. (2011). The effect of aqueous extract of gross and commercial yerba mate (Ilex paraguariensis) on intra-abdominal and epididymal fat and glucose levels in male Wistar rats. Fitoterapia, 82(6), 818-826.

119. Smidsrød, O., \& Skja, G. (1990). Alginate as immobilization matrix for cells. Trends in Biotechnology, 8, 71-78.

120. Smitha, B., Sridhar, S., \& Khan, A. (2005). Solid polymer electrolyte membranes for fuel cell applications-a review. Journal of membrane science, 259(1-2), 10-26.

121. Sujka, M., \& Jamroz, J. (2007). Starch granule porosity and its changes by means of amylolysis. International Agrophysics, 21, 107-113.

122. Sultana, K., Godward, G., Reynolds, N., Arumugaswamy, R., Peiris, P., \& Kailasapathy, K. (2000). Encapsulation of probiotic bacteria with alginatestarch and evaluation of survival in simulated gastrointestinal conditions and in yoghurt. International Journal of Food Microbiology, 62(1-2), 47-55.

123. Syed, K. A., Pang, S.-F., Zhang, Y., \& Zhang, Y.-H. (2013). Micro-Raman observation on the H2PO4- association structures in a supersaturated droplet of potassium dihydrogen phosphate $\left(\mathrm{KH}_{2} \mathrm{PO}_{4}\right)$. The Journal of chemical physics, 138(2).

124. Terry, D. (1990). Regulatory models for slow release fertilizer. Nutrient Cycling in Agroecosystems, 25(2), 133-137.

125. Timilsena, Y. P., Adhikari, R., Casey, P., Muster, T., Gill, H., \& Adhikari, B. (2015). Enhanced efficiency fertilisers: a review of formulation and nutrient release patterns. Journal of the Science of Food and Agriculture, 95(6), 11311142.

126. Toğrul, H., \& Arslan, N. (2007). Moisture sorption isotherms and thermodynamic properties of walnut kernels. Journal of Stored Products Research, 43(3), 252-264. 
127. Tomaszewska, M., \& Jarosiewicz, A. (2002). Use of polysulfone in controlledrelease NPK fertilizer formulations. J Agric Food Chem, 50(16), 4634-4639.

128. Trenkel, M. E. (1997). Controlled-release and stabilized fertilizers in agriculture (Vol. 11): International fertilizer industry association Paris.

129. Trenkel, M. E. (2010). Slow- and Controlled-Release and Stabilized Fertilizers: An Option for Enhancing Nutrient Use Efficiency in Agriculture. Paris, France.

130. Tyagi, N., Sutton, E., Hunt, M., Zhang, J., Oh, J. H., Apte, A., Mehrara, B. (2017). Morphologic Features of Magnetic Resonance Imaging as a Surrogate of Capsular Contracture in Breast Cancer Patients With Implant-based Reconstructions. International Journal of Radiation Oncology• Biology• Physics, 97(2), 411-419.

131. Valduga, A., Finzer, J., \& Mosele, S. (2003). Processamento de erva-mate. Erechim: Edifapes, 183.

132. Velázquez, M. L., Scipioni, G. P., Ferreyra, D. J., \& Schmalko, M. (2006). Subproductos obtenidos en el procesamiento de la yerba mate (Ilex paraguariensis): Caracterización fisicoquímica. IV Congreso Sudamericano de la Yerba Mate, Posadas, Misiones, Argentina. Acta de Congreso.

133. Vieira, M. A., Rovaris, A. A., Maraschin, M., Simas, K. N. D., Pagliosa, C. M., Podesta, R., Amante, E. R. (2008). Chemical Characterization of Candy Made of Erva-Mate (Ilex paraguariensis A. St. Hil.) Residue. Journal of Food Agriculture and Food Chemistry, 56, 4637-4642.

134. Villamizar, L. F., \& Martínez, F. (2008). Determinación de las condiciones de microencapsulación de un baculovirus entomopatógeno mediante coacervación con Eudragit S100®. Vitae, 15(1).

135. Villena, M. M., Hernández, M. M., Lara, V. G., \& Martínez, M. R. (2009). Técnicas de microencapsulación: una propuesta para microencapsular probióticos. Ars Pharmaceutica, 50(1), 43-50.

136. Wang, Y., Liu, M., Ni, B., \& Xie, L. (2011). k-Carrageenan-Sodium Alginate Beads and Superabsorbent Coated Nitrogen Fertilizer with Slow-Release, 
Water-Retention, and Anticompaction Properties. Industrial \& Engineering Chemistry Research, 51(3), 1413-1422.

137. Wang, Y., Liu, M., Ni, B., \& Xie, L. (2012). K-Carrageenan-sodium alginate beads and superabsorbent coated nitrogen fertilizer with slow-release, waterretention, and anticompaction properties. Industrial \& Engineering Chemistry Research, 51(3), 1413-1422.

138. Washburn, E. W. (1921). The Dynamics of Capillary Flow. Physical Review, 17(3), 273-283.

139. Wu, L., \& Liu, M. (2008). Preparation and properties of chitosan-coated NPK compound fertilizer with controlled-release and water-retention. Carbohydrate Polymers, 72(2), 240-247.

140. Wu, Z., Guo, L., Qin, S., \& Li, C. (2012). Encapsulation of R. planticola Rs-2 from alginate-starch-bentonite and its controlled release and swelling behavior under simulated soil conditions. Journal of industrial microbiology \& biotechnology, 39(2), 317-327.

141. Xie, L., Liu, M., Ni, B., \& Wang, Y. (2012). New environment-friendly use of wheat straw in slow-release fertilizer formulations with the function of superabsorbent. Industrial \& Engineering Chemistry Research, 51(10), 38553862.

142. Xie, L., Liu, M., Ni, B., Zhang, X., \& Wang, Y. (2011). Slow-release nitrogen and boron fertilizer from a functional superabsorbent formulation based on wheat straw and attapulgite. Chemical Engineering Journal, 167(1), 342-348.

143. Yañez, J., Salazar, J., Chaires, L., Jiménez, J., Márquez, M., \& Ramos, E. (2002). Aplicaciones biotecnológicas de la microencapsulación. Avance y perspectiva, 21, 313-319.

144. Zhang, S., Yang, Y., Gao, B., Wan, Y., Li, Y. C., \& Zhao, C. (2016). Bio-based interpenetrating network polymer composites from locust sawdust as coating material for environmentally friendly controlled-release urea fertilizers. Journal of Agricultural and Food Chemistry, 64(28), 5692-5700. 
145. Zhang, Y., Liang, X., Yang, X., Liu, H., \& Yao, J. (2014). An Eco-Friendly Slow-Release Urea Fertilizer Based on Waste Mulberry Branches for Potential Agriculture and Horticulture Applications. ACS Sustainable Chemistry \& Engineering, 2(7), 1871-1878. 